\title{
WestVirginiaUniversity
}

THE RESEARCH REPOSITORY @ WVU

Graduate Theses, Dissertations, and Problem Reports

2014

\section{Three essays on institutions and development in sub-Saharan}

\section{Africa}

Amanda M. Mandzik

West Virginia University

Follow this and additional works at: https://researchrepository.wvu.edu/etd

\section{Recommended Citation}

Mandzik, Amanda M., "Three essays on institutions and development in sub-Saharan Africa" (2014). Graduate Theses, Dissertations, and Problem Reports. 229.

https://researchrepository.wvu.edu/etd/229

This Dissertation is protected by copyright and/or related rights. It has been brought to you by the The Research Repository @ WVU with permission from the rights-holder(s). You are free to use this Dissertation in any way that is permitted by the copyright and related rights legislation that applies to your use. For other uses you must obtain permission from the rights-holder(s) directly, unless additional rights are indicated by a Creative Commons license in the record and/ or on the work itself. This Dissertation has been accepted for inclusion in WVU Graduate Theses, Dissertations, and Problem Reports collection by an authorized administrator of The Research Repository @ WVU.

For more information, please contact researchrepository@mail.wvu.edu. 


\title{
THREE ESSAYS ON INSTITUTIONS AND DEVELOPMENT IN SUB-SAHARAN AFRICA
}

\author{
Amanda M. Mandzik \\ Dissertation Submitted to the \\ College of Business and Economics at \\ West Virginia University \\ In partial fulfillment of the requirements for the degree of
}

\author{
Doctor in Philosophy \\ In \\ Economics \\ Andrew Young, Ph.D., Chair \\ Linda Kinney, Ph.D. \\ Donald Lacombe, Ph.D. \\ Shuichiro Nishioka, Ph.D. \\ Amanda Ross, Ph.D. \\ Department of Economics \\ Morgantown, West Virginia \\ 2014
}

Keywords: institutions, development, religion, infant mortality, life expectancy, shadow economy, economic freedom, sub-Saharan Africa

Copyright 2014 Amanda M. Mandzik 


\title{
ABSTRACT \\ THREE ESSAYS ON INSTITUTIONS AND DEVELOPMENT IN SUB- SAHARAN AFRICA
}

\begin{abstract}
Amanda M. Mandzik
As a region, sub-Saharan Africa lags behind the rest of the world in both human development and economic growth. However, a portion of the development literature suggests that institutions may play a role in explaining, and perhaps changing, the outcomes that are observed in these countries. Therefore, this dissertation explores how institutions have shaped and continue to shape the health and economic outcomes of this region. In Chapter 2, jointly with Andrew Young, we seek to explain the correlation between high HIV prevalence rates and the Christian share of the population that contrasts with low HIV prevalence rates observed with the Muslim share of the population. We conclude that, while male circumcision (a predominantly Muslim tradition) is inversely related with HIV prevalence, some other cultural factor continues to drive the correlation between Christianity and HIV.

Chapter 3 compares the role of democracy to economic freedom in determining health outcomes in African countries. After incorporating controls, I find that economic freedom is associated with higher life expectancy and lower infant mortality while democracy is not. However, I also find that the effectiveness of economic institutions depends in part on the resources that are present in a given country. In the absence of water access, for example, a stronger government may play a role in providing public goods for the benefit of the health of the population.

In Chapter 4, I investigate the institutional determinants of the high levels of shadow economic activity present in the subSaharan region. My findings show that improved legal and property protection in addition to a sound money supply decreases informality within a given country. Furthermore, by employing a spatial econometric model, I find that countries that are neighbors to a country with less intrusive government oversight are likely to experience lower levels of informal activity themselves.
\end{abstract}




\section{ACKNOWLEDGEMENTS}

The journey that has led to the completion of this dissertation would not have been possible for me had it not been for the many people that helped me along the way. First of all, I would like to thank my husband Philip Mandzik, for always being in my corner. He has been supportive and understanding but has always challenged me to do my best. I am so grateful to have the most loyal best friend the world has ever known. Also, I would like to thank my family: Mom and Dad have been my biggest fans since the day I was born and have been there for me for everything I have ever needed. I appreciate them not only for the countless things they have done for me but most of all for how much they have loved me no matter what. I have enjoyed all of the fun memories made with Zak, Luke, and Becky (particularly the late-night jonesing). To Becky, I am so thankful to have a sister who listens to me when I need encouragement but is ready for finding the fun and adventure in life with me too. I would also like to thank my "new" family: Mom and Dad Mandzik, Dan, and Dana. Your support and encouragement has made me feel like I have been with you guys all along. Also thank you to my countless friends, roommates, and peers who have been there with me (and for me) through the years. I love you all!

At both Shepherd University and West Virginia University, I am indebted to so many individuals who helped me and challenged me academically. I would have never considered graduate school had it not been for my undergraduate mentor, Dr. Linda Kinney. Not only has she encouraged me in my academic pursuits, but also she has been a wonderful friend whom I have truly enjoyed spending time with, both in and out of the classroom. At West Virginia University, I owe a tremendous thank you to my advisor and committee chair, Dr. Andrew Young. He has always been there for me for help and reinforcement and has helped me to maintain the momentum that I needed throughout this project. I am entirely grateful for all of the attention that he has given me to help me see this through. I thank the other committee members: Dr. Donald Lacombe, for unceasingly helping me with spatial questions with instantaneous email responses; Dr. Shuichiro Nishioka, for helping me to give my papers direction; and Dr. Amanda Ross, for all of the invaluable job market advice (and for letting me borrow your briefcase!). Also in the economics department, I am nothing but thankful to the head of our department, Dr. Clifford Hawley, for being concerned for the success and well-being of all of the graduate students simultaneously; Dr. Brian Cushing, for the mentoring and support in teaching statistics; and Karen Smith, for the myriad of administrative favors she has done throughout my time at WVU.

Above all, I would like to thank my Heavenly Father for the love that He has always shown me in giving me life, infinite blessings in that life, and salvation after life. 


\section{TABLE OF CONTENTS}

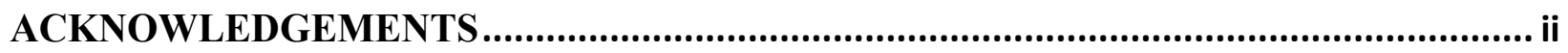

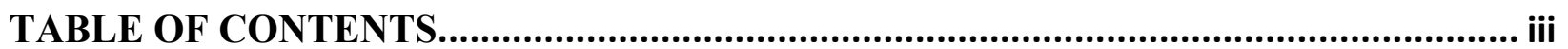

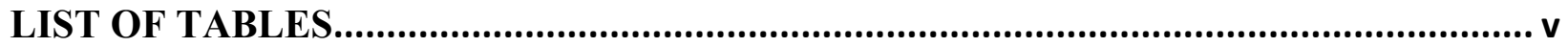

LIST OF FIGURES....................................................................................................... v

Chapter 1: Introduction .................................................................................................. 1

Chapter 2: Religion and AIDS in Sub-Saharan Africa: Unbundling Religious Institutions

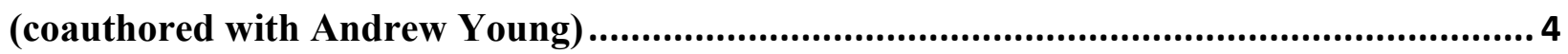

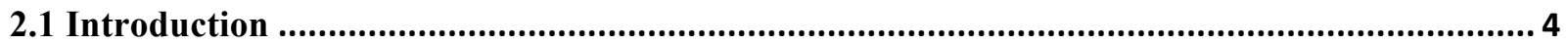

2.2 The Sub-Saharan African HIV/AIDS Pandemic .................................................................... 6

2.3 Previous Studies of HIV/AIDS and Religion in Sub-Saharan Africa ......................................... 8

2.4 Unbundling Religious Institutions....................................................................................... 9

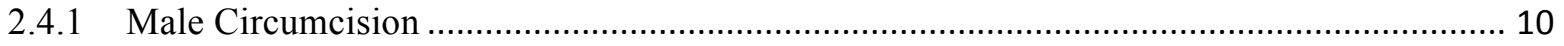

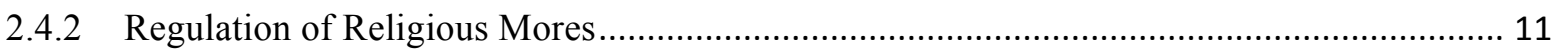

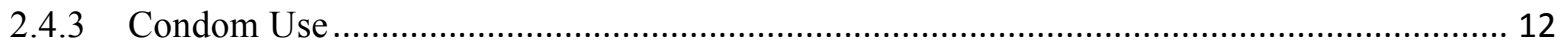

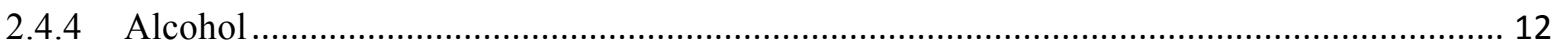

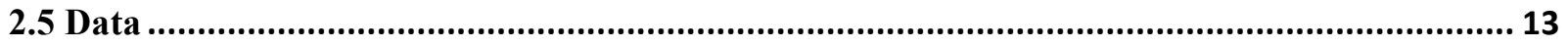

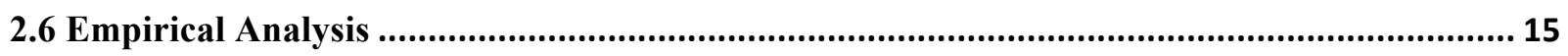

2.6.1 Religious Affiliation and HIV Prevalence..................................................................... 16

2.6.2 Cultural Institutions and HIV Prevalence ..................................................................... 17

2.6.3 Is Religious Affiliation Important Once Institutions are Controlled For? ........................... 20

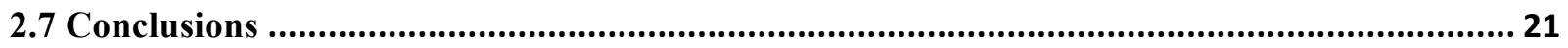

Chapter 3: The Impact of Institutions on Health Outcomes in Sub-Saharan Africa: Which

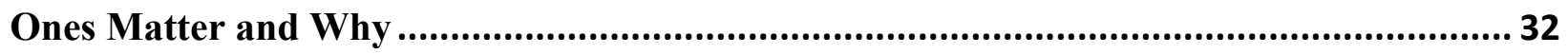

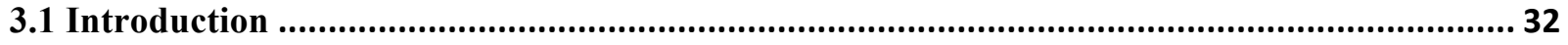

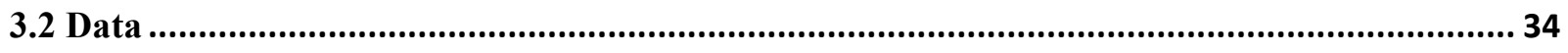

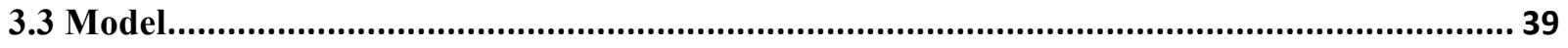

3.4 Empirical Results and Discussion ..................................................................................... 41

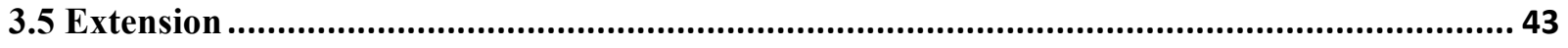

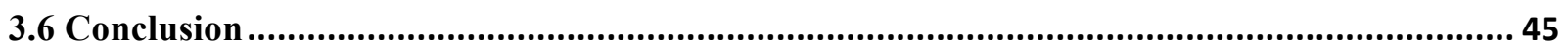

Chapter 4: The Spatial Configuration of the Informal Sector in Sub-Saharan Africa: Do

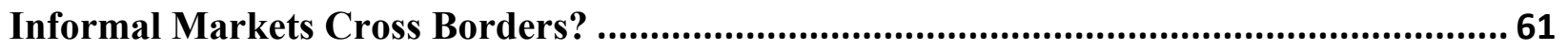

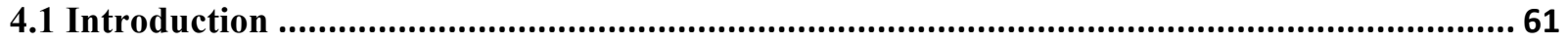

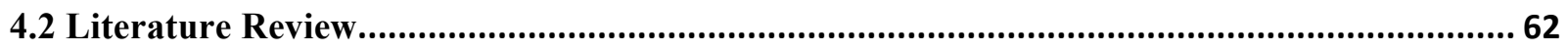

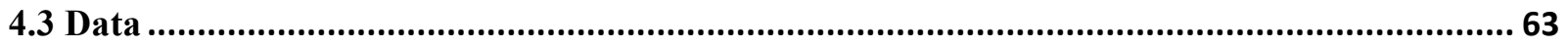




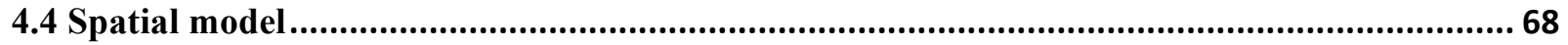

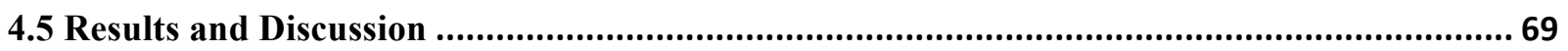

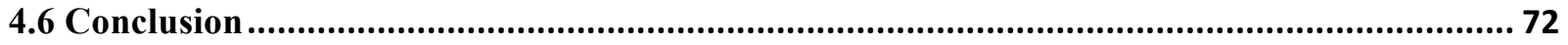

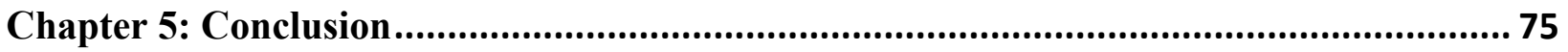

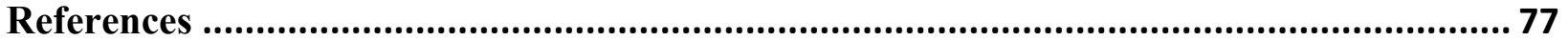




\section{LIST OF TABLES}

Table 1: Preliminary pooled regressions of Sub-Saharan HIV rates on religious affililation ................... 26

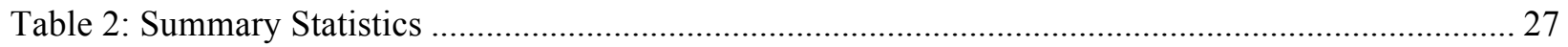

Table 3: Correlation Matrix of HIV Prevalence, Religion Variables, \& Institution Variables .................. 28

Table 4: Regressions of Sub-Saharan HIV rates on religious affiliation with benchmark controls ........... 29

Table 5: Regressions of Sub-Saharan HIV rates on non-religious institutional variables ......................... 30

Table 6: Regressions of Sub-Sahran HIV rates on religious affilaition and non-religious institutional

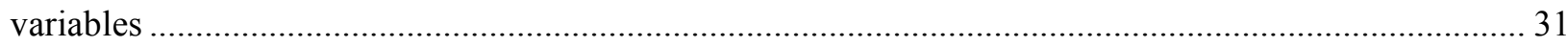

Table 7: Preliminary pooled regressions of Sub-Saharan health outcomes on institutions ...................... 49

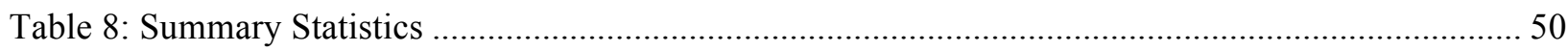

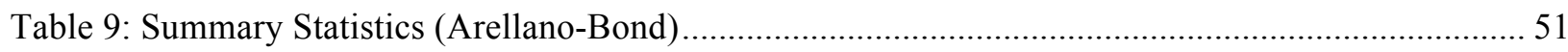

Table 10: Regressions of Sub-Saharan health indicators on economic and political institutions with

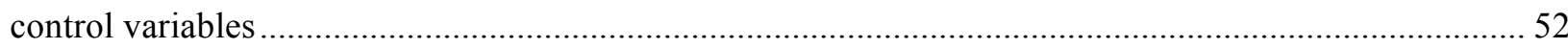

Table 11: Regressions of Sub-Saharan infant mortality on areas of Economic Freedom of the World Index

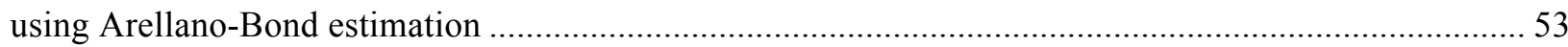

Table 12: Regressions of Sub-Saharan life expectancy on areas of Economic Freedom of the World Index

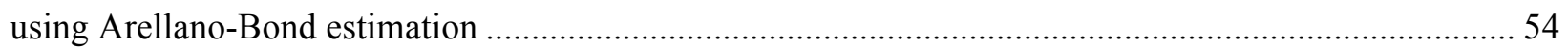

Table 13: Regressions of Sub-Saharan infant mortality on areas of Economic Freedom of the World Index using Arellano-Bond estimation (including interaction variable)........................................................ 55

Table 14: Regressions of Sub-Saharan life expectancy on areas of Economic Freedom of the World Index using Arellano-Bond estimation (including interaction variable) ........................................................ 56

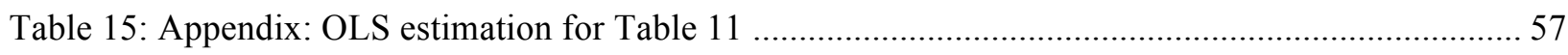

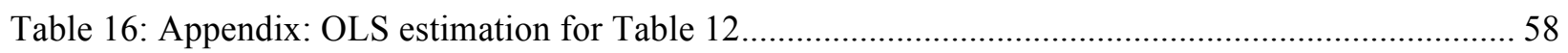

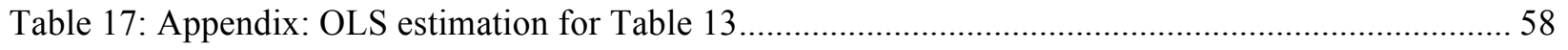

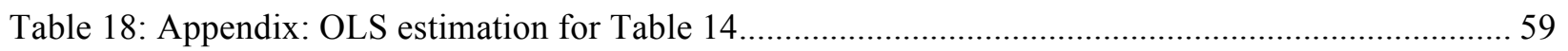

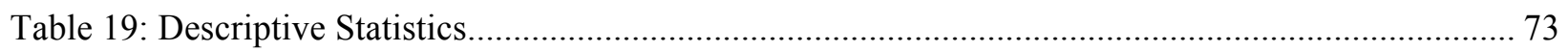

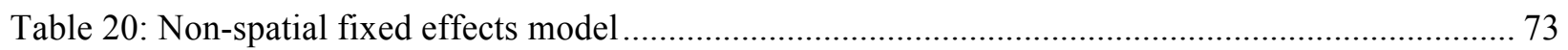

Table 21: Spatial Durbin model (SDM) results .............................................................................. 74

Table 22: Spatial Durbin model (SDM) results controlling for GDP per capita ..................................... 74

\section{LIST OF FIGURES}

Figure 1: Muslim share of the population compared to HIV prevalence rates ....................................... 24

Figure 2: Relationship between Sub-Saharan HIV prevalence and religious affiliation .......................... 25

Figure 3: Comparison of relationship between Sub-Saharan Health Outcomes with Economic versus

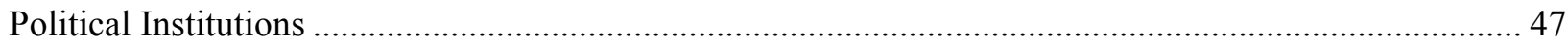

Figure 4: Detecting Autocorrelation in Life Expectancy and Infant Mortality: Plots of residuals against

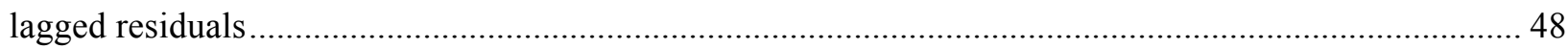




\section{Chapter 1: Introduction}

A great deal of attention has been given to understanding why some nations perform so much better than others both economically and developmentally. A portion of the development literature contends that this is a result of geography or natural resources - or, figuratively, the cards that have been dealt to a country from the beginning. Gallup, Sachs, and Mellinger (1999) observe that nearly all tropical countries are poor while almost all countries in higher latitudes are rich. Furthermore, temperate countries in the northern hemisphere are the wealthiest. They conclude that location, climate, and geography affect growth and development through transport costs, disease burden, agricultural productivity, and economic policy. As an alternative explanation, resource endowments may determine success or failure. Sachs and Warner (2001) propose that a nation may suffer from natural resource abundance, which creates high-price economies that cause a country to miss out on export-led growth.

Beyond geography and resources, a case is also made for the visibly intangible characteristics of a country as the most significant determinants of development: institutions. Institutions structure the way a society runs and are established both formally and informally in everything from legal codes to markets to religions to a simple social norm such as a handshake. Acemoglu et. al (2001) find evidence that geography has no independent effect on development but instead that institutions are the significant indicator of development. This provides a more optimistic view that less developed countries can both determine and restructure the rules of their societies to generate future growth and development.

In the following chapters, I turn my attention specifically to sub-Saharan Africa where institutions may have a role to play moving forward. Sub-Saharan Africa is the region of the world facing the lowest levels of development in terms of health and economics. Sub-Saharan Africa has been hit the hardest by the HIV/AIDS epidemic with 68 percent of the world's HIV positive patients living in the region (UNAIDS World AIDS Day Report 6, p. 7). The infant mortality rate in Africa is about six times higher than that in Europe, and average life expectancy is under 60 years of age (WHO, 2014). In 2010, almost $50 \%$ of the sub-Saharan population was living on less than $\$ 1.25$ day, and the average income per capita was just over $\$ 1,000$ as 
compared to about $\$ 50,000$ in the United States (World Bank, 2014). Sub-Saharan Africa has the largest shadow economy (as a percentage of "official" gross domestic product) with a median of 40.5 percent, which indicates that there is a large portion of the population that cannot or chooses not to participate in the official economy of their own country (Schneider, et al. 2010).

North (1990) asserts that "institutions, together with the standard constraints of economic theory, determine the opportunities in a society" (North, 1990, p. 7). Therefore, I employ an institutional approach to modeling how the prevailing institutions in the region have and continue to shape the AIDS crisis, poor health outcomes, and the large informal sector. In Chapter 2, with Andrew Young, I explore the role of religion in sub-Saharan Africa. A map (see Figure 1 in Chapter 2) of HIV rates reveals that the northern part of the continent is relatively less affected (near $0 \%$ ) by the HIV virus while some southern countries have experienced HIV prevalence rates as high as $25 \%$ and above (World Bank, 2014). This geographical pattern corresponds with the religious demographic composition of the continent: the north is predominantly Muslim while the south is predominantly Christian. Interpreting religion as a "bundle" of institutions, we attempt to unwrap the cultural norms associated with each religion in order to determine the more specific drivers of HIV prevalence in sub-Saharan Africa. We find that male circumcision, which is culturally linked to Islam, has a large negative effect on HIV prevalence. Nevertheless, the Christian population share remains to robust to controlling for male circumcision which indicates that there is some other unaccounted factor associated with being a Christian in this region that is causing the relatively high HIV rates in the south.

In Chapter 3, I examine the impact of both political and economic institutions on health outcomes of infant mortality and life expectancy in sub-Saharan Africa. However, the broad characterization of the term "institutions" extends across a wide range of contexts failing to consider the more specific channels of both political and economic institutions. Furthermore, the actual mechanisms through which institutions may improve health are not easily disentangled. In this study, I first compare the impact of economic and political institutions on health. Next, I investigate specific institutional determinants of health by breaking down the institutional index into its sub-components. As an extension, I then interact these specific channels with the availability of water to see if institutions react with other resources to stimulate positive health outcomes. I conclude that economic institutions, specifically limited regulations, sound money 
supply, trade freedom, and small government, are the institutional conduits of improved health outcomes in sub-Saharan Africa. As an extension to this study, I find that the presence of economic freedom in a country may allow improved water access to impact health outcomes more effectively than improved water access would by itself. However, there is also evidence that there may be a role for more government intervention in the provision of public goods, specifically water, in order to reduce infant mortality.

Finally, in Chapter 4, I consider the role of institutions in a country or in neighboring countries on the extent of informal sector activity that is present. By definition, the shadow economy exists outside of the recognition of a national government's oversight. Therefore, it would seem as though national borders should matter little when considering the spread of the informal sector. Nevertheless, it reasonable to think that the set of institutions fostered by a given country will motivate an individual's decision of whether to operate within the formal or informal economy. Stronger, business-friendly institutions are more apt to encourage people to participate in the official economy while weaker institutions attract individuals to alternatives to the official economy. With one of the largest shares of shadow economic activity worldwide, sub-Saharan Africa offers a lens to study the geographic flows of informal sector activity among countries. By employing a spatial econometric model, this study examines the extent to which informality spills across national borders in sub-Saharan Africa through specific economic institutional channels. 


\section{Chapter 2: Religion and AIDS in Sub-Saharan Africa: Unbundling Religious Institutions (coauthored with Andrew Young)}

\subsection{Introduction}

An estimated 34 million people suffer from HIV worldwide, and although the sub-Saharan African region accounts for only 12 percent of the global population, 68 percent of HIV positive individuals reside in sub-Saharan Africa (UNAIDS World AIDS Day Report 6, p.7). In 2010 alone, AIDS claimed 1.2 million lives in sub-Saharan African countries (AVERT, 2011). The loss of life and health is especially destructive to a region of the world that is characterized by a lack of economic development.

HIV is neither an airborne nor a waterborne virus, and unlike other devastating viruses (e.g., Malaria), HIV does not transmit across human populations via contact with other species. ${ }^{1}$ The evolution of the HIV/AIDS pandemic is, therefore, almost exclusively determined by human interactions. The institutions governing those interactions are therefore of first-order importance to understanding the pandemic. As the "rules of the game in a society" (North, 1990, p.3), institutions shape the incentives - the relative costs and benefits - that individuals face in deciding how to act and interact with others.

Religions represent particular bundles of institutions, and this paper explores the role of religions in the sub-Saharan HIV/AIDS pandemic. There are compelling prima facie reasons to believe that religious institutions are critical to understanding this pandemic. Figure 1 provides two maps: the one to the left displays the Muslim share of the population (average from 20002009) while the one to the right shows HIV prevalence rates for this time period. These maps effectively paint an account in which the northern, predominantly Muslim countries are relatively less affected by HIV while the southern, predominantly Christian countries are relatively more affected by HIV prevalence. Figure 2 plots, using data from the year 2000, HIV prevalence rates against, separately, Christian and Muslim population shares. Christianity positively correlates with HIV rates while Islam negatively correlates with HIV rates. Best-fit OLS regression lines are included in figure 2 and the estimates of the slopes are both statistically

\footnotetext{
${ }^{1}$ It is commonly believed that HIV did initially jump the species barrier in Western or Central Africa to the human population from another primate species.
} 
significant at the $1 \%$ level. Eyeballing the scatter plots suggests that the relationships may be logarithmic and columns 1 and 2 of Table 1 report the bivariate regression results. ${ }^{2}$ The $\mathrm{R}^{2} \mathrm{~s}$ are both greater than 0.340 . Either religion variable accounts for more than a third of the variation in sub-Saharan cross-country HIV rates. Column 3 of table 1 reports results from a regression of HIV rates on both religious variables. The coefficient estimates are again positive for the Christian share, negative for Muslim share, and statistically significant in both cases (though now at the 10 percent level in the case of Muslim).

Neither religion (at least in its major variants) is known to explicitly advocate "high risk" behavior such as intravenous drug use, prostitution, promiscuity, or homosexuality. ${ }^{3}$ The puzzle, then, is how these respective frameworks structure human interactions and lead, directly or indirectly, towards relatively higher or lower occurrences of infection. In other words, we seek to unbundle Christianity and Islam in a way that identifies institutional components (e.g., sexual norms) that are likely to affect the relative rates of HIV infection. ${ }^{4}$ Having done so, we construct a panel of data on up to 43 sub-Saharan African countries that includes proxies for these institutional components. Using this data, we attempt to empirically assess which of these are important determinants of cross-country variation in sub-Saharan HIV rates. In doing so we include various additional controls that are suggested by the literature: population density, urban population shares, GDP per capita levels, date of first recorded HIV case, and a country's latitude.

We proceed as follows. Section 2 provides some brief background on the HIV virus and the sub-Saharan HIV/AIDS pandemic. In regards to the role of religion in this pandemic, we review the contributions of previous researchers in section 3 . In section 4 we unbundle Christianity and Islam into what we believe to be relevant institutional components and then, in section 5, we describe a data set constructed to include proxies for those components. An

\footnotetext{
${ }^{2}$ The Christian and Muslim population shares have 1 added to them before taking logs to account for observations where the reported share is zero.

${ }^{3}$ To be clear, "high risk" in this context only refers to the likelihood of the virus spreading through the human contact associated with the behavior.

${ }^{4}$ As North (1989, p. 1321) stresses, institutions include "rules, enforcement characteristics of rules, and norms of behavior" (emphasis added). For example, there can be large differences in effect between, e.g., premarital abstinence norms across religions. One way that we address this in the empirical analysis that follows is by controlling for a measure of the strength of social regulation of religious mores.
} 
empirical analysis of the role of these component institutions is found in section 6. Concluding discussion follows in section 7.

\subsection{The Sub-Saharan African HIV/AIDS Pandemic}

Human immunodeficiency virus (HIV) is the retrovirus that causes acquired immunodeficiency syndrome (AIDS). The retrovirus functions by converting its own genetic template (viral RNA) to the host organism's genetic information (host DNA) while using the host cells' energy and chemical resources for this replication process (Marlink and Kotin, 2004, p. 2). The DNA of a host cell becomes integrated with the viral DNA leaving the host cell invisible to the immune system. Upon infection, the mutation of host cells occurs rapidly, although the HIV virus may remain dormant for some time. As the HIV virus progresses into advanced stages, the condition turns into AIDS, which ultimately is the condition that results in the deterioration of the immune system. Consequently, AIDS deaths typically result from opportunistic infections and tumors that the body could normally fend off.

The African strain of the AIDS virus was first officially identified in 1983 among several African patients treated in Belgium and France (Carael, 2006). Experts now believe, however, that the virus has been present in humans for a considerably longer time. In particular, there is a consensus that HIV was transferred from chimpanzees to humans in Central Africa at some point between the 1930s and 1940s (AVERT, 2013). HIV has been traced to stored human blood from 1959, and it is likely that the first epidemic occurred in Kinshasa of the Democratic Republic of Congo in the 1970s (Denis 2006; AVERT, 2013). Geographically, the virus began to spread in the early 1980s within the central band of the continent stretching from West Africa to the Indian Ocean, and it progressively moved southward at the end of the decade (UNAIDS and WHO, 2003). In 1990, the Sub-Saharan HIV prevalence rate was 2.5\%, and this rate increased steadily until 2000 when it reached 5.95\% (World Bank, 2013). Despite campaigns to curtail the virus' spread, the 2011 prevalence rate was still a disturbingly high 4.9\% (World Bank, 2013).

Although the virus has permeated throughout Africa, the severity of the epidemic varies widely depending on region. The northern and western regions have remained relatively less affected while southern countries have been the most devastated. At the peak of the epidemic in 
2000, the southern countries of Botswana and Swaziland experienced HIV prevalence rates of $26 \%$ and $22.3 \%$, respectively, whereas the HIV prevalence rate was $1 \%$ or less in the northern countries of Mauritania, Niger, Sudan, and Senegal (World Bank, 2013).

Initially, the African HIV/AIDS epidemic was met with unresponsiveness both regionally and globally (AVERT, 2013). Little was known about the virus, and African governments were not only weak but faced more immediate political problems including civil war (Lewis, 2006). Moreover, the taboo sexual nature of HIV/AIDS transmission created stigmas that resulted in rejection and censure of scientific evidence by some African leaders (Denis, 2006). For example, in Zimbabwe, doctors were not permitted to reference AIDS on death certificates. Also, under President Mobutu, press members in the Congo were prohibited from publicly discussing AIDS until 1987 (AVERT, 2013).

The worsening of the crisis in the 1990s forced countries to make the issue a national priority (Carael, 2006). Globally, the world responded with the creation of UNAIDS in 1995 as a Joint United Nations Programme on HIV/AIDS and began to take an active role in assisting the Sub-Saharan African region (UNAIDS, 2013).

Currently, there is an antiretroviral treatment that can be administered to patients daily to allow HIV patients to live longer. Antiretroviral drugs (ARVs) are not a cure for HIV/AIDS, but they slow the progression of HIV to AIDS permitting patients to live relatively normal lives (AVERT, 2012). While the cost of the treatment was prohibitively high when it was first introduced in 1996, over time, as a result of the introduction of generic versions, price competition, and pressure from organizations, the treatment for an individual is now available at a cost of $\$ 64$ per year--or $18 \notin$ a day.

Despite the decline in the cost for ARVs and great strides made in its availability, currently, only 49\% of Africans infected with HIV are receiving the treatment (AVERT, 2012). This is a reflection of sub-Saharan Africa as among the poorest regions of the world. According to the World Bank, in 2008, $47.5 \%$ of the sub-Saharan African population was living on $\$ 1.25$ a day, and $69.2 \%$ of the population was living on $\$ 2$ a day (World Bank, 2012). In 2012, the subSaharan GDP per capita was $\$ 1,433$ in comparison to the United States' GDP per capita of $\$ 49,965$ (World Bank, 2013). 
The antiretroviral treatment is not a cure for HIV/AIDS, nor is such treatment universally available, so preventive measures offer the most effective means for addressing the epidemic. One of the goals of this study is to trace the cultural channels of the infection from the knowledge of the proximate causes. Direct HIV transmission results from shared bodily fluids during birth, breast-feeding, sexual intercourse, drug injection with shared equipment, or contaminated blood transfusions (Marlink and Kotin, p. 5). However, because "poverty in Africa precludes drug use" and homosexuality is uncommon in this region of the world, AIDS is chiefly transmitted through sex between men and women and, as a consequence, perinatally to infants (Fredland, 2001, p. 222). According to AVERT, there is a 15 to 45 percent chance of mother-toinfant transmission from HIV-positive mothers (AVERT, 2014). This can be reduced to a rate of less than $5 \%$ by administering antiretroviral treatment, however, and significant improvements have been seen in recent years in a number of countries. Therefore, this study will focus on the adult population, where HIV prevalence is highest, and the reasons that some groups may be more or less likely to expose themselves to the kind of contact that would put them at risk for acquiring HIV.

\subsection{Previous Studies of HIV/AIDS and Religion in Sub-Saharan Africa}

There are only a handful of empirical studies on the relationship between religion and the HIV/AIDS pandemic in sub-Saharan Africa. None of these studies are undertaken by economists.

Gray (2004) reports that Muslim population shares are negatively related to HIV prevalence rates in sub-Saharan Africa. As potential explanations, he points to elements of the Islamic moral code: prohibitions on premarital and extramarital sex, as well as alcohol. Gray's survey of a small number of country case studies also suggests that the Muslim practice of male circumcision may be important for hindering the virus' spread. While Gray suggests underlying links between HIV prevalence and Islamic religious institutions, he presents no explicit evidence of their relevance or lack thereof.

In a study incorporating an array of economic, social, political, cultural, and regional factors as explanatory variables, Tiruneh (2009) concludes that interactions between religious 
affiliation and other controls account for most of the variation in African adult HIV prevalence rates. He reports a significant positive correlation between southern Christian African countries and HIV rates, and a significant negative correlation between northern Islamic African countries and HIV rates. Tiruneh suggests that these results are indicative of more severe punishments for sexual transgressions within the Muslim cultures. Sharia law, which dictates Islamic moral code and religious law, allows for physical punishments including whipping and stoning. In contrast, while "Christianity prohibits pre- and extra marital sex, there is no legal enforcement to such practices" (Tiruneh, 2009, p. 116). Furthermore, commercial sex is most prevalent in the southern African countries that are predominantly Christian (Tiruneh, 2009, p. 116). ${ }^{5}$

Hargrove (2008) notes the lower rates of HIV prevalence in Muslim versus Christian countries in sub-Saharan Africa. He reports evidence that circumcision rates are an important determinant of HIV prevalence but that controlling for them does not eliminate the significant, negative correlation between Muslim population share and HIV prevalence. He suggests that this may be due in part to the strong family coherence among the Muslim cultures that contrasts with the migratory work patterns of southern Africans who are predominantly Christian. However, Hargrove presents no explicit evidence on this hypothesis. Furthermore, the only additional controls that he includes are regional (West/Central, East, and South) dummy variables.

\subsection{Unbundling Religious Institutions}

Although the literature shows a link between Islam and decreased HIV/AIDS rates, the extant analyses of underlying institutional determinants are incomplete at best. In this paper we seek to explore a more comprehensive set of potentially relevant religious institutions.

Both Christianity and Islam teach that followers should avoid sexual promiscuity, one of the most common channels of HIV transmission. Paul's first letter to the Corinthians counsels

\footnotetext{
${ }^{5}$ McIntosh and Thomas (2004) also explore economic and societal determinants of HIV prevalence. However, they study a broader cross-country sample (which does, of course, include sub-Saharan Africa). They also report that predominantly Muslim countries had lower prevalence rates. However, they also find that Orthodox Christianity also negatively correlates with the prevalence of HIV infection. Drain et al. (2004) explore a large number of socioeconomic determinants for 122 developing countries. However their results are almost exclusively from univariate regressions and are therefore difficult to interpret.
} 
Christians to "flee from sexual immorality" (1 Corinthians 6: 18); likewise, a passage from the Qur'an warns that one should "not approach unlawful sexual intercourse" (Qur'an: Surat Al'Isra' 17:32). Despite these clear commands, unsafe heterosexual relations remain the prominent means of transmission of the epidemic in sub-Saharan Africa (de Waal, 2006, p. 60; Fredland, 2001, p. 222). Therefore we elaborate on institutions that may affect either the probability of unsafe contact or the probability that unsafe contact transmits the HIV virus.

\subsubsection{Male Circumcision}

Since the 1980s, scientists have hypothesized that male circumcision decreases the risk of HIV transmission, and recent medical studies have provided supporting evidence. Clinical trials in South Africa, Uganda, and Kenya have shown that circumcision reduces men's risk of sexual HIV transmission by approximately 50 percent and up to 60 percent (AIDS Vaccine Advocacy Coalition 2007). It is hypothesized that removal of the male foreskin eliminates a concentrated area of cells that are targeted by HIV in the early stages of infection. Furthermore, circumcision may reduce the likelihood of genital ulcers as an HIV risk factor, and the procedure eliminates the possibility that small tears in the foreskin will make it easier for the virus to enter the body (Morris and Wamai, 2012).

Although the Qur'an does not explicitly require circumcision of males, Muslims are the largest single religious group to traditionally circumcise males (Rizvi et al., 2009). Circumcision evolved as a ritual for cleanliness, but it has since become intrinsically incorporated into Islamic culture as an initiation into the Muslim faith (Morse, 2002). Depending on the family, region, and country, circumcision may be performed symbolically at various landmarks in a Muslim boys' youth: on the seventh day after birth, at the age of seven, after being able to recite the entire Qur'an, or during puberty. Muslim support for the practice has been strengthened by evidence suggesting it is effective as a preventive measure against infection and disease (BBC, 2009).

Of course, circumcision does not offer 100\% protection against HIV infection (Bonner, 2001). Furthermore, the association between circumcision and decreased infection has led to the concern that circumcision "might substitute, tragically, for other efforts such as condom use and 
behavioral modifications" (Silverman, 2004, p. 427). However, the practice of male circumcision in Muslim communities predates the HIV/AIDS pandemic. Therefore, circumcision rates can be reasonably taken as exogenous potential determinants of prevalence rates.

The role of Muslim circumcision draws a significant distinction from Christian cultures in the Sub-Saharan African region. Whereas Muslims continue to practice this time-honored tradition, male circumcision is not nearly as prominent within the Christian populations of Africa (Williams et al., 2006). Furthermore, some Christian missionaries have attempted to end the tradition of circumcision because the rites "were bound up with so much 'pagan' culture" (Becker, 2007, p. 26).

\subsubsection{Regulation of Religious Mores}

Another factor that has been suggested as a link to lower HIV prevalence rates in Muslim populations is the institution of Sharia (Islamic) Law (Tiruneh, 2009). In contrast to the pursuit of a secular government, "Muslims believe the separation of religion and state lead to moral decadence in society, therefore only Sharia, divine injunctions and positive law, can curb moral decline" (Sindima, 1998, p. 152). Consequently, the Islamic worldview holds that religious law should become the state law. Muslims uphold traditional values forbidding fornication, and trespassers are subject to punishments specified by the Qur'an. Clearly, this creates a greater incentive to follow Islamic moral code that is not present in many Christian communities. The decrease in promiscuous behavior may contribute to the lower prevalence of HIV.

Aside from the threat of physical and judicial enforcement, it is possible that some religious communities are more effective at enforcing their religious sexual rules than others by means of a socially perceived obligation or peer pressure. A religious community with the ability to influence the behavior of both members (and non-members) may effectively impact the prevalence of religious sexual transgressions. For this reason, a stricter or more conservative society would be expected to see lower levels of HIV prevalence. 


\subsubsection{Condom Use}

The use of condoms is a specific and straightforward means of preventing the spread of HIV. Traditionally, the Catholic Church has been outspoken in its opposition to the use of condoms to control the spread of HIV (Benagiano et al., 2011). However, condom usage has also been passionately debated within Islamic communities, and Muslim clerics and leaders have led campaigns against the promotion of condoms (Moszynski, 2008). Nevertheless, several subSaharan country governments have adopted the AIDS/HIV prevention slogan: "ABC: Abstinence, Be Faithful, and Use a Condom" and have seen considerable increases in condom use according to the United Nations Population Fund (Deegan, 2009, p. 138). UNAIDS, UNFPA, and WHO have released the official position statement that "the male latex condom is the single, most efficient, available technology to reduce the sexual transmission of HIV" (UNAIDS, 2009). However, some experts argue that "consistent condom use has not reached a sufficiently high level ... to produce a measurable slowing of new infections in the generalized epidemics of Sub-Saharan Africa" (Potts et al, 2008, p. 749).

\subsubsection{Alcohol}

Accepted wisdom warns that alcohol in excess lowers inhibitions and may lead to risky behavior including unsafe sex. Heavy episodic drinking is higher in Africa than anywhere else in the world (WHO, 2011, p. 16). Furthermore, crime statistics from South Africa indicate that alcohol plays an important role in the occurrence of rape. In 1996, according to the Crime Information Centre, alcohol or drugs played a role in over $25 \%$ of reported rape cases in the Western Cape and in 36\% of those in the Northern Cape of South Africa (Deegan, 2009, p. 97).

Northern Africa tells a different story about the consumption of alcohol, however. Strict adherents of the Muslim faith abstain from alcohol as the Qur'an asserts that "intoxicants . . . are but defilement from the work of Satan" (Qur'an; Surat Al-Maidah 5:90). Globally, abstention from alcohol is highest in the Northern African Muslim countries (WHO, 2011). In our sample

of sub-Saharan African countries (see section 5 below) the pairwise correlation between Muslim 
population shares and alcohol consumption per capita is -0.0405 and statistically significant at the $1 \%$ level.

\subsection{Data}

We construct a panel for up to 43 sub-Saharan African countries where average HIV prevalence is recorded for two periods: 1990-2000 and 2000-2010. The dependent variable of interest is the (log) HIV_PREVALENCE rate (UNAIDS \& WHO's Report on the Global AIDS Epidemic).

Average CHRISTIAN and MUSLIM population shares for the two periods are based on the available 1990-2009 yearly estimates from the CIA Factbook. We also consider the alternative measures reported in La Porta, et al. (1999). These measures are based on data going back to 1980 and do not give us any variation across the two time periods of our panel. However, they allow us to decompose Christianity into protestant (PROTESTANT_LLSV) and Catholic (CATHOLIC_LLSV) shares. Since the religious composition of a population often varies slowly, being able to make the distinction between protestant and Catholic populations might be worth that cost.

We consider four variables as proxies for relevant religious institutions. The first of these is adult (15+ years) $A L C O H O L$ yearly consumption per capita. This data are from the WHO and we use 1990-2000 and 2000-2008 averages. That being stated, we expect $A L C O H O L$ to be associated with unsafe sexual behavior and, therefore, positively related to HIV_PREVALENCE.

For the remainder of our institutional variables, we unfortunately must rely entirely on cross-sectional variation. However, they all represent cultural practices that likely vary slowly over time. We consider MALE_CIRCUMCISION rates based on the 2003 estimates reported by Williams (2006). We expect that MALE_CIRCUMCISION decreases the likelihood of the virus spreading during sexual intercourse and, therefore, is negatively related to HIV_PREVALENCE.

We employ an index of the social regulation of religion (SOC_REG_RELIGION) that is described in Grim and Finke (2006) and coded by Grim (2005). This index measures the "general social attitudes toward religion and the actions of social movements and religious institutions toward other religious groups, especially new, foreign, or minority religions" (Grim 
and Finke, 2006, p. 2). It is based on answers to 5 questions included in the surveys conducted by the US State Department for its International Religious Freedom Reports. Specifically, these questions gauge (a) societal attitudes toward other or nontraditional religions, (b) relations between different religious communities, (c) social attitudes to conversations about other religions, (d) whether attitudes and/or edicts of a clerical establishment discourage proselytizing, and (e) whether established religions attempt to shut out new religions. (See Grim (2005, ch. 3) for more detail.) We anticipate using this variable to capture the "religiosity" of a given country and the potential for social pressure to adhere to religious commands of the predominant faith, be it either Christian or Muslim. We expect that a "stricter" society will exhibit lower levels of HIV_PREVALENCE as a result of fewer risky sexual encounters. This variable is particularly relevant for Islamic populations with Sharia Law. We take the average of values reported for 2001, 2003, and 2008.

Finally, we include a variable measuring male CONDOM use as a percentage of the male population ages 15-24. This data comes from the World Bank, and we take the average yearly values available from 1990-2009. While the data span both the 1990-2000 and 2000-2010 time periods of our panel, the reporting for individual years is sparse and idiosyncratic across countries. ${ }^{6}$ Therefore we treat $C O N D O M$ as fixed across time periods. Our prior is that condom use will impact HIV_PREVALENCE negatively. However, it is also possible that condom use decreases the perceived riskiness of sexual intercourse and leads to a more than offsetting increase in intercourse. In that case the effect on the spread of HIV could be positive.

For additional controls we begin by following Gray (2004) and consider population density (POP_DENSITY), the urban population share $(U R B A N)$, GDP per capita $\left(G D P \_P C\right)$, and year of a country's first recorded AIDS (FIRST_CASE). Intuition might at first suggest that POP_DENSITY and URBAN are negatively related to HIV_PREVALENCE. Both variables are positively related to the number of people that a given individual can expect to come into contact with. However, The Food and Agriculture Organization (FAO) of the United Nations reports that AIDS is increasingly becoming a greater threat in rural areas than cities (FAO, 2013). According to FAO, "many urban dwellers and migrant labourers return to their village of origin when they

\footnotetext{
${ }^{6}$ For examples, Benin only has a recorded observation for 2001 (31.7\%); Ghana has recorded observations for 1998 (31\%), 2003 (44.5\%), and 2008 (40.1\%); Liberia has a single recorded observation for 2007 (18.6\%).
} 
fall ill" (FAO, 2013). Similarly, while there are numerous reasons to think that GDP_PC correlates negatively with $H I V \_P R E V A L E N C E$ (e.g., higher incomes are associated with more education about the nature of HIV, its transmission, and its prevention) there may actually be a higher rate of risky sexual contact amongst the wealthy. This may be related to the fact that the wealthy tend to have better access to health care and therefore, all else equal, perceive infection as less costly. Indeed, existing studies report a positive correlation between HIV and income and wealth (Mishra et al. (2007) and Shelton et al. (2005)). Additionally, we include the LATITUDE of a country's geographic center to account for the stark contrast in HIV prevalence between Northern and Southern Africa (Hargrove, 2008 and Tiruneh, 2009).

Summary statistics, descriptions, and sources for all of the above variables are provided in table 2. Table 3 then provides a correlation matrix for the HIV prevalence, religion, and institutional variables. Unsurprisingly, CHRISTIAN (MUSLIM) correlates positively (negatively) with HIV_PREVALENCE. Also, three of the institutional variables (CIRCUMCISION, $A L C O H O L$, and SOC_REG_RELIGION) have the expected correlation with HIV_PREVALENCE (negative, positive, and negative, respectively). However, CONDOM's pairwise correlation with $H I V_{-} P R E V A L E N C E$ is positive (0.54). Without putting too much stock in a simple pairwise correlation, this is consistent with the availability of condoms increasing the quantity of sexual intercourse demanded and/or the misuse or ineffectiveness of condoms in preventing HIV transmission. (As it turns out, CONDOM is not a statistically significant correlate once other variables are controlled for - see below in section 6.)

\subsection{Empirical Analysis}

In this section we report the results of regression analyses. We first explore the associations between HIV prevalence and religious affiliations in our 1990-2010 panel of sub-Saharan African countries. Once we establish the religion/prevalence partial correlations that are robust to our control variable set (table 4), we proceed to an analogous exercise using our institutional variables (table 5). Since we are interested in what underlying institutions drive the negative (positive) correlations between Muslim (Christian) affiliation and HIV prevalence, we explore whether or not the inclusion of particular institutional variables renders religious affiliation insignificant in a regression (table 6). 


\subsubsection{Religious Affiliation and HIV Prevalence}

We first consider the empirical relationships between religious affiliation and HIV prevalence. All variables enter regressions in natural $\log$ form. In the case of religious affiliations, we add one to variables before taking logs to avoid problems with observations of zero. Table 4 reports the results of ordinary least squares (OLS) regressions of the log HIV prevalence rate on religious affiliation along with our control variables. Columns (1) and (2) use the religion variables obtained from the more recent CIA Factbook data with and without period fixed effects respectively. These results establish that the expected positive and significant (at the $1 \%$ level) relationship between CHRISTIAN and HIV_PREVALENCE is robust to including MUSLIM and the additional control variables. A $1 \%$ increase in a country's Christian population share is associated with, all else equal, an increase in the HIV positive population share of about $0.4 \%$. (This is true whether or not period fixed effects are included. The redundancy of these effects, in any case, cannot be rejected.) To put this in perspective, the sample mean of CHRISTIAN is about 37 percent. Starting from that mean, a 10 percentage point increase in CHRISTIAN is about a $27 \%$ increase. This would be associated with an increase in HIV_PREVALNCE of about 11 percentage points. Alternatively, the coefficient estimate on MUSLM is actually positive when CHIRISTIAN is controlled for, but it is both small and insignificant. (This is also true with and without period fixed effects.)

Columns (3) and (4) are analogous to columns (1) and (2) except that they report regressions that substitute the La Porta et al. (1999) data for the CIA Factbook data on religious affiliation. While the coefficients on CHRISTIAN_LLSV are smaller than those reported based on CHRISTIAN, the results for religious affiliation are not qualitatively changed. The La Porta et al. (1999) data allows us to further differentiate Christians as either protestant or Catholic (columns (5) and (6)). Apparently it is the protestant population share (PROTESTANT_LLSV) that drives the significant relationship between HIV prevalence and Christianity in the sub-Saharan country sample. At face value this might suggest that Catholicism's antagonism towards condom use is not a driving factor. If Catholic antagonism towards condom use was driving the positive Christian affiliation/prevalence relationship, we would expect CATHOLIC_LLSV to be itself positive and significant in the regressions. That the protestant population share seems to matter 
more is an interesting puzzle, and one about which we can only speculate. One possibility is that British and Dutch colonizers in the south of Africa brought both their (predominantly protestant) religion as well as other institutional changes (e.g., production patterns that put stress on indigenous family structures). However, column (7) reports results analogous to those contained in column (5) except that we also include a dummy variable that takes the value of 1 if a country was ever a British or Dutch colony. Not only does that dummy not enter significantly; the coefficient on PROTESTANT_LLSV is virtually unchanged, both in terms of size and statistical significance.

Turning to the remaining control variables, both POP_DENSITY and URBAN are negatively correlated with HIV prevalence. This is contrary to our priors. Also, the simple pairwise correlations between each of these variables and HIV_PREV are both negative. This is consistent with findings of the FAO (2013) and Gray's (2004) estimates for the effects of these variables are also negative (though not significant). Per capita GDP and the HIV prevalence rate are also positively correlated, consistent with the studies of Mishra et al. (2007) and Shelton et al. (2005). Gray (2004) also reports a similar positive and significant effect for sub-Saharan African countries and, though insignificant, McIntosh and Thomas (2004) estimate an effect of the same sign for a broader sample of countries. The signs of these effects maintain throughout other regressions reported below. We also note that the farther a country is from the equator, all else equal, the higher its HIV prevalence rate. Although these variables are not the focus of our study, the partial correlations associated with them may be a fruitful subject of further studies.

The remaining control variable consistently has estimated effects that are consistent with our priors and statistically significant. The later a country's first reported case of AIDS, the lower the HIV prevalence rate. In other words, all else equal, the later on the scene HIV appears, the less time it has had to increase in prevalence.

\subsubsection{Cultural Institutions and HIV Prevalence}

Next we estimate models that relate the (log) HIV prevalence rate to variables that proxy for institutions associated with religious affiliations. The results are contained in table 5. 
Column (1) includes as regressors only the four institutional variables: $A L C O H O L$, MALE_CIRCUMCISION, SOC_REG_RELIGION, and CONDOM. While the social regulation of religion index does not enter significantly, the other three institutional variables do. ALCOHOL, in line with our prior expectation, enters positively and significantly, though only at the $10 \%$ level. MALE_CIRCUMCISION also has the expected negative estimated effect which is significant at the $1 \%$ level. These estimated effects are consistent with alcohol consumption impairing individuals' judgments regarding risky activities and male circumcision decreasing the likelihood of HIV transmission during sexual contact. Alternatively, CONDOM enters positively and significantly, which is surprising to us. A positive effect is consistent with the availability and acceptability of condoms increasing the demand for risky sexual activity to an extent that trumps the decreased likelihood of HIV transmission during "safe" sex.

However, amongst our proxies for institutions, we note that CONDOM is the most likely to be plagued by measurement error and/or reverse causality. First, CONDOM is based on selfreporting. Since, in many cultures, reporting on one's use of condoms is likely more embarrassing than reporting on, say, one's alcohol consumption, the possibility for systematic measurement error is particularly severe. Also, CONDOM has no time variation and is constructed from averaging over observations that are idiosyncratically available for the years 1990-2010. (See section 5 above.) Unlike, say, the social regulation of religion, it is quite plausible that observation on higher condom use were caused by programmatic responses to high HIV rates. For example, the highest observed value of CONDOM is $71.5 \%$ for Namibia. For the years 1990-2000 the average rate of HIV prevalence for Namibia is 7.72\%; very high (though not the highest in our sample). In 1996, the Youth Health Development Program (YHDP) was established in Namibia to promote, among other things, greater use of condoms (Fitzgerald et al., 1999). Nevertheless, the 2000-2010 average HIV prevalence for Namibia rose to $15.24 \%$ ! Surely the initially high HIV prevalence rate played a role in determining the policy response. However, whether the subsequent increase in HIV prevalence was in part caused by or despite of the YHDP and other efforts is difficult to determine based on our data. ${ }^{7}$ Another potential problem in interpretation is measuring how condom use has changed over time (from one period to the

\footnotetext{
${ }^{7}$ Fitzgerald et al. (1999, p. 52) report that "[k]nowledge increased significantly among intervention compared to control youth" participants in a YHDP program. However, their study does not directly link these results to HIV prevalence.
} 
next), particularly with regards to the change in HIV prevalence between periods. In order to capture this time variation, we would need data from all countries from both periods; however, in some cases the only available measurement for a country comes from a single year. Without this variation, we cannot determine whether condom use is going up (down) over time and by how much. With these caveats, we note that in all subsequent regressions including CONDOM that we report, the coefficient estimate is always positive; it is also often statistically significant.

Data availability on male condom use is quite limited relative to our sample and the column (1) regression includes only 29 countries. Therefore, column (2) reports a similar regression that drops CONDOM. This increases the number of countries to 40 . However, the results for $A L C O H O L$ and $M A L E \_C I R C U M C I S I O N$ are qualitatively unchanged and, while the point estimates both increase (from 0.244 to 0.397 for the former; from -0.445 to -0.378 for the latter) neither change in a statistically meaningful way.

Columns (3) and (4) report regressions that include all four institutional variables along with our full control variable set (with and without period fixed effects, respectively). MALE_CIRCUMCISION still enters positively and significantly at the $1 \%$ level; the point estimates (-0.389 in both cases) are nearly identical to that reported in column (2) (-0.378). CONDOM does not enter significantly into either regression, nor does $A L C O H O L$. Recall, however, that $A L C O H O L$ was only marginally significant (10\% level) to begin with and that the inclusion of CONDOM diminishes the sample to include only 29 countries. When CONDOM is dropped (columns (5) and (6)) the coefficient point estimates on $A L C O H O L$ remain essentially unchanged but regain their $10 \%$ level statistical significance.

As a summary of the results form table 5, the evidence points most clearly towards the practice of male circumcision as having an important and negative impact on the spread of HIV in sub-Saharan Africa. The sample standard deviation of MALE_CIRCUMCISON is about $31.6 \%$. Taking the smallest point estimate (-0.314 from column (6)) starting from the sample mean level of HIV_PREVALENCE of about $5.25 \%$, an increase of the male population that is circumcised from $0 \%$ to $31.5 \%$ would be associated with the rate of HIV prevalence falling, all else equal, from $5.25 \%$ to only $1.1 \%$. To say that this particular quantitative example should be handled with care is a considerable understatement. However, the point of introducing it is to simply emphasize that the coefficient estimates suggest and quantitatively meaningful effect. 
Alternatively, the evidence for an important $A L C O H O L$ is much weaker and the coefficient estimates are quite small. (The sample standard deviation of $A L C O H O L$ is only about 3.3 liters and the largest coefficient point estimate is 0.397.) CONDOM is rendered an insignificant correlate by the introduction of our control variable set; $S O C_{-} R E G_{-} R E L I G O N$ never enters significantly.

\subsubsection{Is Religious Affiliation Important Once Institutions are Controlled For?}

The results reported in tables 1 and $\mathbf{4}$ establish that while both Christian and Muslim population shares, taken individually, correlate significantly with HIV prevalence rates in sub-Saharan Africa, it is the Christianity/HIV correlation that is robust to the inclusion of both the Muslim population share and a set of other control variables in a regression. We have also identified a set of variables that proxy for specific religious institutions that might drive the relationship between religious affiliation and HIV prevalence. The next logical step is to explore whether the affiliation/prevalence correlation is robust to controlling for these institutional variables.

The results from table 5 suggest that MALE_CIRCUMCISON and perhaps $A L C O H O L$ are relevant. However, it is still possible that CONDOM and SOC_REG_RELIGON are important determinants that are just hard to identify given their collinearity with other variables. Likewise, it is also possible that the omission from the institutional variables from the table 4 regressions leads to the statistical insignificance of MUSLIM. Therefore we report, in table 6, regressions that always include both CHRISTIAN and MUSLIM population shares, as well as the full set of control variables. We introduce each of the four institutional variables separately to see how the coefficient estimates on religious affiliation change. For example, we would be interested to know if introducing $A L C O H O L$ consumption "knocks out" the statistical significance of CHRISTIAN. If it does, this may suggest that more Christianity is associated with greater HIV prevalence because Christianity (relative to other religions) tolerates/promotes greater consumption of alcohol (and the increased risky activity that goes along with it). (As it turns out, the results reported below do not support this particular story.) For each institutional variable we report two regressions - again, one without and one with period fixed effects included. 
Across the eight columns of table 6 there are two immediately striking results: (i) CHRISTIAN always enters significantly (at the 5\% level or better) regardless of the institutional variable that is controlled for and (ii) the coefficient estimate on MUSLIM remains statistically insignificant in all regressions. The institutional variables, taken individually, are always statistically significant, though only SOC_REG_RELIGON and MALE_CIRCUMCISION are significant at the $5 \%$ level or better. The estimated coefficient signs on the institutional variables are always in agreement with those reported in table 5.

Regardless of the institutional variable that is included, the CHRISTIAN population share not only enters statistically significantly but, also, the coefficient point estimate is remarkably stable. Across columns (1) through (8) the point estimate always falls in the 0.365 to 0.491 range. These estimates cannot be statistically distinguished from one another, and they all represent quantitatively meaningful effects. (See the example in section 6.1 above that is given for a coefficient estimate of 0.418 , right in the middle of the 0.365 to 0.491 range.)

\subsection{Conclusions}

We have analyzed a panel of up to 43 sub-Saharan countries covering the period from 1990 through 2010. We have explored the relationships between HIV prevalence and religious affiliations; in particular, the Christian and Muslim population shares. We have then asked what institutions might underlie the HIV/religious affiliation relationships. The particular institutions that we consider are plausibly associated with the Christian and/or Muslim religions.

Here we summarize and discuss what we believe to be the interesting and important conclusions to be drawn from our results.

- The prevalence of male circumcision has a large and negative effect on the spread of the HIV virus in sub-Saharan Africa.

- Despite the conjectures of previous researchers that the practice of male circumcision links Muslim populations to lower HIV prevalence, we find that correlation not to be robust to controlling for the Christian population share even when the prevalence of male circumcision is not controlled for. 
- The positive correlation between the Christian population share and HIV prevalence is robust to controlling for per capita alcohol consumption, male circumcision, condom use, and an index of the social regulation of religion.

- Alcohol consumption may indeed have an intuitively plausible positive effect on risky sexual behavior and the spread of HIV, but the effect is quite small.

- There is some evidence that condom use is associated with greater HIV prevalence, but issues of measurement error and reverse causation make interpretation of the estimated effects perilous.

The robustness of Christian affiliation as a positive correlate with HIV prevalence in subSaharan Africa is certainly an intriguing finding. Its robustness is not only to controlling for a country's Muslim population share and our proxies for institutions; the Christian/HIV correlation is also robust to controlling for population density, the urban population shares, income per capita, the country's latitude, and the date when a case of HIV was first reported. This suggests to us that there are religious institutions - perhaps informal behavioral norms - that are part of Christianity in sub-Saharan Africa and important determinants of the spread of HIV. Unfortunately, we are clearly not controlling for those other institutions. However, while a puzzle remains, a positive contribution of our paper is to cast doubt on some of the "usual suspects" (e.g., Catholic discouragement of condom use).

While we have also confirmed the important contribution of the practice of male circumcision for hindering HIV transmission, our findings call into question the link that previous researchers have made between the Muslim religion and lower HIV prevalence based on the practice. A particularly clear finding is that, controlling for the Christian population share, the Muslim population share does not significantly correlate with HIV prevalence in a country. Yet male circumcision itself $i s$ a robust correlate and is associated with large, negative estimated effects on HIV prevalence. We do not mean to deny the basic fact that Islamic tradition strongly encourages the circumcision of males. Rather, what is interesting is that male circumcision's negative association with HIV prevalence does not align as straightforwardly as one would expect with a country's Muslim population share. This could arise from particular methods of 
male circumcision that are associated with particular Muslim groups and, as well, are particularly effective in hindering HIV transmission. It could also arise from particular complementary but unobserved institutions that correlate more strongly with male circumcision than with Muslim affiliation.

The positive association of reported condom use with HIV prevalence is troubling. Our prior is that it is largely a result of reverse rather than perverse causation. Still, it would be less troubling if the estimated effects were always small and statistically insignificant. Especially given variation in sub-Saharan African HIV prevalence over a 20 year period, one would hope that programs encouraging condom use yielded negative effects on the spread of the virus large enough to prevent positive and statistically significant correlations from manifesting. We are aware of no cross-country studies of Africa that propose an effective strategy to identify and report the true effects on increased condom use on HIV prevalence. Surely this is fruitful avenue for further research. 
Figure 1

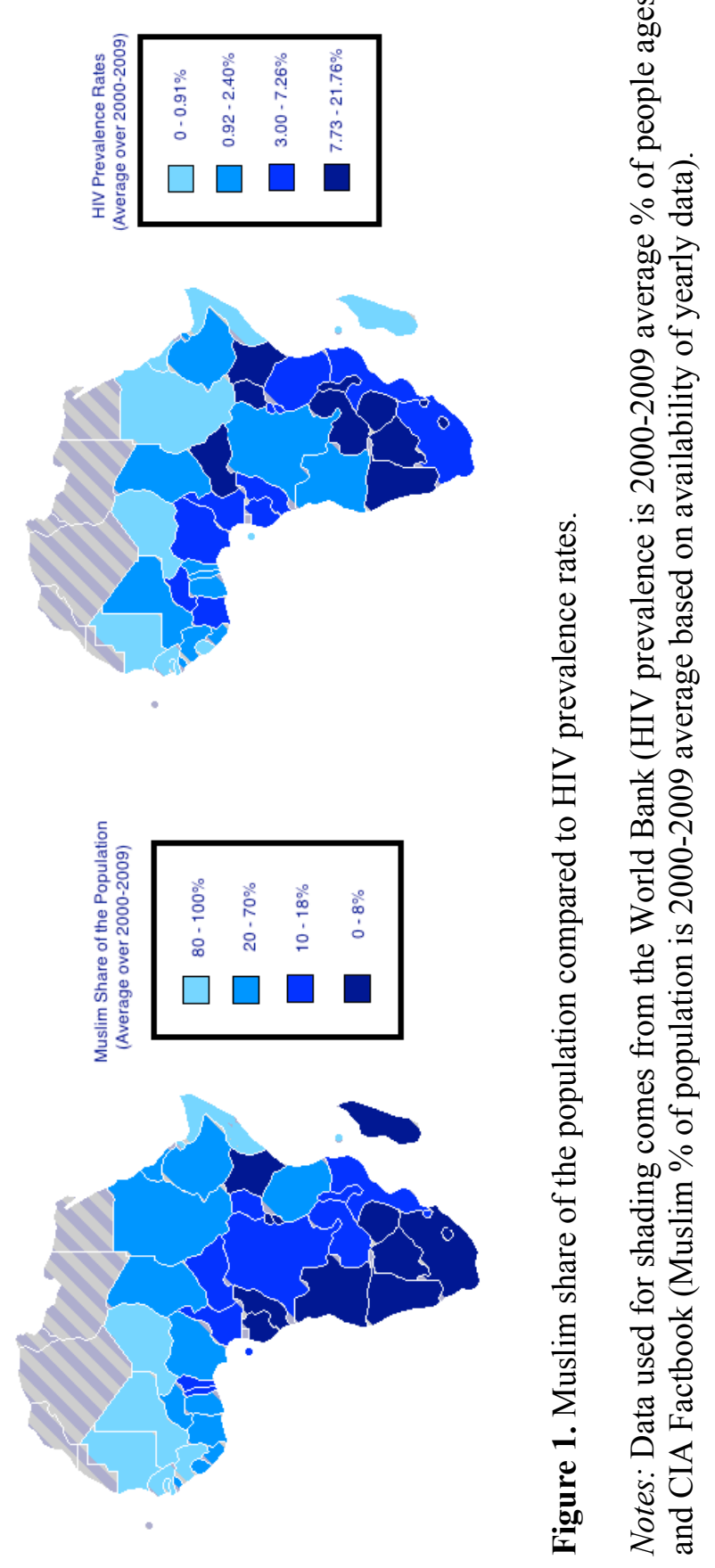



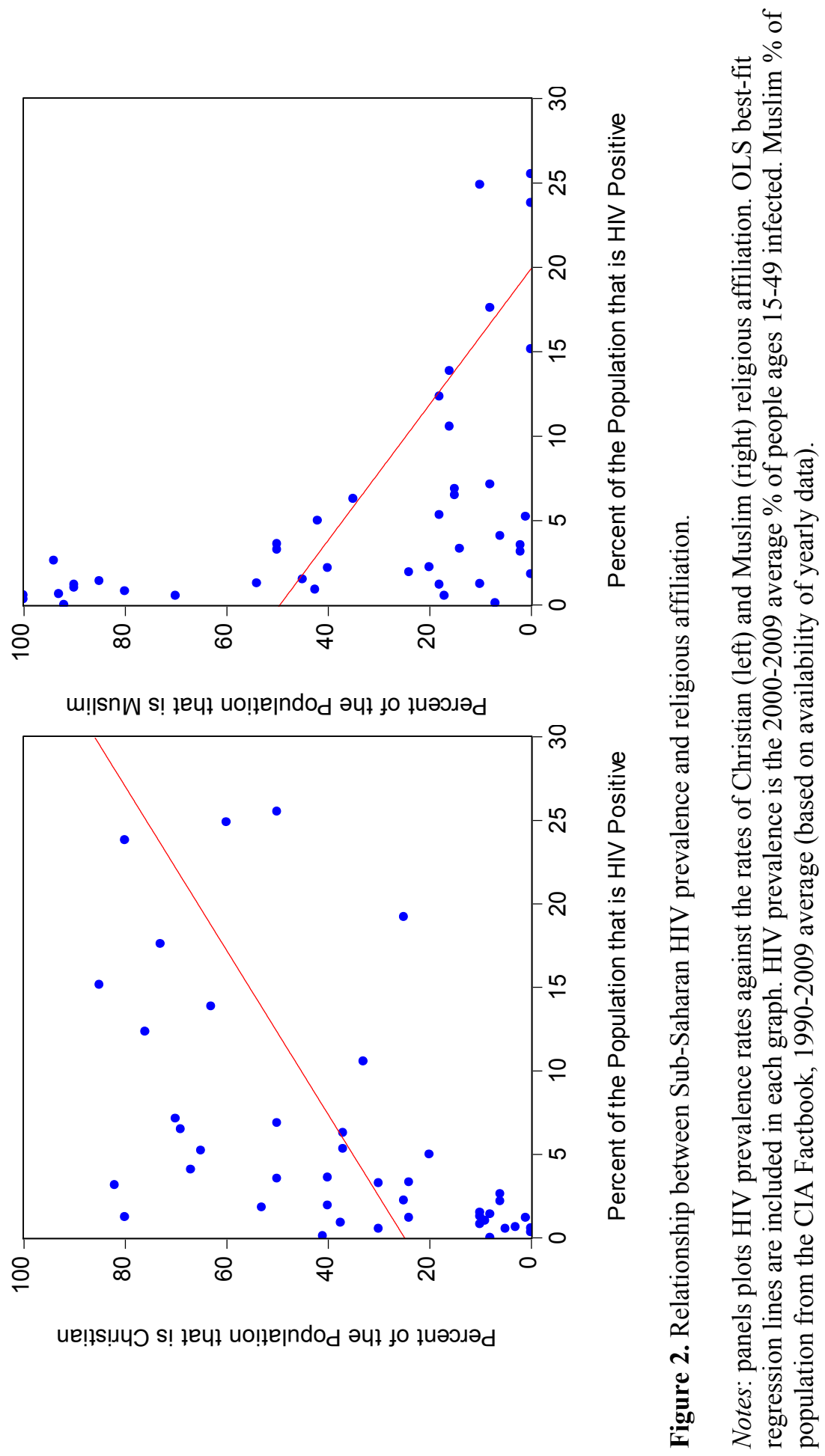
Table 1

Table 1. Preliminary pooled regressions of $(\log )$ Sub-Saharan HIV rates on religious affiliation

(1)

$\log ($ CHRISTIAN+1)

$\log (M U S L I M+1)$

constant

$-0.073$

(0.214)

$0.470 * * *$
$(0.071)$

(2)

(3)

$-0.355 * * *$

$(0.075)$

$-0.135$

$2.433 * * *$

(0.276)

0.664

F-statistic

$\mathrm{R}^{2}$

0.383

Countries

43

86

0.329

42

$0.351 * * *$

(0.113)

(0.119)

Observations

(0.683)

Notes: White HAC-consistent standard errors are in parentheses and $*, * *, * * *$ denote statistical significance at the 10,5, and 1 percent levels, respectively. F-statistic is for a test of joint insignificance of the regressors. 


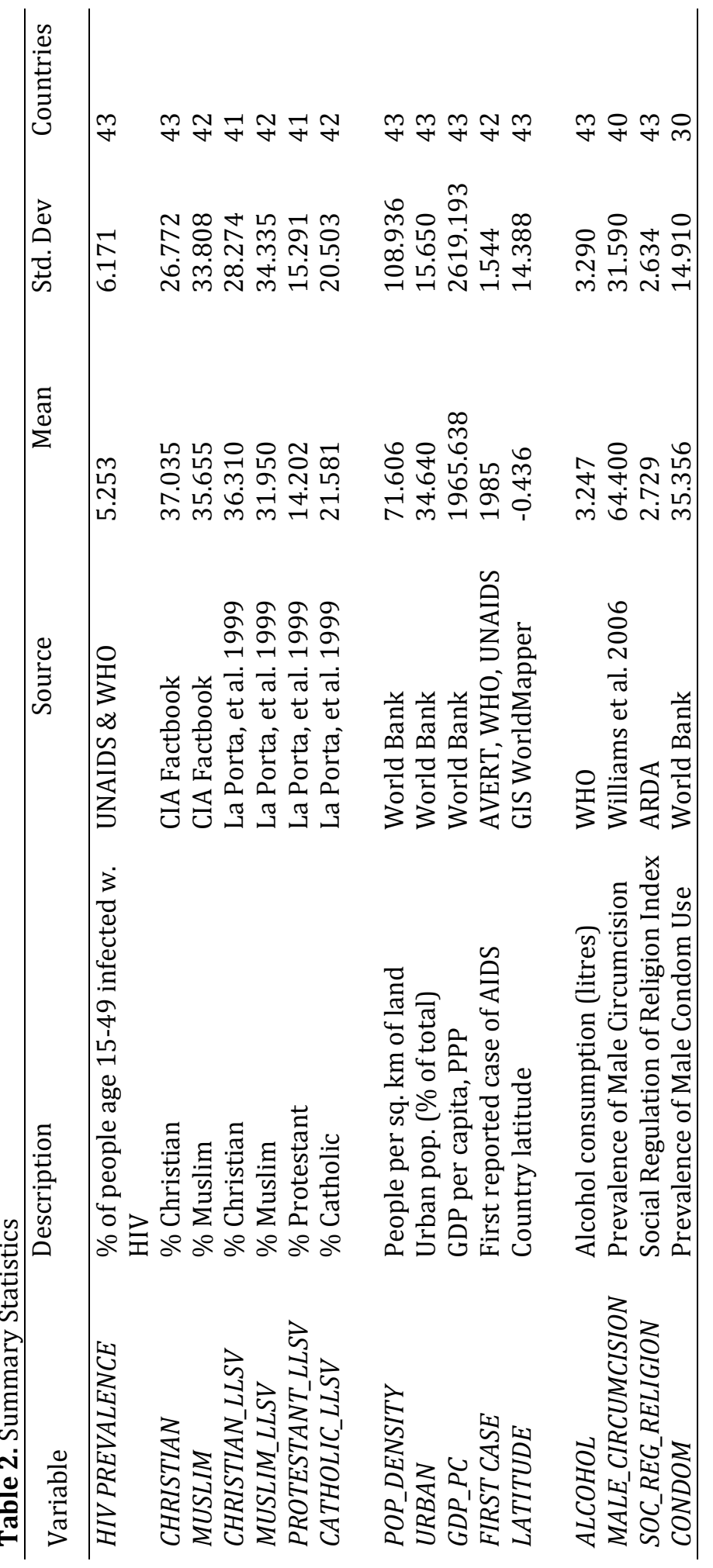


Table 3

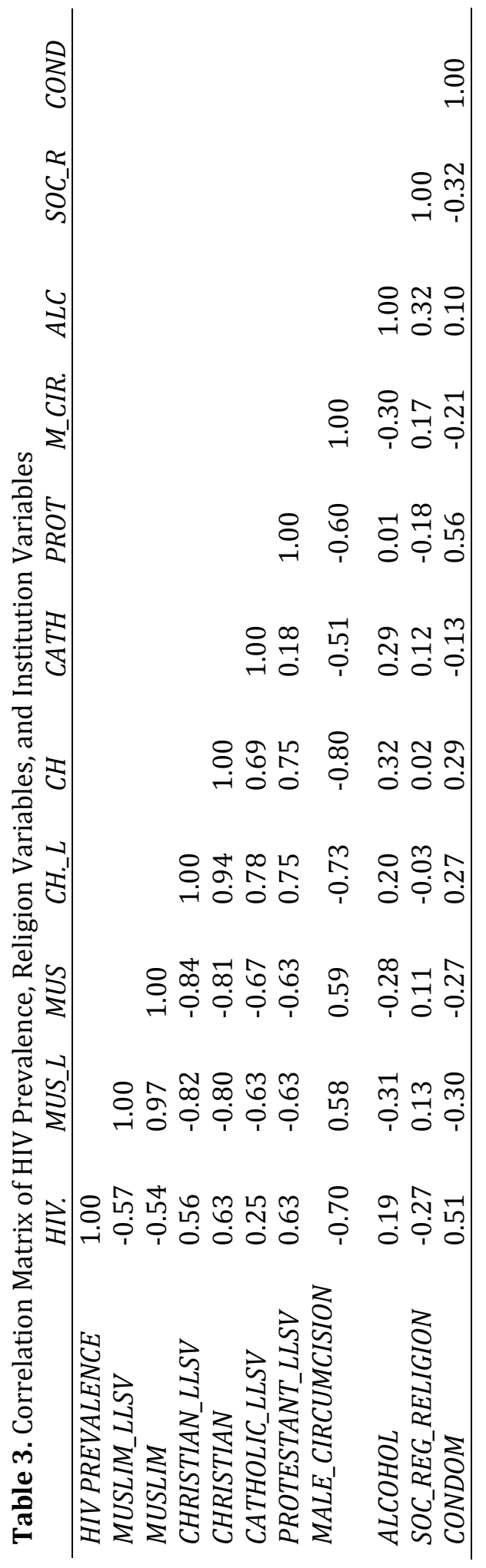




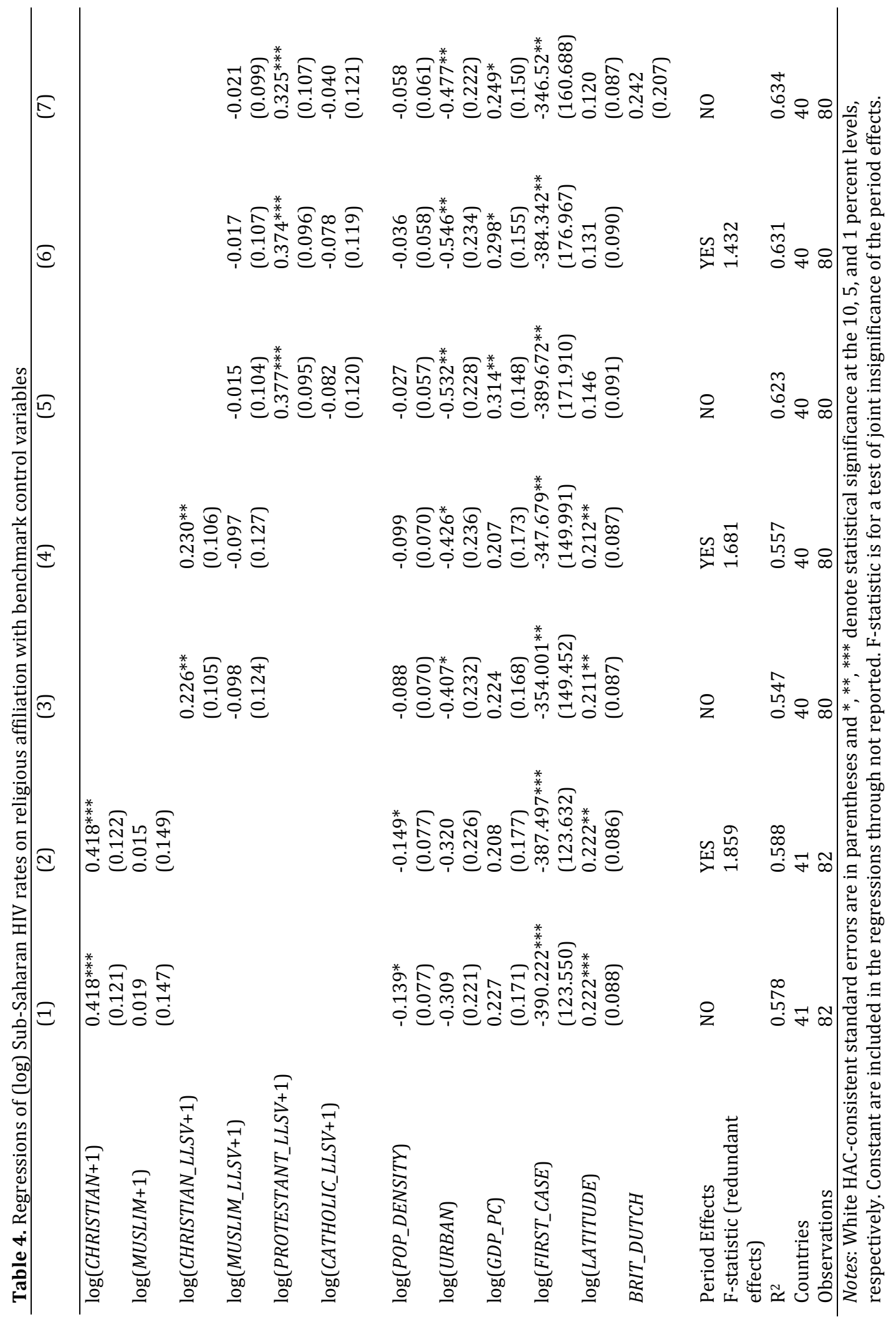




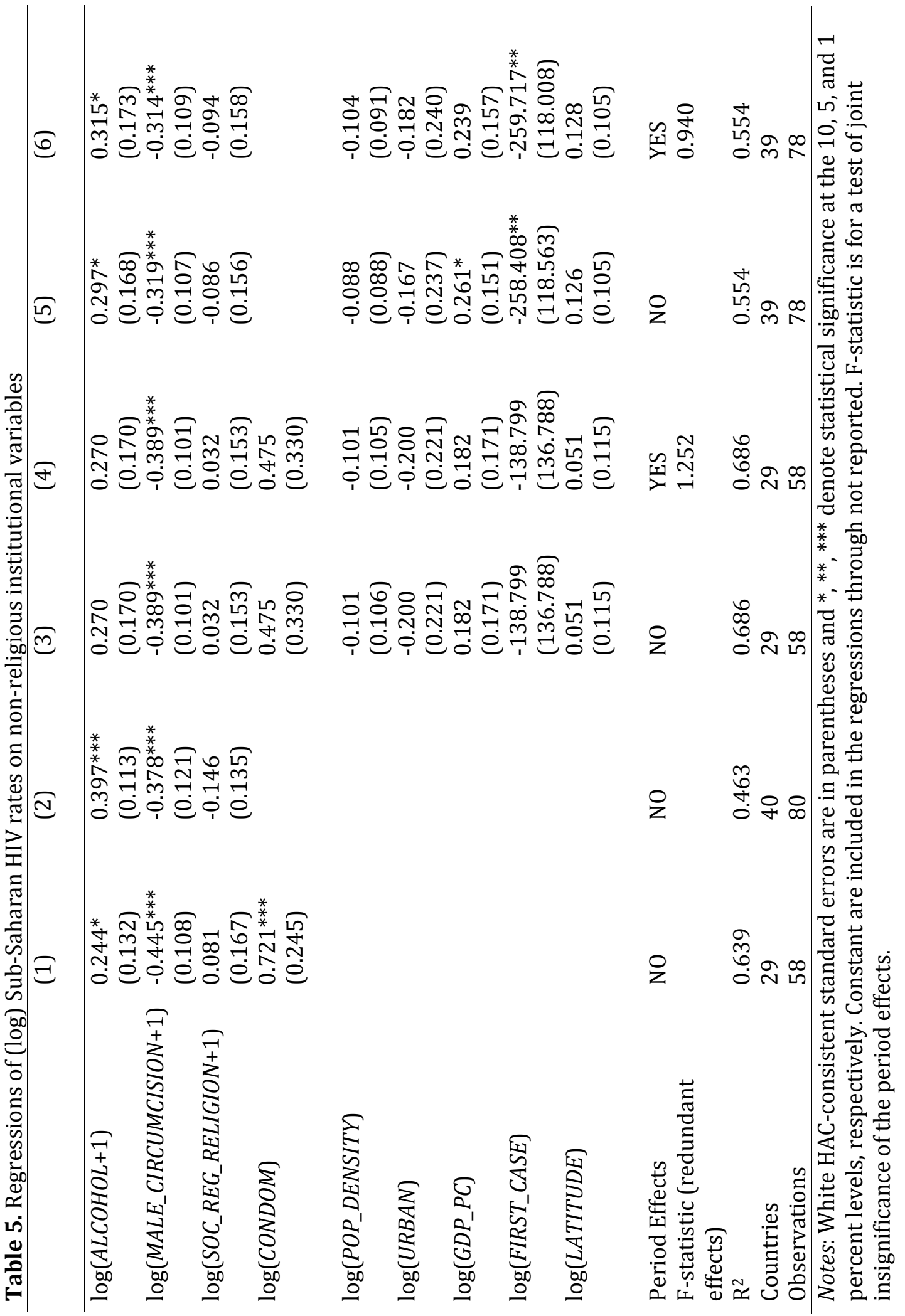




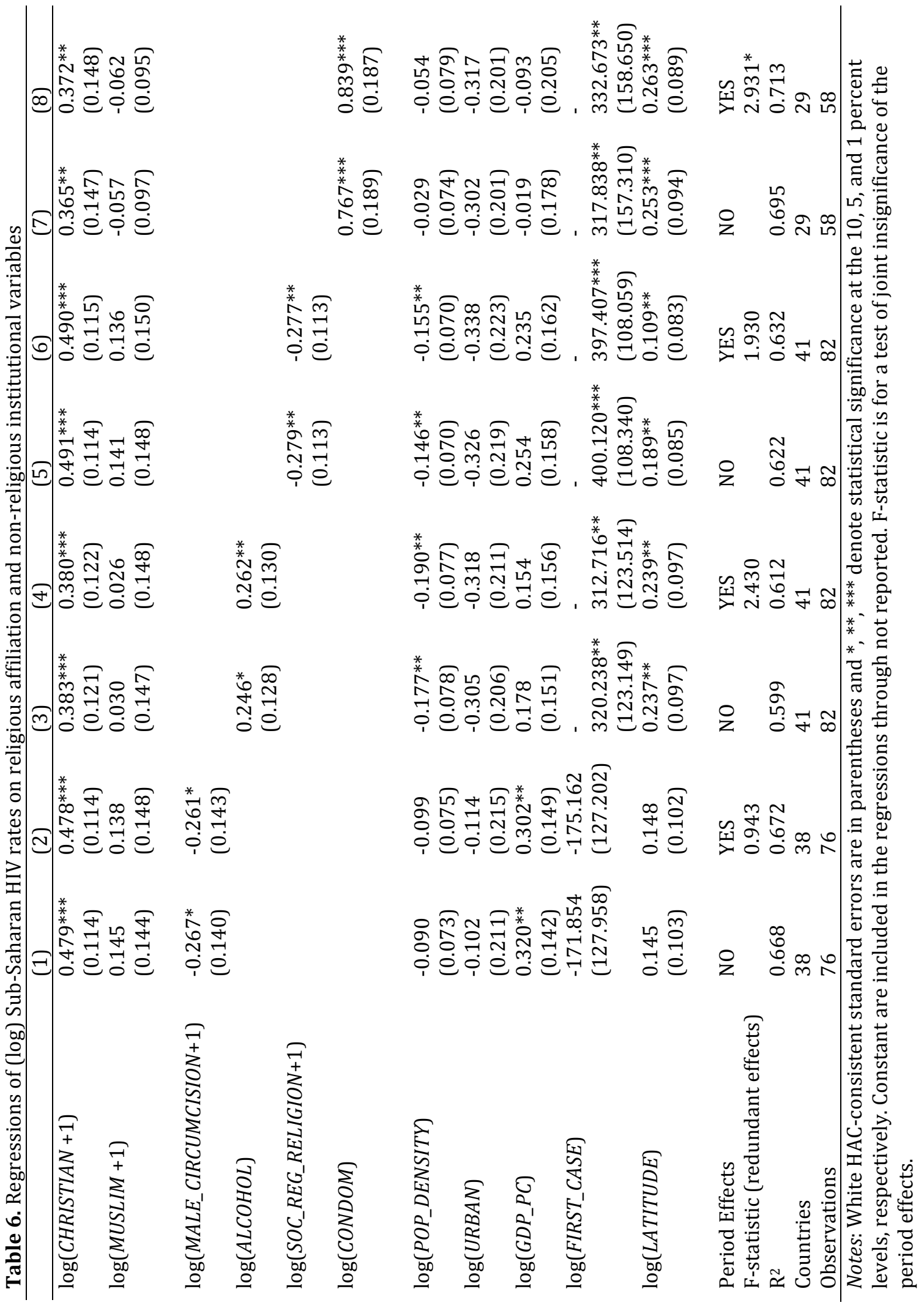




\section{Chapter 3: The Impact of Institutions on Health Outcomes in Sub-Saharan Africa: Which Ones Matter and Why}

\subsection{Introduction}

Rationally, the level of progress in the modern medical care field stipulates that infant mortality should be close to zero. Nevertheless, we see disturbingly high rates in sub-Saharan Africa. In 2011, infant mortality in Sub-Saharan Africa was higher than any other region worldwide at 70 deaths per 1,000 live births (World Bank, 2014). In comparison, high-income countries saw only 5 deaths per 1,000 live births (World Bank, 2014). Similarly, life expectancy in sub-Saharan Africa noticeably contrasts with that of the U.S. In 2011, life expectancy in sub-Saharan Africa was 56 years compared to 78.6 years in the U.S. (World Bank, 2014). In that same year, seven sub-Saharan African countries had average life expectancies less than 50 years of age.

Evidence from the literature suggests that institutions may play a role in improving health outcomes by reducing the high infant mortality rates and increasing life expectancy in this region. Broadly, institutions are the "constraints that shape human interaction" and "structure incentives in human exchange," and as such, a number of studies have investigated the role of institutional elements on outcomes of human welfare, specifically in extending life (North, 1990, p. 3). Boettke and Subrik (2003) found that the rule of law allows for increases in the level of development, which, as a consequence, translate into an increased life expectancy. BaliamounteLutz (2009) showed that improvements in institutional quality led to increases in literacy and life expectancy, specifically in Africa, using both variables to indicate levels of human well-being. In another study, Knowles and Owens (2010) distinguish between "formal" and "informal" institutions then show that both types of institutions have a positive and significant impact on life expectancy. Finally, Moser and Ichida (2001) concluded that, for a given income level in African countries, higher institutional quality and individual freedoms reduce infant mortality.

However, institutions span a wide spectrum of economic and political contexts within a society. Moreover, there is a sharp divide between public choice and neoclassical theory regarding the relationship, and possibly the preeminence, of economic to political freedom, or vice versa, in contributing to human welfare. Public choice economics emphasizes the 
superiority of market to political allocations in fulfilling individual wants. Economic agents make decisions by maximizing utility functions that express individualized preferences given the constraints of limited resources. Outcomes are not contingent upon the will of the majority (Buchanan 1954). Following this approach, empirical studies have linked economic freedom with increased life expectancy (Goldsmith 1997; Gwartney, Lawson, Holcombe 1999; Stroup 2006; Williamson 2008).

On the other hand, neoclassical economics support a leading role for political freedom in the form of democracy. Wittman (1989) argues that "democratic political markets are organized to promote wealth-maximizing outcomes" and are comparable to economic markets in terms of efficiency. Stiglitz (2002) calls for democratic governments to correct for economic market failures. Democratic political institutions have been positively associated with increases in life expectancy (Moser \& Ichida 2001), and Kudamatsu (2007) found a negative relationship between democratization and infant mortality.

The first question to ask is what kinds of institutions (political or economic) affect health outcomes in sub-Saharan Africa. I begin by examining and comparing the broad measures of democracy and economic freedom on health outcomes in sub-Saharan Africa. The next question that can be asked is why either political or economic institutions should be expected to affect health outcomes. Therefore, after comparing broad measures of these institutions, I will further decompose institutions into their sub-components to better understand the nature of the relationship between institutions and health in countries in this region.

As an extension, I create an interaction procedure intended to produce evidence of how these more specific channels of freedom impact the resources in a given country. If institutions are the "rules" of society, it can be expected that these rules affect the way resources are utilized in a that society and thus influence outcomes. Specifically, I look at the case of how economic freedom may interact with increased water access to affect health. To my knowledge, no other study has examined the role of specific channels of institutions and how these channels may affect health in sub-Saharan Africa.

This paper is arranged as follows: in section 2, I examine the measures of institutional freedom and establish the decomposition of the comprehensive indices into their root 
components. I also introduce the control variables that will be used. Section 3 sets up the model to be used in this study, and section 4 reports the results. The extension example is explored in section 5 , and conclusions are drawn in section 6.

\subsection{Data}

In this paper, I examine a panel data set for up to 43 sub-Saharan African countries over 6 periods: 1980-1984, 1985-1989, 1990-1994, 1995-1999, 2000-2004, and 2005-2009. Caselli, Esquivel, and Lefort (1996) advocate the use of panel-data as a means of correcting for the shortcomings of cross-sectional data including the endogeneity of "flow" elements and the absence of the individual effect. Splitting the data into sub-periods of five years captures the time series information for the study, and the panel format can be adapted to correct for potential serial correlation. Using 5-year averages instead of annual variation helps to estimate a measure for variables (such as GDP), which may fluctuate from year to year (due to normal business cycles, etc) but still can be expected to fall in a particular range of values relative to the other countries. Furthermore, the institutional variables are expected to be slow-moving, so I am more interested in the change in institutional quality over a period of at least five years than from one year to the next. The dependent variables of interest are INFANT_MORTALITY, measuring the number of infants dying before reaching one year of age, per 1,000 live births in a given year and LIFE_EXPECTANCY, indicating the number of years a newborn infant would live if current patterns of mortality at the time of its birth remained constant throughout its life (World Bank, 2014).

The motivation for this paper is to investigate the effect of institutions on infant mortality and life expectancy; therefore, it is essential to employ measures that will most accurately reflect this relationship. Institutions are inherently difficult to measure since they represent qualitative data. Nevertheless, assessments of institutions have been captured in widely accepted indices. The Polity IV Project data set has produced an index (DEM_POLITY) to evaluate the level of institutionalized democracy in a country. The eleven-point scale (0-10) draws on three subindices: the competitiveness of political participation, the openness and competitiveness of executive recruitment, and constraints on the chief executive. 
Likewise, economic institutions are measured by an aggregate index, which can be broken down into its component indices. The Economic Freedom of the World Index produced by Gwartney, Lawson, and Hall (2012) is composed of five major areas: size of government (SIZE_GOVT), legal structure and security of property rights ( $L E G A L_{-} P R O P E R T Y$ ), access to sound money (SOUND_MONEY), freedom to trade internationally (TRADE_FREEDOM), and regulation of credit, labor, and business (REGULATION). Each of these indices are based on a scale of 1 to 10 with 10 denoting countries with freer, less obstructed markets (each variable is discussed in more detail in this section). They are reported at 5-year intervals from 1975 to 2000, and then on an annual basis from 2000 thereafter.

The sub-index SIZE_GOVT captures four areas: government consumption, transfers and subsidies, government enterprises and investment, and the top marginal tax rate. A higher rating in this category denotes that a country operates with more personal choice but smaller overall government budgets and involvement. SOUND_MONEY incorporates money growth, inflation, and freedom to own foreign currency. A higher score indicates that a country exhibits low and stable rates of inflation and allows for the use of alternative currencies. The variable LEGAL_SYSTEM describes the strength of a country's legal system and its respect for property rights. Specifically, this index accounts for judicial independence, impartial courts, protection of property rights, military interference in rule of law and politics, integrity of the legal system, legal enforcement of contracts, regulatory restrictions on the sale of real property, reliability of the police, and business costs of crime. REGULATION describes the extent of regulations that exist in credit markets, labor markets, and for businesses. The final economic variable is TRADE_FREEDOM. The freedom to trade internationally incorporates the impact of tariffs, regulatory trade barriers, black-market exchange rates, and controls of the movement of capital and people. A high rating on this sub-index indicates that a country facilitates international trade with low tariffs and few impediments to movement across international borders. In all of these areas, a higher score indicates more economic freedom and will be referenced in this context throughout the paper.

Why might we expect higher levels of economic freedom to play a role in better (or worse) health outcomes? Theoretically and empirically, the literature is mixed. Free trade not only increases potential for material welfare through physical imports, but Owen and Wu (2007) 
suggest that open international borders may allow for knowledge spillovers including in the health field. In their study, a country's openness to international trade is positively associated with improved health of the population: a higher life expectancy and a lower infant mortality. Stroup (2007) points to Friedman's contention that a stable money supply allows the market price system to effectively convey relevant market information. When inflation affects price signals, there is a distortion in the flow of information (Friedman 1980). This could potentially obstruct access to health care. Tracy, et al. (2010) find that improved property rights and access to sound money are associated with lower child mortality. They suggest that without a stable currency, high inflation rates have the potential to destroy household savings thus creating vulnerability if family members fall ill. In a similar manner, better protection of property may offer families an additional means of collateral in case of unforeseen health problems. With regard to the size and involvement of a government, increased regulation and higher taxation is associated with an interventionist government and less economic freedom. Increased stateintervention offers more opportunities for bureaucratic delay and corruption, which could impede health service delivery or shift investment away from high value projects including health (Shleifer and Vishny 1993).

On the other hand, certain areas of economic freedom may either have no effect on health or may actually cause worse outcomes. Tracy, et al. (2010) study the empirical impact of the five economic sub-areas on health outcomes internationally and find that only improved property rights and access to sound money are associated with lower child mortality but can make no other connections between the economic sub-areas and better health in other areas. Fafchamps (2004) suggests that legal institutions may matter little in African nations where poor economies make "most market transactions ... too small to justify court action and most people have no assets to foreclose upon" (Fafchamps 2006, p. 1184). A main finding from La Porta, et al. (1999) is that countries with smaller governments and lower tax collection actually perform worse than countries with larger governments. Smaller governments may lack the structure to collect taxes, and self-interested or corrupt officials may not concern themselves with the needs of constituents. Consequently, these countries may suffer as a result of poor provision of public goods. Similarly, Rauch and Evans (2000) argue that it is the quality of bureaucracy that affects effectiveness of government. 
The goal of this paper is to examine whether these areas of economic freedom play a positive or negative role in health outcomes specifically in sub-Saharan Africa; something that, to my knowledge, has not yet been done in the literature. In the best-fit OLS regression lines of Figure 1, a negative correlation between the economic freedom and infant mortality is observable (fewer infant deaths as economic freedom increases). Likewise, we see the same relationship with the measure of democracy and infant mortality (albeit, the relationship is less pronounced than with economic freedom). These relationships are reversed when looking at life expectancy as the dependent variable, indicating that political and economic institutions are associated with improved health outcomes in both cases. Table 1 reports that, after producing the bivariate regression results, the coefficient estimates of democracy and economic freedom are negatively related to infant mortality and statistically significant at the one percent level.

Likewise, both are positively related to life expectancy. Thus, as a result of this initial inspection and evidence from the literature discussed in the introduction, I proceed with the prior that the institutions will be associated with improved health outcomes.

Additional controls are based on the literature on life expectancy and infant mortality in developing countries, and specifically, sub-Saharan Africa. A review of the literature shows that the variables used in empirically examining the determinants of both life expectancy and infant mortality are fundamentally similar. However the controls are expected to exert opposite effects on infant mortality and life expectancy as decreased infant mortality represents an improved health outcome while increased life expectancy represents an improved health outcome. Nearly all of the reviewed literature incorporates a measure for income or wealth as a determinant of infant mortality and life expectancy (Arik and Arik 2009, Fayissa 2001, Imam and Koch 2004, Kembo and Van Ginneken 2009, Omariba et al. 2007, Pamuk et al. 2011, Kabir 2008, Husain 2002). A higher income indicates a higher level of development within a country, and consequently, these studies have found infant mortality to be inversely related to GDP per capita while life expectancy is positively associated with GDP per capita. ${ }^{8}$ I expect similar findings in this study using the variable GDPPC from the World Bank.

\footnotetext{
${ }^{8}$ A portion of the literature discusses the issue of potential endogeneity between life expectancy and GDP per capita (Pritchett and Summers 1996). In other words, it may be difficult to disentangle the extent to which wealth extends life and the reverse effect of better health on the ability to be more productive. To control for this, I include the variable lagged GDP per capita in the regression for life expectancy. As the results are quantitatively similar, they are not reported.
} 
The intention of health care spending is to extend life and reduce mortality. This would create a positive correlation between health spending and health outcomes. However, Fayissa and Gutema (2005) point out that countries with lower levels of health may allocate more money for health expenditures. Therefore it is also possible that health outcomes will be inversely associated with health expenditures. This study uses World Bank data on health expenditures per capita in current U.S. dollars to measure the sum of public and private health expenditures as a ratio of total population.

Empirical studies by Imam and Koch (2004) and Pamuk, Fuchs, and Lutz (2011) found mother's education and HIV prevalence rates to be among the most significant determinants of infant mortality in sub-Saharan Africa. A higher level of maternal education, all else equal, has been found to be negatively associated with infant mortality as it indicates a greater knowledge of health practices. Additionally, increased education among women decreases birth rates as these women tend to start families later than less educated women (Imam and Koch, 2004, p. 26). Likewise, the literature shows that life expectancy is improved by education. Higher levels of education increase health knowledge allowing people to live healthier lives (Husain 2002, Kabir 2008). The literature specifically uses women's education as a determinant of life expectancy as it affects women's productivity and knowledge, which in turn has the capacity to positively impact family health. In this study, I use the average number of years of female education obtained from the Institute for Health Metrics and Evaluation and anticipate an inverse relationship with infant mortality and a positive relationship with life expectancy.

On the other hand, HIV prevalence, which is more severe in sub-Saharan Africa than anywhere else in the world, is consistently positively related to a higher infant mortality rate in these studies and negatively related to life expectancy. HIV-positive women are more likely to give birth to babies that suffer from complications of low birth-weight and inadequate nutrition (Noel, et al. 2008). Life expectancy is unquestionably adversely affected by HIV prevalence. It is estimated that in countries where HIV is most severe, life expectancy is 10-20 years shorter than in it would be otherwise (Kabir 2008). HIV prevalence in this study is obtained from World Bank figures.

The final two controls are FERTILITY and WATER_ACCESS (World Bank, 2013). Higher fertility rates are characteristic of less developed countries and may indicate the absence 
of family planning (Arik and Arik 2009). Studies have shown this variable to be positively related to infant mortality. Husain (2002) suggests that high fertility points towards increased births that may be closely spaced. This may have harmful effects on women or cause other birth complications, which may decrease average life expectancy and increase infant mortality. WATER_ACCESS is a variable that measures the percentage of the population with access to an improved water source (World Bank, 2013). In the sub-Saharan African region, some countries are affected by household contamination, inadequate access to water, and poor sanitation - all factors which can lead to increased infant mortality and decreased life expectancy (Kembo and Van Ginneken 2009). For this reason, I expect increased access to safe water to be inversely related to infant mortality and positively related to life expectancy.

Several of these studies additionally control for the urban/rural share of the population. It is expected that rural areas have less access to better health resources, nutrition and water increasing infant mortality rates and decreasing life expectancy. However, Pamuk, Fuchs, and Lutz (2011), find that "the rural disadvantage with respect to infant mortality is entirely eliminated" by controlling for education and economic composition of rural and urban areas (Pamuk, Fuchs, and Lutz, 2011, p. 657). Therefore, I do not include this among the controls.

Table 2 lists the summary statistics, descriptions, and sources for the variables discussed above.

\subsection{Model}

This section establishes the approach to investigating the relative impact of political and economic institutions on health outcomes in the sub-Saharan African region. The initial part of this analysis compares the role of political and economic institutions in impacting life expectancy and infant mortality. The goal is to examine the broad measures of institutions and compare these results to the literature. A basic model can be written as:

HEALTH_OUTCOME $=\beta_{1}($ INSTITUTION $)+\beta_{2} X+\varepsilon$ 
where HEALTH_OUTCOME alternates as life expectancy and infant mortality, INSTITUTION indicates either political or economic freedom, $X$ represents the set of controls, and $\varepsilon$ is the error term.

First, however, it is critical to consider the nature of the data being studied. The sample of data comes from up to 43 sub-Saharan African countries suggesting that I may need to account for fixed effects. A Hausman test reveals that the (country) fixed effects model is superior to the random effects model with both life expectancy and infant mortality as the dependent variable. ${ }^{9}$ The test for period-fixed effects indicates that time fixed effects should be included for the regressions with INFANT_MORTALITY (F statistic: 5.94, p-value: 0.0054). However when repeating the test for $L I F E_{-} E X P E C T A N C Y$, the null hypothesis that dummies for all years are zero cannot be rejected (F statistic: 1.62, p-value: 0.2109 ). Therefore, I do not include periodfixed effects in the life expectancy regression. The results of the OLS fixed effects regressions are reported in Table 2 in columns (1) and (3). ${ }^{10}$

With a panel that spans from 1980 to 2005, the next concern to address is the possibility of serial correlation. In other words, it is likely that both dependent variables (life expectancy and infant mortality) are influenced by their own values in previous periods. Estimating OLS in the presence of autocorrelation may lead to inefficient estimates, underestimated standard errors, and an overestimated $\mathrm{R}^{2}$. Examining the residuals plotted against the lagged residuals for the each of the OLS regressions exposes an upward trend suggesting autocorrelation (See Figure 2). The presence of autocorrelation can be specifically tested using the Wooldridge test for autocorrelation in panel data. In both cases, the null hypothesis that there is no first-order autocorrelation is rejected (Infant mortality: F-statistic $=74.433$, p-value $=0.000$; Life expectancy: F-statistic $=26.302$, p-value $=0.000)$.

\footnotetext{
${ }^{9}$ P-values of Hausman test less than 0.01 using life expectancy and infant mortality in the main specification.

${ }^{10}$ Heteroskedasticity is tested using White's test for heteroskedasticity. In the cases of infant mortality $\left(\chi^{2}=60.77, p\right.$-value $\left.=0.0475\right)$ and life expectancy $\left(\chi^{2}=59.48, p\right.$-value $\left.=0.0596\right)$, I reject the null hypothesis of homoscedasticity. Therefore, all of the regressions reported throughout this paper include robust standard errors.
} 
In order to correct for autocorrelation, I follow the GMM estimation designated by Arellano and Bond (1991). This approach creates estimators designed to deal with both autocorrelation and heteroskedasticity by the transformation of regressors through differencing and then the use of generalized method of moments (Roodman 2009). In the process, the dependent variable is lagged and used in the estimation process. This corrects for the issue of autocorrelation. Additionally, by first-differencing the regressors, the fixed country-specific effect is removed as it does not vary with time (Mileva 2007). The Arellano-Bond methodology is intended for panels with few time periods and many individuals ("small T, large N"), and it utilizes "internal" instruments based on the lags of the regressors, which suits it well for my data set (Roodman 2009). The results are reported in columns (2) and (4) of Table 3. The results of the Arellano-Bond specification prove to be more conservative than the previous estimates (nevertheless, they still indicate that there are significant results). Consequently, I choose to continue the use of this approach for the next part of this study. ${ }^{11} 12$

Having established a model to compare the overall relationship between economic and political institutions and health outcomes, I now turn to breaking down the Economic Freedom of the World index into its sub-indices in order to trace the more specific sources of this connection. One by one, I include each of the economic areas (SIZE_GOVT, SOUND_MONEY, TRADE_FREEDOM,LEGAL_SYSTEM, REGULATION) in the specification as the "institution" and evaluate the impact on health outcomes. These results are reported in Tables $\mathbf{4}$ and $\mathbf{5}$ and discussed in the following section.

\subsection{Empirical Results and Discussion}

The first goal of this study is to evaluate whether economic or political institutions, namely, economic freedom and democracy, are more effective in improving health outcomes. The

\footnotetext{
${ }^{11}$ The Hansen J statistic (used in robust estimations) reports the null hypothesis that the instruments as a group are exogenous. This means that the higher the p-value the better. In all cases throughout this study, the null hypothesis cannot be rejected.

${ }^{12}$ Across the specifications for both infant mortality and life expectancy, the Arellano-Bond test for autocorrelation $\left(\mathrm{H}_{0}\right.$ : no autocorrelation) is applied to the differenced residuals. In all cases, it cannot be rejected providing no evidence for model misspecification.
} 
preliminary pooled regressions in Table 1 suggest that both may contribute to better health; in all regressions, both variables exhibit a positive and statistically significant relationship with life expectancy and a negative and statistically significant association with infant mortality. This supports evidence found in the literature as discussed in the introduction. However, adding the controls into the analysis shows that democracy is no longer a significant determinant of life expectancy and infant mortality (Table 3). On the other hand, economic freedom is consistently related to better health outcomes across all specifications. Using the results from the ArellanoBond model (the most conservative estimates), a one standard deviation increase in economic freedom is associated with almost a one-year increase in life expectancy and a decrease of 3.5 infant deaths per 1,000 births. To provide perspective, one standard deviation separates Chad from Sierra Leone from Botswana in order of least economically free to most economically free.

Turning to the controls used in the Table 3 regressions, the variables generally exhibit the expected sign discussed earlier. Using life expectancy as the dependent variable, HIV_PREVALENCE is consistently statistically significant and negatively related with life expectancy across all specifications. Likewise, GDPPC is positively associated with increased lifespan. It is feasible to see either sign on the variable FERTILITY: increased fertility may indicate a healthy population that is simultaneously seeing longer lifespans, but increased fertility could also be associated with lower life expectancies as developing countries are known for having higher birthrates. Looking at the controls for infant mortality, the only other statistically significant result in the Arellano-Bond estimation besides the economic freedom variable is HEALTH_EXPEND, which proves to be negatively related to infant mortality. This result shows that increased health expenditure decreases infant mortality.

I now turn to Tables $\mathbf{4}$ and $\mathbf{5}$ to examine the results of a more specific decomposition of how economic freedom may affect health using the five sub-components of the index. Looking first at infant mortality as a health outcome (Table 4), there is only one sub-area of economic freedom that proves to be statistically significant. Nevertheless, a one standard deviation increase in SOUND_MONEY alone is related to a decrease of 3.2 infant deaths per 1,000 live births. Consistently across the regressions of Table 4, increased health expenditure is related to a decline in infant mortality, and increased HIV prevalence is associated with higher levels of infant mortality. It is also apparent from the lagged infant mortality variable that higher levels of 
infant mortality in the past are associated with higher levels of infant mortality as in the future providing support for the GMM model choice.

Table 5 reports the results when life expectancy is the dependent variable. In this case, all of the economic sub-areas prove to be statistically significant and positively related to life expectancy with the exception of the variable $L E G A L_{-} P R O P E R T Y$. In terms of magnitude, increased REGULATION is associated with the largest increase in life expectancy. One standard deviation increase in REGULATION equates to 1.2 additional years of life.

When looking at the controls used in the model with infant mortality, the variables mirror the results for life expectancy in terms of improved health outcomes. Increased health expenditure is related to higher life expectancy while HIV prevalence is inversely related to life expectancy. Again, we can observe the positive coefficient on the lagged life expectancy variable. One new observation is the positive association between FERTILITY and life expectancy. According to this model, increased fertility relates to longer life expectancy.

\subsection{Extension}

The goal of this paper is to determine not only which institutions are significant for health in subSaharan Africa, but also how these institutions improve health outcomes. By breaking the economic freedom index into its sub-areas, we can get a better idea of what types of institutions serve as the best conduits of better health: a sound money supply, fewer regulations, a less intrusive government, and freer trade. In this section, I intend to see if economic freedom variables interact with a given resource in society to accomplish relatively better outcomes than without the interaction. Specifically, I look at the control variable WATER_ACCESS for this procedure. Inadequate water provision in sub-Saharan Africa is a severe issue in many of the countries in this region. But, in most cases, this is not actually due to an absolute lack of water. According to UNDP 2006 Human Development Report, in the country of Tanzania, households in Moshi use an average of 5 gallons a day while wealthier residents of Dar es Salam use about 45 gallons a day (UNDP 2006, p. 53). The report points to underlying issues of inequality as a result of divergent demographic access between the rich and the poor as the cause of insufficient water provision. Africans living in slums cannot connect to piped water as a utility but instead 
rely on water provided by (often informal) intermediaries who charge much higher prices. For this reason, those "living in slums and low-income settlements typically pay 5-10 times or more for their water than high-income residents of the same city" (UNDP 2006, p. 52).

In the following interaction procedure, I hope to uncover whether the simultaneous presence of a specific economic freedom and improved water access will allow for better health outcomes than either would by themselves. A generalized version of this model can be written as:

INFANT_MORTALITY $=\beta_{1}(I N S T I T U T I O N)+\beta_{2}($ WATER_ACCESS $)+\beta_{3}\left(\right.$ INSTITUTION $\left.* W A T E R \_A C C E S S\right)+\beta_{4} X+\varepsilon$

The term INSTITUTION*WATER_ACCESS represents the interaction between the water access variable and the economic freedom sub-area while $X$ represents the remaining control variables.

The results are reported in Table 6 and 7. Two interaction variables prove to be statistically significant and inversely related to infant mortality: (SOUND_MONEY*WATER_ACCESS) and (SIZE_GOVT*WATER_ACCESS). In both cases, the coefficient on this interaction term indicates that the combination of improved water access and the respective economic freedom is more effective at reducing infant mortality than either variable is by itself. Although it is not statistically significant, WATER_ACCESS interacted with the other economic freedom areas carries a negative sign except when interacted with TRADE_FREEDOM.

One interesting result to note in particular is the large positive coefficient on SIZE_GOVT in column (1) of Table 6. It indicates that a one standard deviation increase in SIZE_GOVT is associated with nearly 19 more infant deaths per 1,000 births. Nevertheless, as previously discussed, the interaction term (SIZE_GOVT*WATER_ACCESS) in the same regression is statistically significant and negatively associated with infant mortality. This result is consistent with the findings of La Porta, et al (1999) that larger governments perform better than smaller governments. It is likely this can be explained by the issues related to the disparity in water prices between Africans who are linked to a municipal water network and those who must 
purchase water informally from vendors or other intermediaries. A higher score on SIZE_GOVT indicates smaller government transfers and subsidies, less government enterprises and investment, and a lower top marginal tax. This means that the government will be less involved in providing local utilities, including water, to its citizens. Therefore, residents have no other choice but to pay high informal prices for water by private providers, and consequently there are higher infant mortality rates. In the case of provision of public goods, a smaller size of government may actually hurt health outcomes by failing to meet basic needs more efficiently than citizens can individually. This is a situation where the government is precluded from intervening by providing a public good as a result of a limited tax base and limited ability to organize (Fafchamps 2006). On the other hand, the negative sign that is present on the term (SIZE_GOVT*WATER_ACCESS) may reveal that if a country has relatively improved water access, a smaller government (higher score on SIZE_GOVT) will help create better health outcomes.

\subsection{Conclusion}

Using a panel of up to 43 sub-Saharan African countries over 6 periods from 1980 to 2009, I have considered the relative impact of economic versus political institutions on infant mortality rates and life expectancy. Furthermore, I have looked at the specific channels through which economic institutions may affect these health outcomes.

This study supports the finding that economic institutions are more beneficial in reducing infant mortality rate and increasing life expectancy than political institutions. Most specifically, I find that the areas of sound money, size of government, trade freedom, and regulation serve as the specific institutional conduits of improving heath outcomes. SOUND_MONEY, in particular, remains robust across all specifications and interacts with water access as a significant factor associated with reduced infant mortality. At the same time, the interaction of water access with different types of economic freedom indicates that the role of economic institutions may not be entirely straightforward. In the relative absence of certain resources, a more involved government may improve health outcomes by providing public goods and services. 
The difficulty of exploring institutions lies in the inherent difficulty of adequately capturing their effects. However, this study begins a journey to narrow broader economic freedom concepts and indices to specific areas that serve as the drivers of the improved health outcomes. Future research on this topic may delve into an even more detailed investigation of the role of specific sub-Saharan African policy or practices stemming from the soundness of money supply, regulations, openness of trade, and the size of government in a given country. Discovering more precise indicators and measurements will help eliminate the vagueness of qualitative understandings of institutions and their impact on human welfare outcomes. 
Figure 3
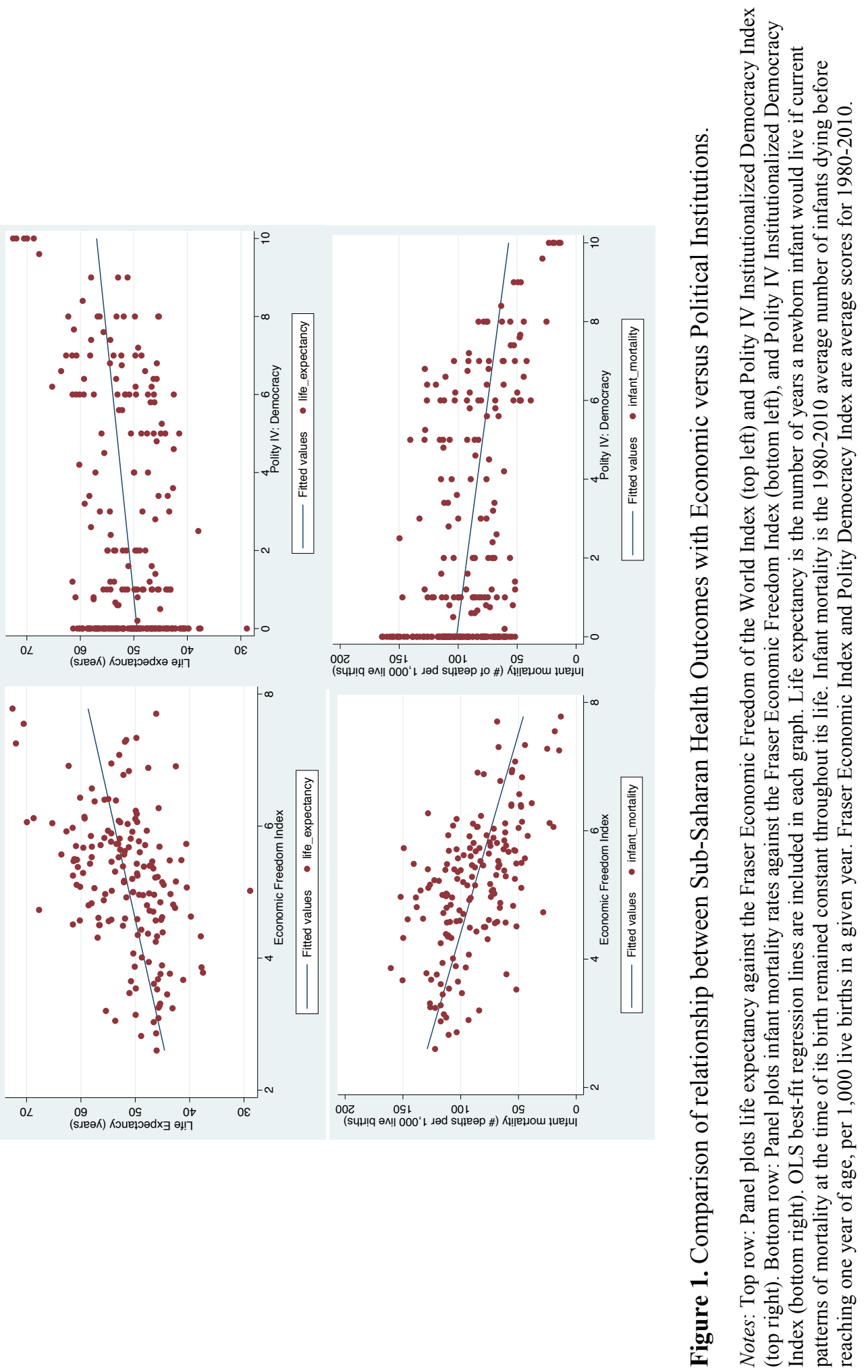
Figure 4

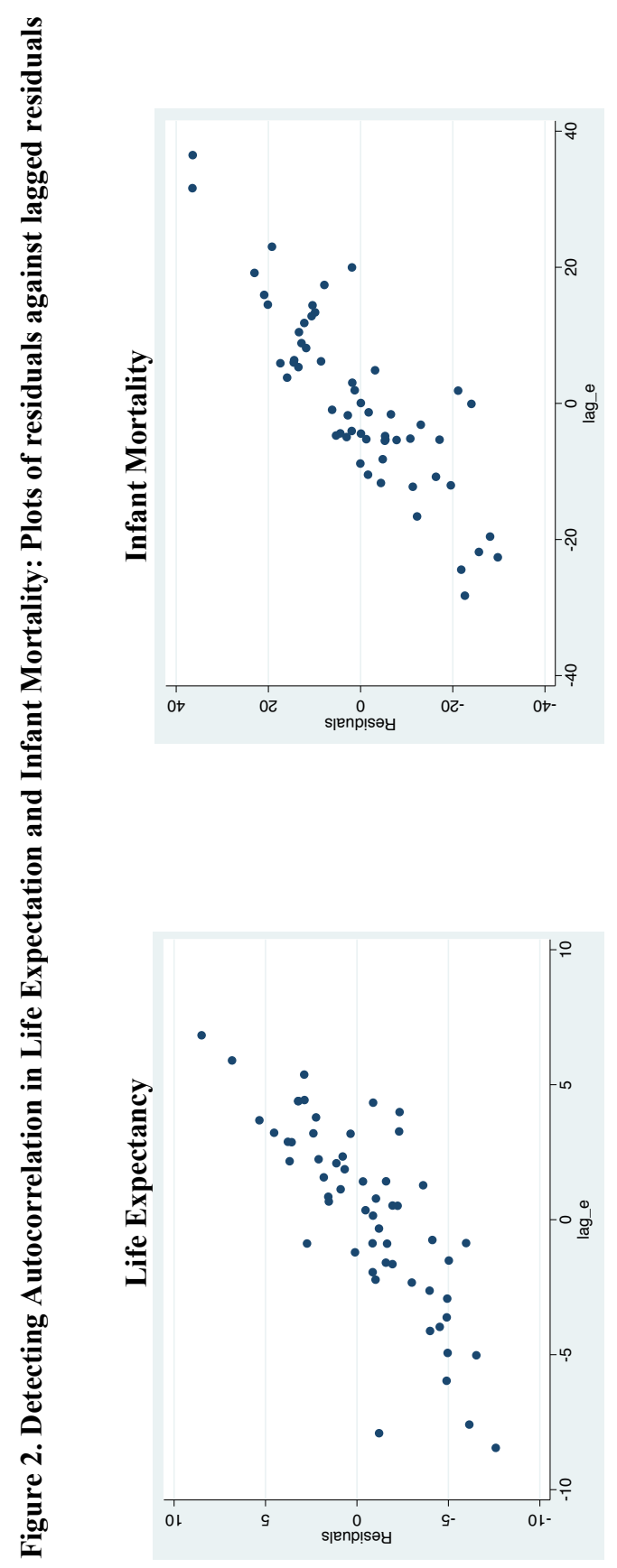




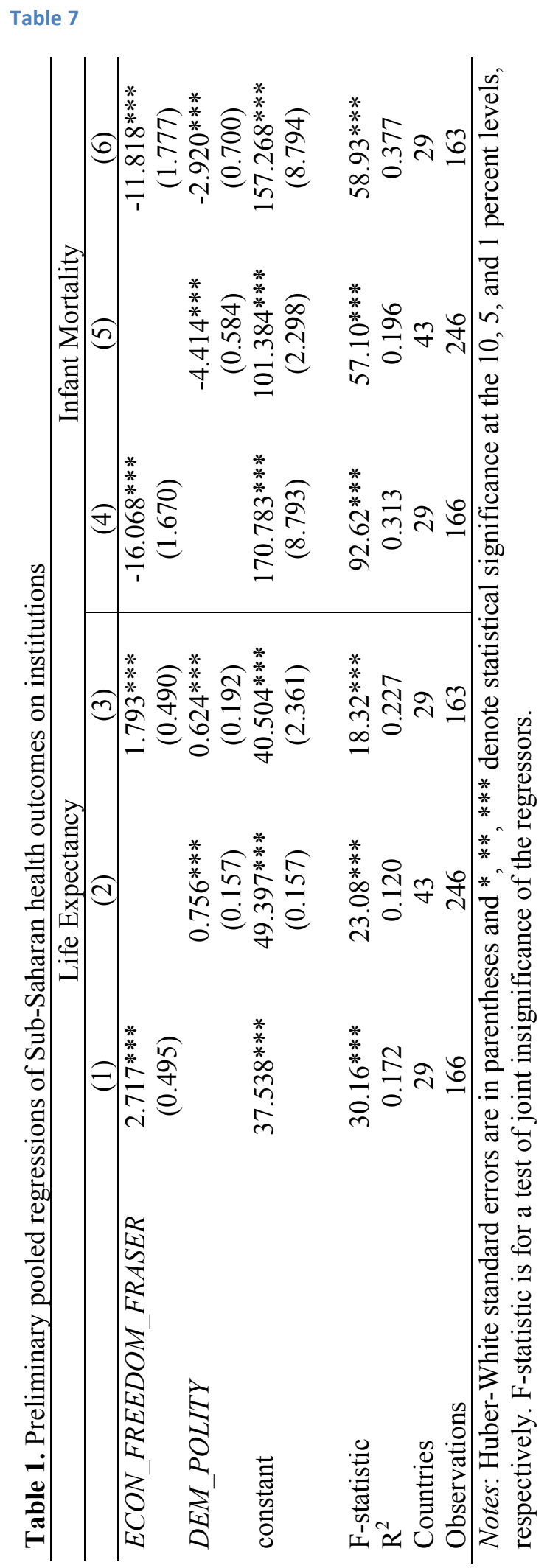




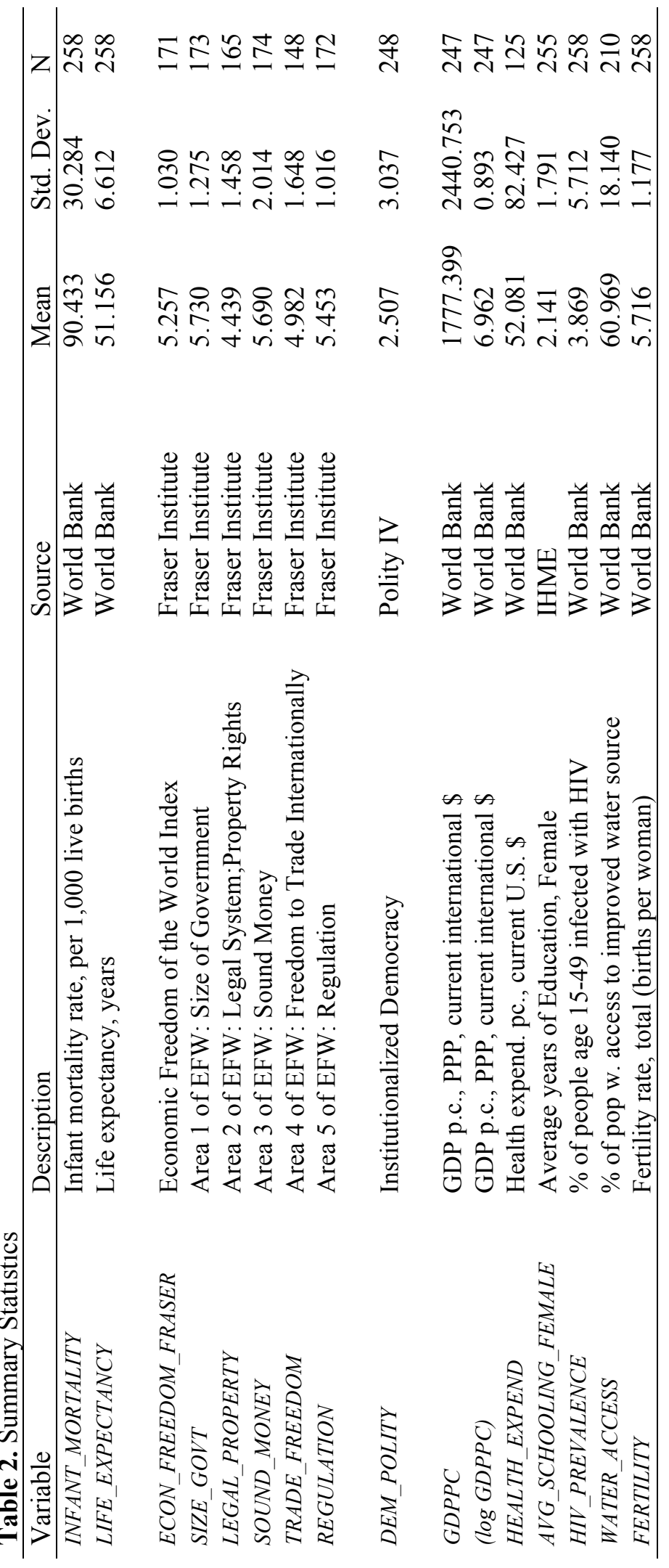




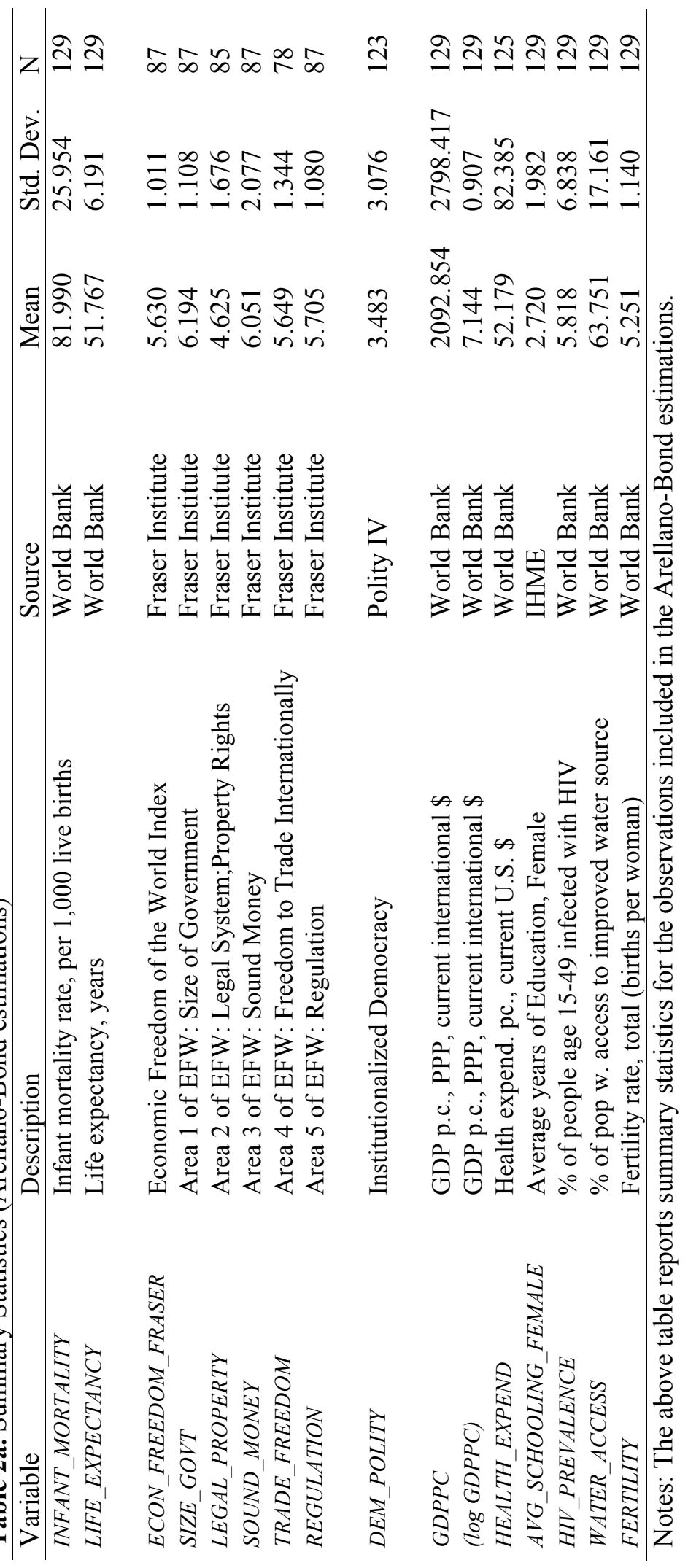




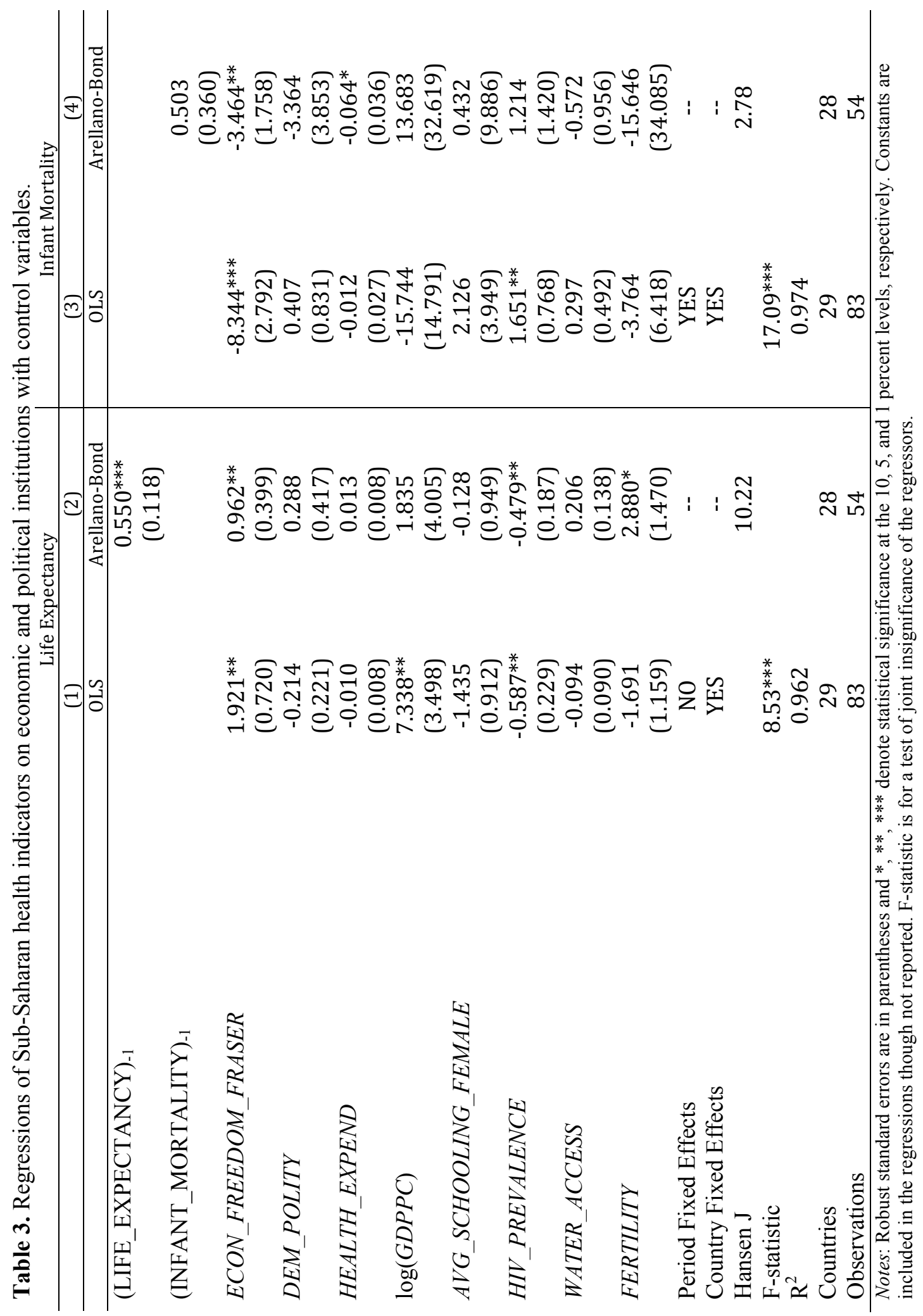




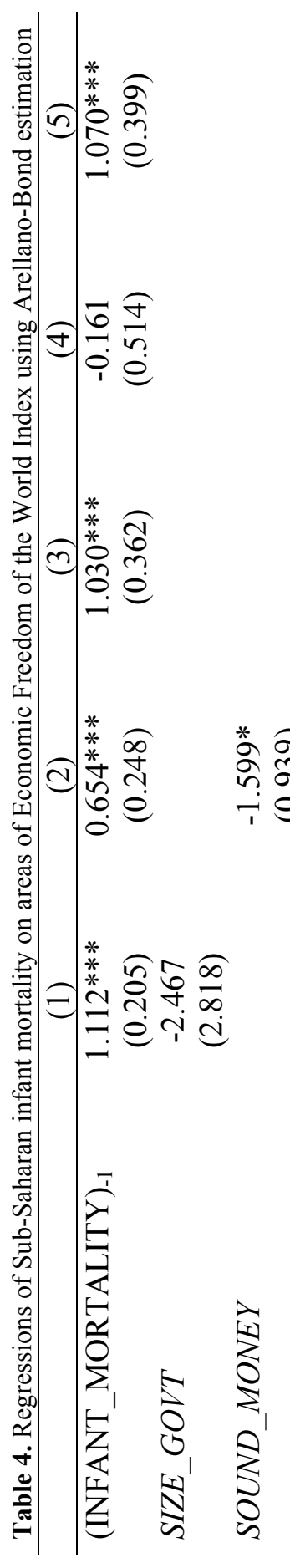

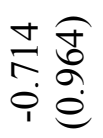

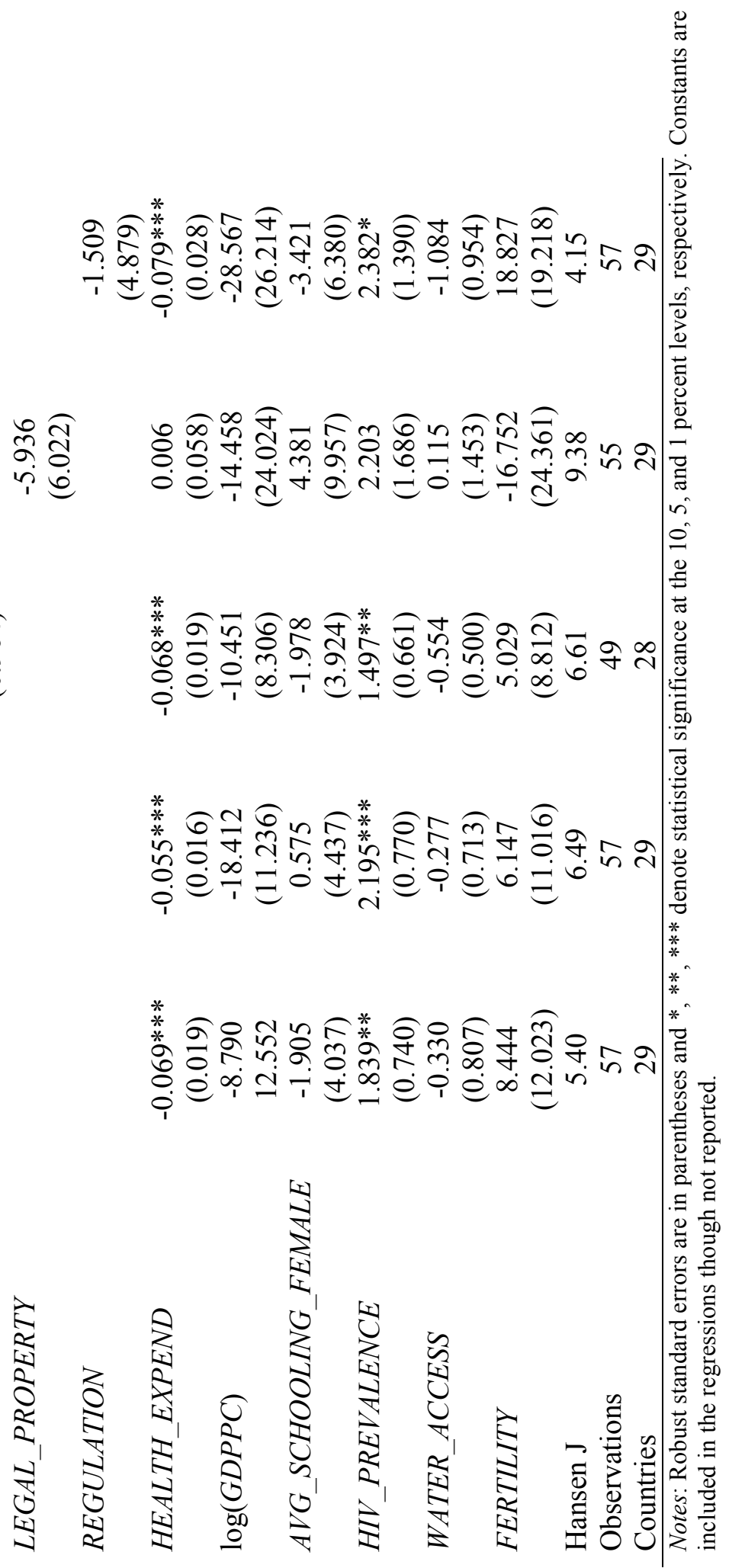




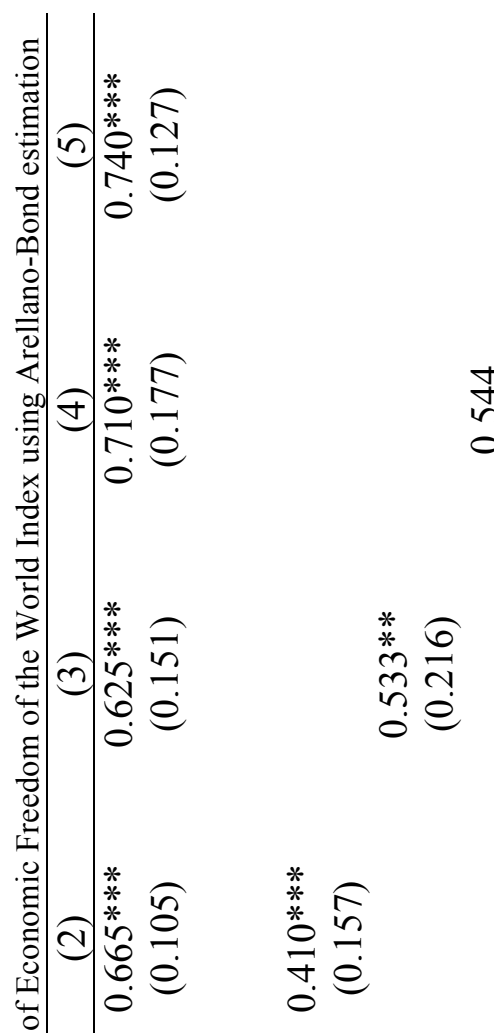

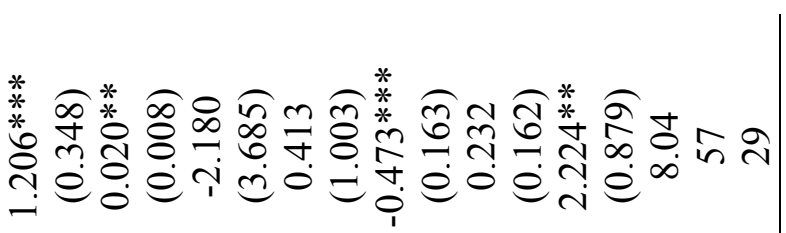

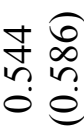

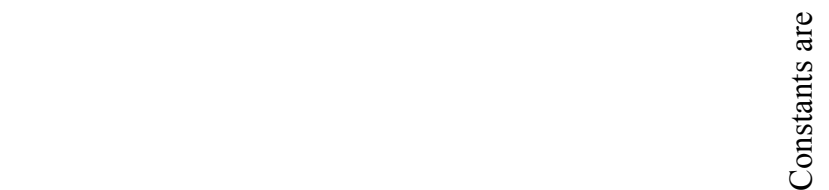




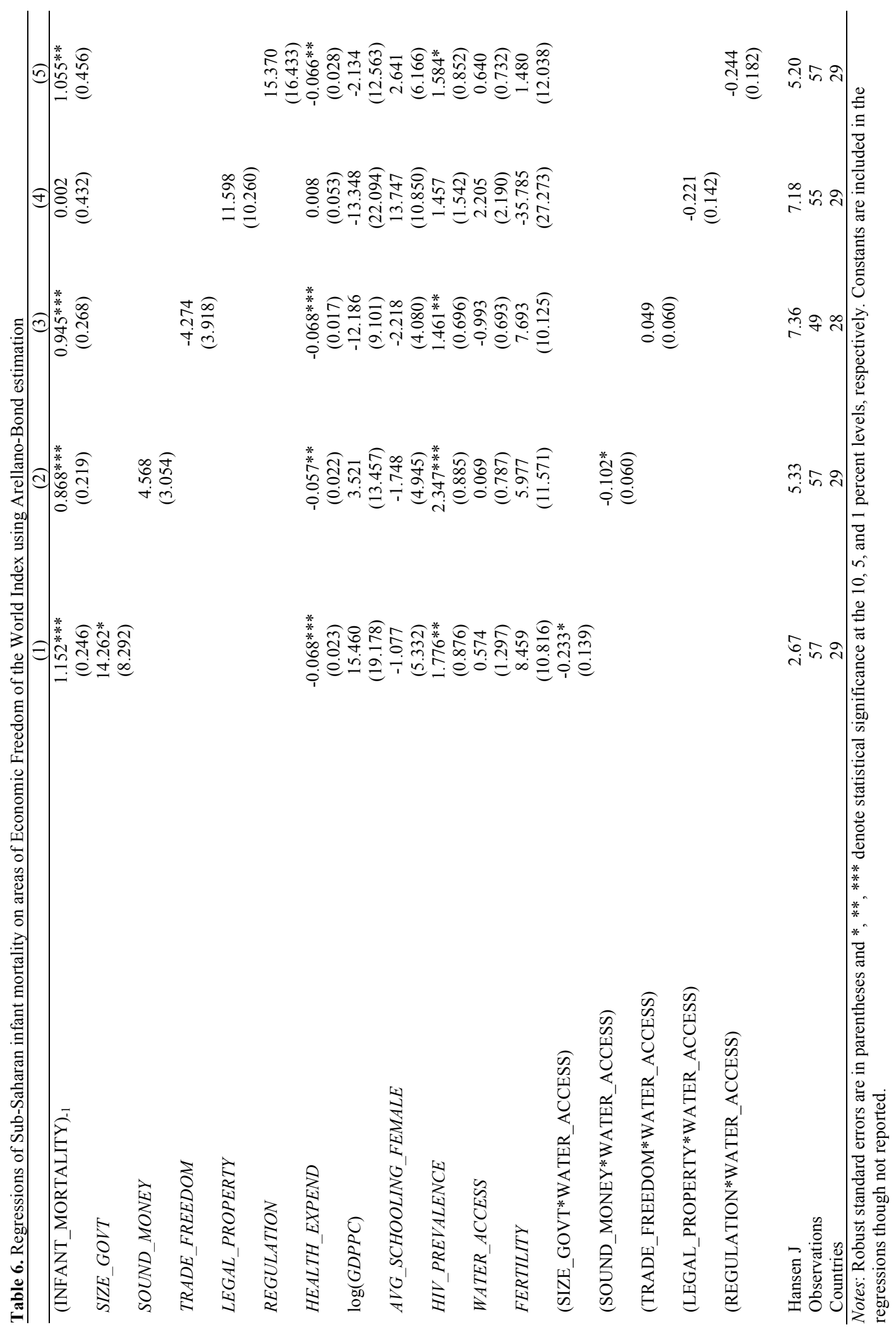


Table 14

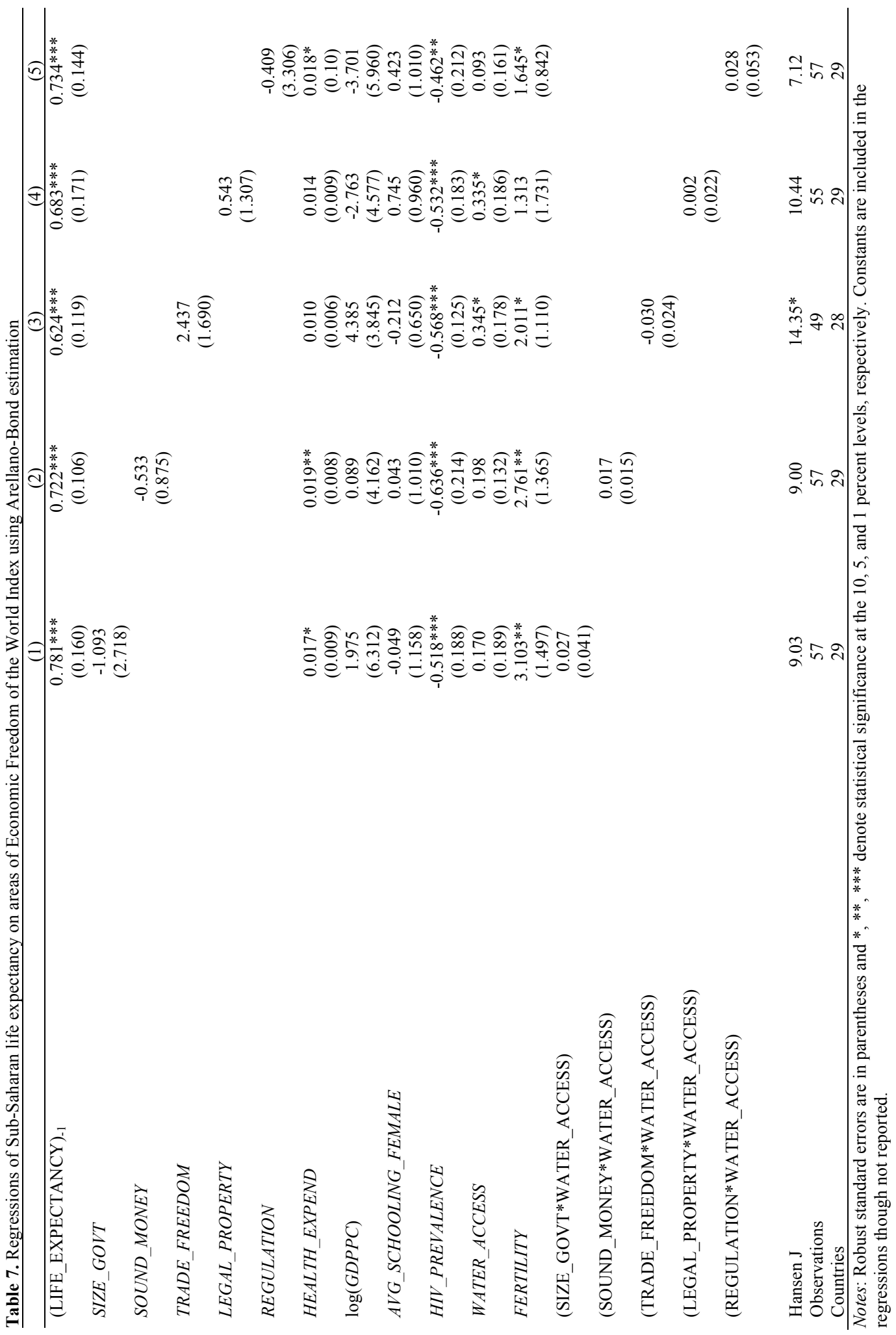




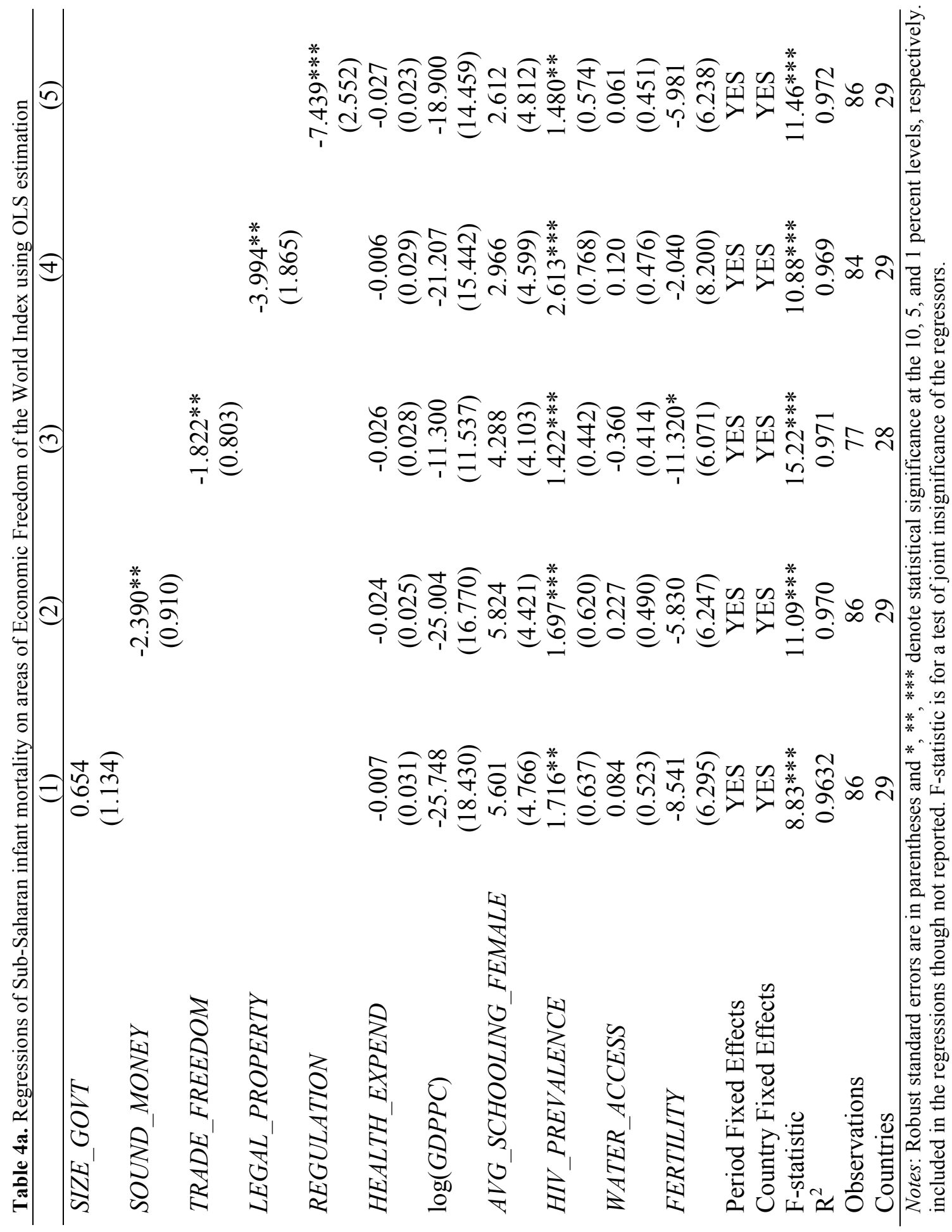




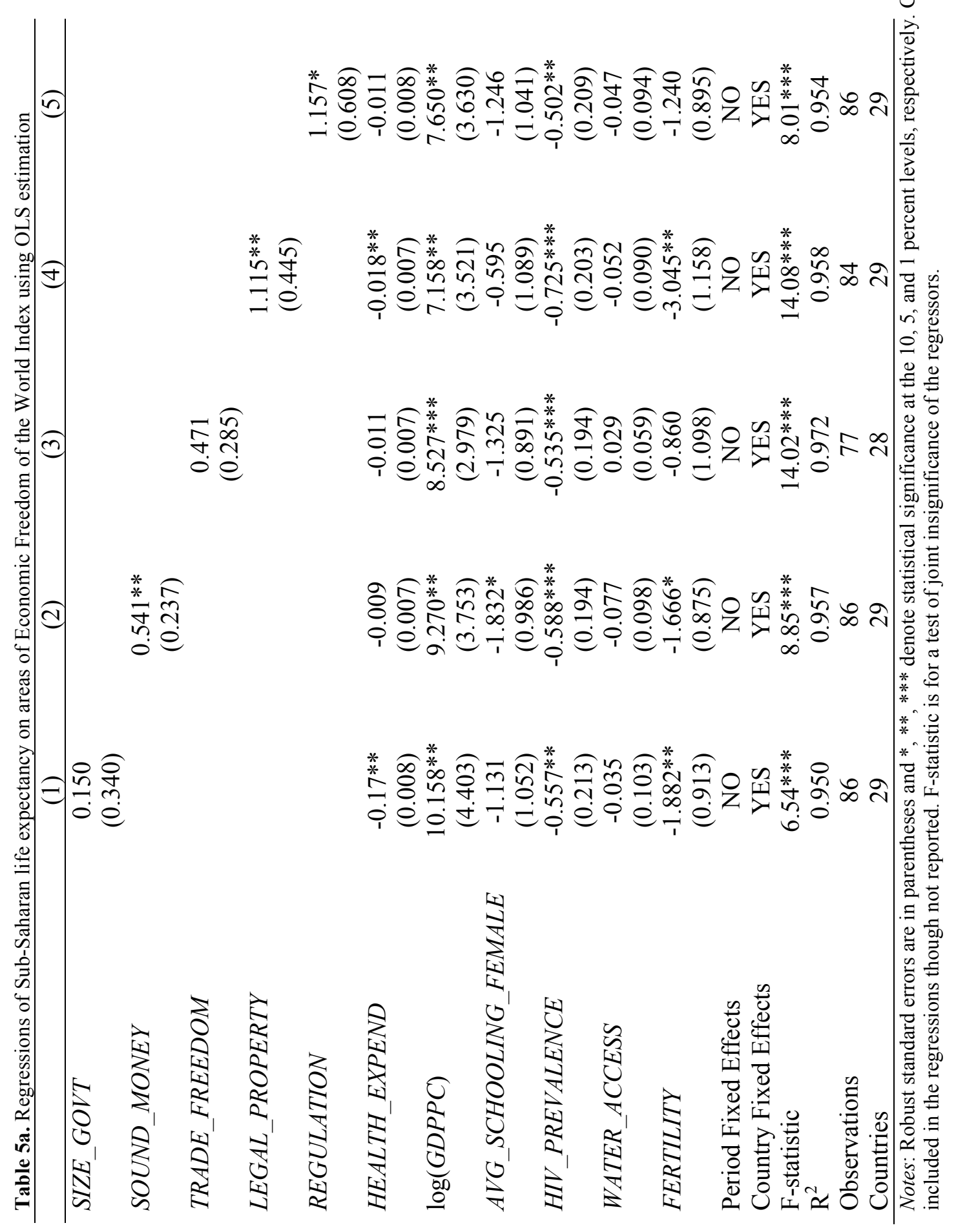




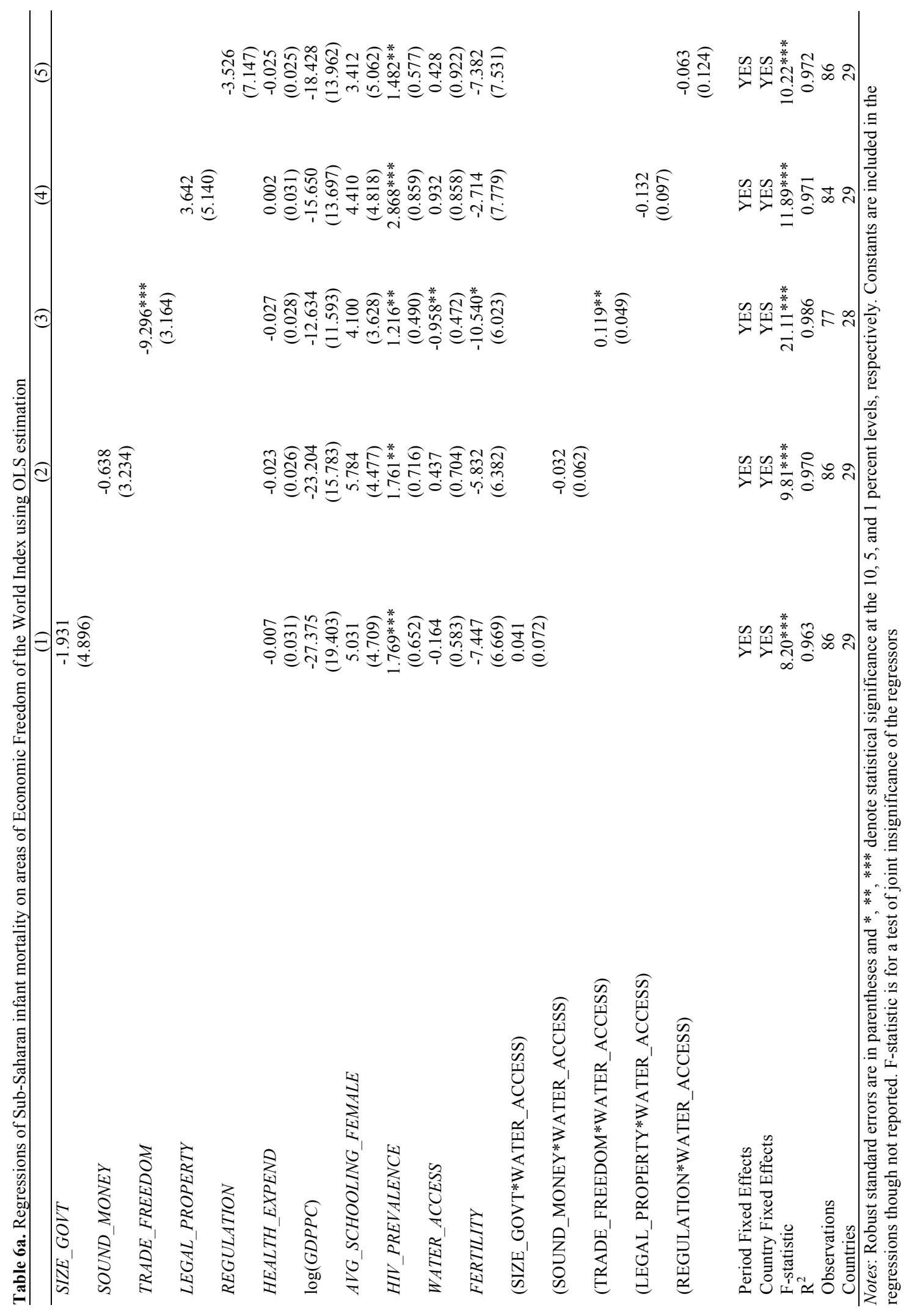

Table 18 


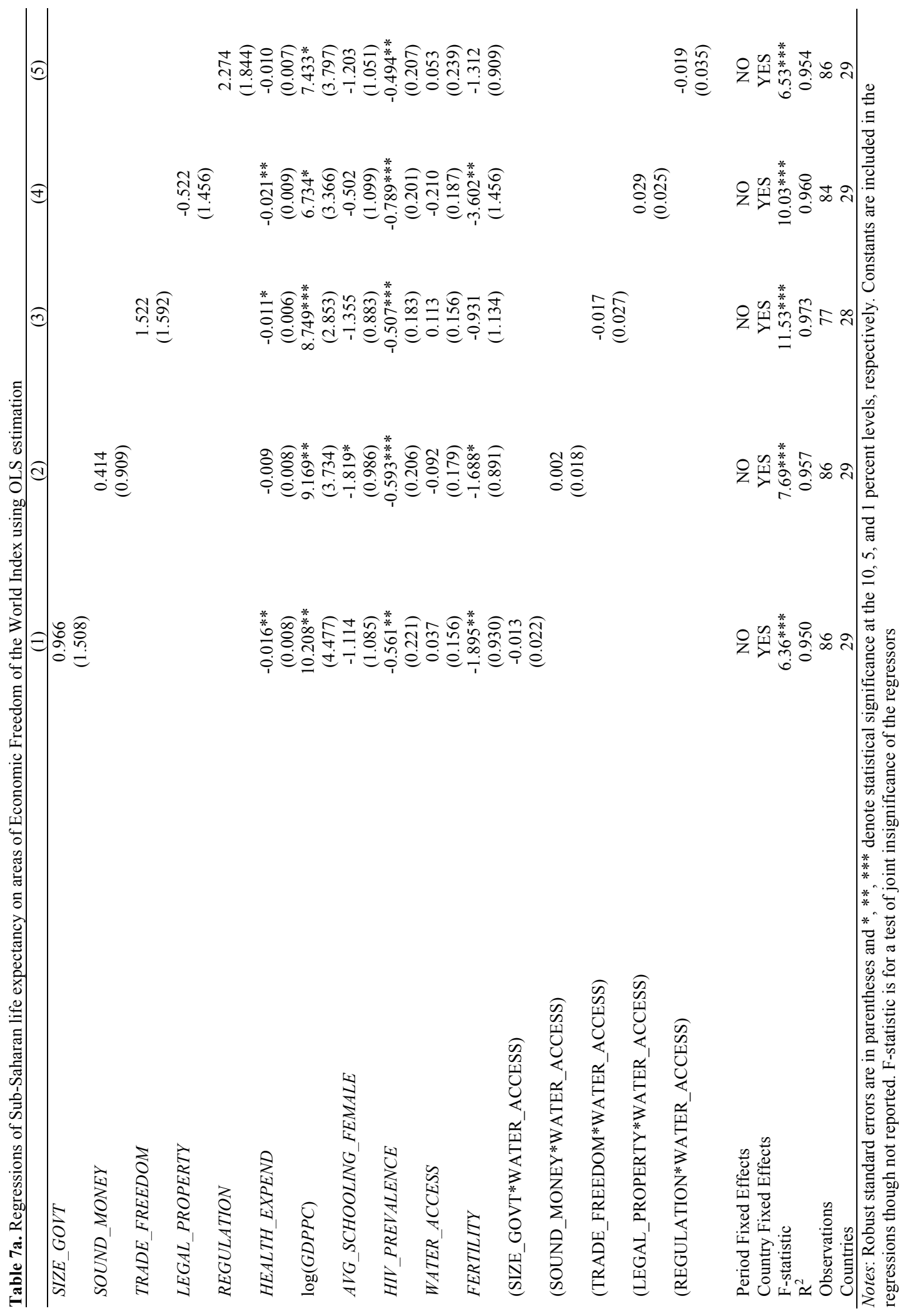




\section{Chapter 4: The Spatial Configuration of the Informal Sector in Sub-Saharan Africa: Do Informal Markets Cross Borders?}

\subsection{Introduction}

The emergence of an informal sector indicates relatively higher opportunity costs for businesses and individuals to operate within the formal economy of a given country. This shadow economy tends to arise in environments that are unfriendly to the creation and operation of legal businesses (De Soto 2000). The complexity and the magnitude of the tax system are frequently cited in the literature as determinants of informality (Schneider 2012, Ruge 2010, Benjamin and Mbaye 2012). Additionally, governments that are unable or unwilling to recognize the rule of law, and protect property and contracts specifically, make it exceedingly difficult for businesses to function successfully within the confines of the formal economy (Friedman et al. 2000). Therefore, a proliferating shadow economy can be a consequence of business climate, tax burden, general governance, and the state of the official economy, particularly its labor market. It is consistent, then, that "extralegality has become the norm" in developing economies where these issues are most pronounced (De Soto 2000, p. 30).

Globally, sub-Saharan Africa accommodates the largest share of informal markets. Estimations by Schneider, et al. (2010) show that regionally, sub-Saharan Africa has the largest shadow economy (as a percentage of "official" gross domestic product) with a median of 40.5 percent as compared to OECD countries with a median of 16.0 percent. This assessment parallels this region's poor record of governance, corruption, poverty, and business climate. According to the 2012 Ease of Doing Business index, sub-Saharan Africa ranked lowest as a region (World Bank, 2014). Sub-Saharan Africa scored a 2.7 out of 6 ( $1=$ low to $6=$ high) on the CPIA index for transparency, accountability, and corruption in the public sector as a consequence of its weak political and economic institutions (World Bank, 2014). In 2010, almost 50\% of the sub-Saharan population was living on less than $\$ 1.25$ day, and the average income per capita was just over $\$ 1,000$ as compared to about $\$ 50,000$ in the United States (World Bank, 2014). Examining these figures reveals a region where incentives are few to operate within the formal economy.

However, there is another factor that may contribute to the rampant increase of the shadow economies in sub-Saharan Africa, which has not yet been explored. This is the physical spatial configuration of black markets across the continent. As certain institutions strengthen or 
weaken in one African country, the institutions of neighboring countries are likely affected. This, in turn, may impact the level of informal sector activity. In other words, the proliferation of the shadow economy in Sub-Saharan Africa may be a result, in part, of spatial spillovers.

In this paper, I propose a spatial approach to analyzing the emergence of informality in Sub-Saharan Africa. Through the estimation of a spatial econometric model, this paper explores the extent to which black markets in one country "spill over" onto other neighboring countries, specifically through different institutional economic channels. This paper proceeds as follows: in section 2, there is more development of the relevant literature on institutions and spatial spillovers. Section 3 presents the data to be used for this paper while section 4 describes the spatial econometric model in which it will be used. The results of the model are reported and analyzed in section 5, and conclusions are drawn in the final section.

\subsection{Literature Review}

It seems natural that proximity might create institution building among neighboring countries. This concept has been examined with particular regard to sub-Saharan Africa by Easterly and Levine (1998). They conclude that policy choices are contagious across borders and that growth resulting from effective policy changes is relatively larger when neighboring countries act together. Simmons and Elkins (2004) study the diffusion of liberal economic practices across international borders and find support that economic policies are transmitted through both the emulation of success as well as imitation induced by cultural ties. Using a spatial econometric model, Kelejian, Murrell, and Shepotylo (2013) similarly show that the level of institutions in a country's immediate neighbors affects the country's own institutions. They suggest that this diffusion occurs through "a variety of mechanisms" including learning, imperialism, and economic competition (Kelejian et al. 2013, p. 298). Ultimately, spatially-established institutions may influence the level of shadow economic activity that is observed across nations.

The underground economy can be considered to be a type of corruption with the capacity to spill over from one nation to another. Therefore, the literature on corruption and the institutional channels by which it spreads are relevant for this discussion. Ortega, Florax, and Delbecq (2010) investigate the international spatial distribution of corruption and its economic 
and political determinants. They conclude that the economic and political actions of a country significantly impact levels of corruption in surrounding countries. Similarly, Bonaglia, Macedo, and Bussolo (2001) look at the effect of globalization on governance. They reach the specific conclusion that import openness reduces corruption.

Goel and Saunoris (2014) hypothesize that corruption and shadow economic activity may be both intertwined and contagious across national borders and present two possible scenarios for the link. On the one hand, corruption and the informal sector may be substitutes for one another in that informal firms may diminish rent-seeking opportunities for corrupt officials. The opposite view is that corruption and the informal sector may serve as complements when the black market firms and officials work cooperatively through bribery, support, and kickbacks. As a result of their study, they find evidence of spatial contagion between corruption and informality across borders with cross-contagion traced to substitution between own informality (corruption) and neighboring corruption (informality).

The spatial approach taken by these papers underline a common assertion: the institutions of one country do not affect that country alone but instead have the potential to spill over onto neighboring countries. However, no other study has explored how the strength of economic institutions impact the spread of informality within this spatial framework. This study will additionally utilize the extensive shadow economy dataset recently developed by Elgin and Oztunali (2012).

\subsection{Data}

The concealed nature of black markets renders measurements of informal market activity difficult to fully capture with absolute confidence. However in order to engage in an empirical study of informal markets, it is necessary to establish some approximation, even if imperfect, of black market activity.

Even in spite of the difficulty in obtaining such data, it is clear that informal markets comprise a significant part of economies worldwide (Schneider and Enste 2000). Globally, the shadow economy appears to be growing. In 2009, the OECD estimated that half of the workers 
of the world were a part of the informal sector, and by 2020, it is expected that two-thirds of the world's workers will be informal (Rabinowitz 2011). Observation of the rapidly growing sector worldwide has given rise to a new name for this phenomenon: "System D" (Neuwirth 2011). System D originated from the French word débrouillard, which refers to to a remarkably effective or motivated individual (Neuwirth 2011). Over time, the spirit of this word has been broadened to speak collectively of those "entrepreneurs" who have evaded the regulations and restrictions of government by leaving the official economy altogether. Specifically in Africa, estimates by Schneider (2012) indicate that the average share of informal employment in total non-agricultural employment has increased steadily from $40 \%$ in the 1980 s to over $60 \%$ in the 2000s.

There has been no consensus on the best way to approximate the size of the shadow economy; however there have been a several popular approaches. These attempts can be broadly categorized as the indirect, direct, and MIMIC approaches (Schneider 2012; Elgin and Oztunali 2012). Indirect approaches utilize macroeconomic indicators as a proxy for "true" economic activity in contrast with the nationally reported GDP figures. For example, Kaufmann and Kaliberda (1996) contend that the consumption of electricity represents all economic activity including informal activities unreported by official measures. By tracking the growth of electricity consumption, their paper establishes estimates for the size of the underground economy. Direct approaches to estimating the size of the informal economy include surveys, interviews, and questionnaires. The 2006-2007 Global Competitiveness Report released by the World Economic Forum provided underground economy figures as a result of the responses of top business leaders from 125 countries (World Economic Forum 2007). Finally, the MIMIC (multiple indicators multiple causes) approach has been popularized in recent years by Schneider (2012). Through this method, the shadow economy is considered to be an unobserved phenomenon (or latent variable) approximated by "using quantitatively measurable causes of illicit employment, e.g. tax burden and regulation intensity, and indicators reflecting illicit activities, e.g. currency demand, official GDP and official working time” (Schneider 2012).

Assessments of the strength of the estimates produced by these methodologies indicate that problems may arise from the simplification of assumptions (indirect approach), measurement error (direct approach), and ad-hoc specifications without micro-foundations 
(MIMIC) (Elgin and Oztunali 2012). However, recently, a new approach pioneered by Elgin and Oztunali (2012) establishes a dynamic general equilibrium composed of the official and shadow economies. The model is calibrated and solved for each country by incorporating each country's capital stock, formal employment, and aggregate consumption. The result of this paper is a new panel dataset of informal economic activity for 161 countries ranging from 1950 to 2009. My study employs these shadow economy estimations (as a percent of GDP) as the dependent variable of the model that I construct.

Within the shadow economy literature, a number of papers have considered the determinants of informal sector activity (Johnson, Kaufmann and Zoido-Lobaton 1998b, Friedman, et al. 2000). Schneider (2012) summarizes the findings of 22 different empirical studies into six main causes of increased shadow economic activity: (1) increase of the tax and social security contribution burdens, (2) quality of state institutions, (3) transfers, (4) specific labor market regulations, (5) public sector services, and (6) tax morale. Advantageously, these six determinants match well with the sub-indices of the Fraser Institute's Economic Freedom of the World index: SIZE_GOVT,SOUND_MONEY,LEGAL_SYSTEM, REGULATION, and TRADE_FREEDOM (Gwartney, Lawson, Hall 2012). As such, the independent variables of interest in this study are these Fraser Institute sub-indices. Each of these indices are based on a scale of 1 to 10 with 10 denoting countries with freer, less obstructed markets (each variable is discussed in more detail in this section). They are reported at 5-year intervals from 1975 to 2000, and then on an annual basis from 2000 thereafter.

The sub-index SIZE_GOVT captures four areas: government consumption, transfers and subsidies, government enterprises and investment, and the top marginal tax rate. A higher rating in this category denotes that a country operates with more personal choice but smaller overall government budgets and involvement. In the context of this model, it is expected that higher rating for SIZE_GOVT (or smaller government) will decrease shadow activity. Individuals in countries with a lower tax burden will not demand an underground economy to escape the opportunity costs of higher taxes. Furthermore, corruption is often tied to big government, and Goel and Saunoris (2014) have shown that corruption is related to increased informal activity. Cote d'Ivoire has the highest rating for this category (8.376) while Tanzania is ranked the lowest at (1.96). 
SOUND_MONEY incorporates money growth, inflation, and freedom to own foreign currency. A higher score indicates that a country exhibits low and stable rates of inflation and allows for the use of alternative currencies. A stable money supply would encourage individuals to operate formally, thus decreasing the need for the shadow economy. Furthermore, fewer restrictions on foreign currency use would additionally decrease the need to hide economic activity. Mauritius ranks highest for SOUND_MONEY while Uganda and Democratic Republic of the Congo are ranked lowest.

The variable LEGAL_SYSTEM describes the strength of a county's legal system and its respect for property rights. Specifically, this index accounts for judicial independence, impartial courts, protection of property rights, military interference in rule of law and politics, integrity of the legal system, legal enforcement of contracts, regulatory restrictions on the sale of real property, reliability of the police, and business costs of crime. All of these factors help determine how friendly a country is to official business; businesses have more incentive to operate formally if they know that they will have the legal support and protection of the country's government. Therefore, one would expect that a higher score in this variable would equate to a lower level of informal activity. The countries Botswana and Mauritius receive the highest ratings for this category while the Democratic Republic of the Congo is ranked lowest.

REGULATION describes the extent of regulations that exist in credit markets, labor markets, and for businesses. According to this definition, the Democratic Republic of the Congo is considered most highly regulated while Botswana, South Africa, and Mauritius are the least regulated. All else equal, I expect that for a higher score of REGULATION, there will be lower levels of informal sector activity. Similar to the reasoning put forth for the LEGAL_SYSTEM variable, an environment more favorable for the growth of formal business will not cause individuals to resort to hiding in the shadow economy.

The final economic variable that I consider is TRADE_FREEDOM. The freedom to trade internationally incorporates the impact of tariffs, regulatory trade barriers, black-market exchange rates, and controls of the movement of capital and people. A high rating on this subindex indicates that a country facilitates international trade with low tariffs and few impediments to movement across international borders. The literature on trade liberalization and its effect on the informal sector is mixed. Jansen and Lee (2007) describe the arguments for why trade 
liberalization may decrease or increase informal sector activity. On the one hand, free trade creates new markets and job opportunities through increased trade on the international level. At the same time, new foreign competition may cause domestic firms to reduce the cost of labor by diminishing the role of current employees or even subcontracting with informal establishments. Goel and Saunoris (2014) point out that "underground businesses deal with other firms, who themselves might not also be operating underground." Trade is freest in Zambia, Uganda, and Botswana while it is most controlled in Ghana, Sierra Leone, and Nigeria.

So far, I have considered the direct effects that each of these economic institutional variables should create in a country. However, the objective of the spatial analysis is to also consider the spillover effects of these economic variables on the basis of a country's geographical neighbors. There are two main possibilities. On the one hand, countries with lower (or higher) institutional ratings may share similar institutional structures as their neighbors. Whether by specific economic ties or cultural similarities shared in a particular region, these neighbors may therefore exhibit similar shadow economy levels as a result. If black markets have the potential to spill over across borders, we would expect higher or lower levels of unofficial activity to be regionally similar. On the other hand, it is possible that countries with lower (or higher) shadow economies as a result of internal institutional channels (direct effects only) may appear to have a relatively larger or smaller unofficial economy when compared to their neighbors. From this perspective, the spatial analysis would accentuate the contrast between two countries and their respective levels of informal activity. Because of these possibilities, the existence and the sign of the indirect effects of institutional quality on the shadow economies of neighboring countries are ambiguous at this point. The results will reveal more information about the nature of the channels of black markets in this region.

Using the variables described above, I create a panel of 18 sub-Saharan African countries averaged over five 5-year periods from 1980 to 2004. Descriptive statistics are displayed in Table 1. For context within the framework of this paper, the country with the lowest GDP per capita in the sample is $\$ 236$ (Democratic Republic of the Congo) and the country with the largest is $\$ 9,677$ (Botswana). Countries with the smallest informal sector as a share of GDP include Mauritius and South Africa (about 25\%) while the countries with the largest informal sector as a share of GDP are Tanzania and Zimbabwe (about 65\%). Countries that fall about in the middle 
of the range are Botswana and the Democratic Republic of the Congo (informal sector of about $42 \%$ of GDP).

\subsection{Spatial model}

In order to develop the geographical relationship among the 18 sub-Saharan African countries in my study, I draw on the family of spatial panel econometric models tailored from the general form $^{13}$ :

$$
\begin{gathered}
y_{i t}=\delta \sum_{j=1}^{N} w_{i j} y_{j t}+x_{i t} \beta+\sum_{j=1}^{N} w_{i j} x_{i j t} \gamma+\mu_{i}+\lambda_{t}+u_{i t} \\
u_{i t}=\rho \sum_{j=1}^{N} w_{i j} u_{i t}+\varepsilon_{i t}
\end{gathered}
$$

In the context of my model, $i$ indexes the cross-sectional dimension of the 18 countries being considered $(i=1, \ldots, 18)$ while $t$ represents the five time periods $(t=1, \ldots, 5)$. Each observation of the dependent variable Shadow_economy is defined for a specific $i$ and $t$ by $\mathrm{y}_{\mathrm{it}}$. The independent variables are contained in the $(1, K)$ row vector shown as $\mathrm{x}_{\mathrm{it}}$, and $\beta$ represents the corresponding $(K, 1)$ vector of unknown parameters. Space- and time-period fixed effects are incorporated in the terms $\mu_{\mathrm{i}}$ and $\lambda_{\mathrm{t}}$. The error is denoted by the term $u_{i t}$.

The spatial weights matrix, W, establishes the geographical relationship among the countries. Based on the latitude and longitude coordinates of the countries, $w_{\mathrm{ij}}$ is designated as 1 if countries $i$ and $j$ are neighbors and 0 if they are not. The three closest countries to a given country, based on latitude and longitude coordinates, are considered to be neighbors; all others are not. It is this weights matrix upon which the applicable spatial modeling will hinge. As a result of its inclusion, in the presence of spatial autocorrelation in either the dependent variable or the error term, $\delta$ and $\rho$ will capture this relationship.

\footnotetext{
${ }^{13}$ Notation for spatial panel data models described in Elhorst (2010a).
} 
Given the general form of the model (Equation 1), different cases can be considered. This is accomplished by restricting the parameters $\Upsilon, \delta$, and $\rho$ in order to create the spatial autoregressive model (SAR), spatial error model (SEM), and spatial Durbin model (SDM). In the case of the SAR model, the parameters are set so that $\Upsilon=0$ and $\rho=0$. This means that the spatial dependence exists only in the dependent variable. On the other hand, when spatial dependence occurs only in the error term, the SEM model is constructed with $\Upsilon=0$ and $\delta=0$. Finally, the SDM model places the restriction $\rho=0$ which allows for spatial dependence in both the independent and dependent variables.

Given that I hope to uncover the channels of spatial spillovers causing varying levels of informal sector activity across borders, it is most reasonable to employ the spatial Durbin model (SDM) in the context of this paper. This will allow me to consider the individual institutional economic variables as conduits of spatial spillovers. In determining if a fixed effects model (country and/or time) is necessary, two Likelihood Ratio tests assess the null hypothesis that each type of effect is equal to zero when comparing a restricted and unrestricted model. When testing for country fixed effects $\left(\mathrm{H}_{0}: \mu_{1}, \mu_{2}, \ldots, \mu_{\mathrm{n}}=0\right)$, the conclusion is to reject the null hypothesis (LR: 204.63, $p$-value 0.0000). However, the results of the period fixed effects indicate a decision to fail to reject (LR: $-2.8649, p$-value 0.7248$)$ the null hypothesis $\left(\mathrm{H}_{0}: \lambda_{1}, \lambda_{2}\right.$, . $\left.\ldots, \lambda_{t}=0\right)$. Therefore, a spatial Durbin model using country fixed effects is most appropriate. The results of this model are reported and discussed in the following section.

\subsection{Results and Discussion}

As a baseline, Table 2 provides the results of an ordinary least squares (OLS) non-spatial model with country fixed effects. Two of the independent variables prove to be significant:

LEGAL_SYSTEM and SOUND_MONEY. From this non-spatial approach, the model shows that as there is an increase in the rating of a country's legal system (stronger legal system and protection of property rights), there is a decrease in the shadow economy. Likewise, less shadow activity is perceived in countries with a sounder money supply. Both of these findings support the hypothesis that individuals in a more stable country with a strong legal foundation would have less need for an underground economy. 
However, the OLS model ignores the possibility of spatial dependence. According to LeSage and Pace (2009), estimating the model with OLS could lead to biased, inconsistent, or inefficient results because of the possibility of spatial correlation. LeSage and Pace note that the SDM model should be used when (1) there is an omitted variable that is spatially correlated, and (2) this omitted spatially correlated variable is correlated with an included independent variable. As discussed earlier, the SDM model allows for spatial dependence in both the independent and dependent variables making it most appropriate for this investigation where independent institutional variables are expected to be the conduits of spatial spillovers.

The results of the SDM model are displayed in Table 3 and 4. Johnson, Kaufmann, and Zoido-Lobaton 1998b suggest that estimating the unofficial share of the economy should incorporate a control for the "wealthy country" effect. Wealthier countries have been shown to have a lower level of unofficial economy across studies. For this reason, I include GDP per capita as an additional independent variable in Table 4. GDPPC carries the expected negative sign; as a country is wealthier, that country's informal activity goes down. This supports the hypothesis that a stronger official economy will have less need for an unofficial economy.

The results in both tables are quantitatively similar with the exception of additional significance of the variable REGULATION when controlling for GDP. Therefore, I begin by reporting the results of Table 3. The spatial autocorrelation in the dependent variable is (measured by $\rho$ ) is equal to -0.306 and is significant at the 5 per cent level. This negative result indicates a "checkerboard pattern" where neighbors actually have dissimilar levels of shadow economic activity. This parameter shows that a country with a relatively high level of informal activity will have neighbors with relatively lower levels of informal activity. Looking at the dependent variable alone, it does not appear that informal sector activity crosses borders.

However, for each independent variable, we can measure the direct, indirect, and total effects on shadow economic activity. By looking at these effects, it can be determined whether some of the institutional variables do in fact spill over onto neighboring countries, which in turn, may affect the level of informal sector activity. The direct effects describe the impact that the economic variables of a single country have on its own country. Although numerical magnitudes cannot be compared between spatial models and OLS, the results show that there is a negative and statistically significant relationship between SOUND_MONEY and LEGAL_SYSTEM and 
informal activity in that country consistent with the sign in the OLS model. As a country demonstrates a relatively stable money supply, there will be less demand for hidden economic activity. Likewise, a stronger legal system with protection of property rights provides incentive for business owners to operate legally within the confines of the official economy without turning to an alternative market. On the other hand, the variable TRADE_FREEDOM is positive and significantly associated with informal activity. This supports the hypothesis that as economic flows between countries become more open, there may be more opportunity for black market networks to grow as well.

Next, I turn to a discussion of the indirect effects. In the context of this model, the indirect effects can be thought of as the impact that the level of institutional quality in one country has on a neighbor's informal activity. One significant result is obtained in both Table 3 and 4. As a country's SIZE_GOVT index increases (an increase in this index means a smaller government, smaller tax burden), a neighbor's overall level of shadow activity decreases. This suggests that sub-Saharan neighbors may tend to share similar levels of government involvement (either learned or developed alongside one another). Alternatively, this finding can be explained by the ties between the shadow economy and corruption that Goel and Saunoris (2014) explored. Smaller government size in one country may reduce corruption in both that country and decrease opportunities for corruption ties between countries.

The final column of Table 3 captures the total effects of each independent variable on shadow economic activity. As the sum of the direct and indirect effects, total effects indicate how changes in the economic explanatory variables affect total shadow economic activity by including both own-country and neighboring country spillover effects. Increased ratings in SIZE_GOVT are related to lower levels of shadow activity.

Turning to the slightly diverging results in Table 4, the other significant indirect effect is the positive relationship between REGULATION and the shadow economy. This implies that as the REGULATION score in one country increases (an increase in the index denotes less regulatory interference), informal activity in a neighboring country actually increases. This indirect effect may be capturing a relative comparison between countries. Less regulation in a given country is expected to decrease shadow economic activity in that country. However, if 
shadow economic activity in that country decreases as a result of less regulation, this may make surrounding areas appear to have relatively higher levels of informal activity.

\subsection{Conclusion}

One conclusion of this study is evident from the direct effects of the spatial Durbin model: improved legal and property protection in addition to a sound money supply decrease informality within a given country. This corresponds with findings across the literature (Schneider 2012). On the other hand, TRADE_FREEDOM is associated with higher levels of shadow economic activity. Freer markets in this area may create and expand market networks within both formal and informal categories of economic activity.

There is also evidence of indirect effects across the region. The results show that these indirect spatial spillovers occur through the channel of SIZE_GOVT; countries that are neighbors to a country with less intrusive government oversight are likely to have lower levels of shadow economic activity themselves. This is likely an indication that neighboring countries imitate and establish governments with similar roles and tax regimes as local neighbors.

Tracing potential sources of shadow economic activity is particularly critical in the developing world. Johnson, Kaufmann, and Shleifer (1997) suggest that unofficial sector growth creates a downward-spiraling chain reaction fueled by the ensuing low tax collection and subsequent inadequate public goods in the official sector. A vicious cycle such as this would be difficult to break out of in order to achieve (official) economic growth.

At the same time, the existence of a strong informal sector in a country indicates potential resources that could be used for growth if they were formalized. De Soto refers to the underground economy as "dead capital" but proposes that governments of these nations have the opportunity "to integrate [informal] resources into an orderly and coherent legal framework" (De Soto 2000 , p. 30). This integration process might mean bolstering economic institutions as indicated by the results of this paper. In turn, since institutions in one country have the capacity to spill over onto neighboring countries, this could create a ripple across the sub-Saharan region via neighbors. 
Table 19

Table 1. Descriptive Statistics $(\mathrm{N}=90)$

\begin{tabular}{lllll}
\hline Variable & Mean & Std deviation & Minimum & Maximum \\
\hline Shadow_economy & 42.641 & 10.918 & 22.884 & 66.512 \\
GDPPC & $1,603.507$ & 2011.222 & 236.487 & 9677.452 \\
SIZE_GOVT & 5.664 & 1.402 & 1.960 & 8.376 \\
SOUND_MONEY & 5.121 & 2.460 & 0 & 9.522 \\
LEGAL_SYSTEM & 4.556 & 1.419 & 1.490 & 7.580 \\
REGULATION & 5.244 & 1.039 & 2.910 & 7.544 \\
TRADE_FREEDOM & 4.420 & 1.943 & 0 & 8.636 \\
\hline
\end{tabular}

Table 20

Table 2. Non-spatial fixed effects $\operatorname{model}(\mathrm{N}=90 \mathrm{~T}=5)$

Dependent variable: Shadow economy estimate (\% of GDP)

Explanatory variables

\begin{tabular}{ll}
\hline SIZE_GOVT & 0.031 \\
& $(0.478)$ \\
SOUND_MONEY & $-0.601^{*}$ \\
& $(0.351)$ \\
LEGAL_SYSTEM & $-0.782^{* *}$ \\
& $(0.352)$ \\
REGULATION & 0.111 \\
& $(0.973)$ \\
TRADE_FREEDOM & 0.436 \\
& $(0.300)$ \\
constant & $46.600^{* * *}$ \\
& $(7.297)$ \\
$\mathrm{R}^{2}=0.1439$ & \\
\hline Notes: Robust standard errors are in parentheses. *, **,*** denote statistical significance at the 10,5, and \\
1 percent levels, respectively.
\end{tabular}


Table 21

Table 3. Spatial Durbin model $(\mathrm{SDM})$ results $(\mathrm{N}=90, \mathrm{~T}=5)$

\begin{tabular}{|c|c|c|c|}
\hline \multicolumn{4}{|c|}{ Dependent Variable: Shadow economy estimate (\% of GDP) } \\
\hline Explanatory variables & Direct effect & Indirect effect & Total effect \\
\hline$S I Z E \_G O V T$ & $\begin{array}{l}0.215 \\
(-0.529,0.912)\end{array}$ & $\begin{array}{l}-1.049 * * \\
(-1.992,-0.155)\end{array}$ & $\begin{array}{l}-0.834^{*} \\
(-1.758,0.066)\end{array}$ \\
\hline SOUND_MONEY & $\begin{array}{l}-0.820 * * * \\
(-1.293,-0.354)\end{array}$ & $\begin{array}{l}0.432 \\
(-0.196,1.042)\end{array}$ & $\begin{array}{l}-0.388 \\
(-0.944,0.136)\end{array}$ \\
\hline LEGAL_SYSTEM & $\begin{array}{l}-0.825 * * \\
(-1.578,-0.083)\end{array}$ & $\begin{array}{l}0.065 \\
(-1.231,1.284)\end{array}$ & $\begin{array}{l}-0.759 \\
(-2.041,0.398)\end{array}$ \\
\hline REGULATION & $\begin{array}{l}0.874 \\
(-0.726,2.457)\end{array}$ & $\begin{array}{l}0.321 \\
(-1.684,2.434)\end{array}$ & $\begin{array}{l}1.195 \\
(-0.623,3.008)\end{array}$ \\
\hline TRADE_FREEDOM & $\begin{array}{l}0.965^{* *} \\
(0.208,1.679)\end{array}$ & $\begin{array}{l}-0.386 \\
(-1.313,0.454)\end{array}$ & $\begin{array}{l}0.578 \\
(-0.199,1.322)\end{array}$ \\
\hline \multicolumn{4}{|c|}{$\begin{array}{l}\rho=-0.306 \\
\text { (t-stat: }-2.101 p \text {-value: } 0.036 \text { ) } \\
\mathrm{R}^{2}=0.9477, \text { Corr }^{2}=0.2312\end{array}$} \\
\hline
\end{tabular}

Table 22

Table 4. Spatial Durbin model (SDM) results $(\mathrm{N}=90, \mathrm{~T}=5)$ controlling for GDP per capita

\begin{tabular}{|c|c|c|c|}
\hline \multicolumn{4}{|c|}{ Dependent Variable: Shadow economy estimate (\% of GDP) } \\
\hline Explanatory variables & Direct effect & Indirect effect & Total effect \\
\hline$G D P P C$ & $\begin{array}{l}-0.002 * * * \\
(-0.003,-0.001)\end{array}$ & $\begin{array}{l}-0.001 \\
(-0.003,0.001)\end{array}$ & $\begin{array}{l}-0.002 * * \\
(-0.004,-0.001)\end{array}$ \\
\hline SIZE_GOVT & $\begin{array}{l}0.162 \\
(-0.446,0.736)\end{array}$ & $\begin{array}{l}-1.247 * * \\
(-2.104,-0.393)\end{array}$ & $\begin{array}{l}-1.085^{* *} \\
(-2.052,-0.219)\end{array}$ \\
\hline SOUND_MONEY & $\begin{array}{l}-0.540 * * \\
(-1.013,-0.065)\end{array}$ & $\begin{array}{l}-0.252 \\
(-0.928,0.390)\end{array}$ & $\begin{array}{l}-0.793 * * \\
(-1.416,-0.222)\end{array}$ \\
\hline$L E G A L \_S Y S T E M$ & $\begin{array}{l}-0.681 * \\
(-1.326,-0.001)\end{array}$ & $\begin{array}{l}-0.242 \\
(-1.391,0.854)\end{array}$ & $\begin{array}{l}-0.924 \\
(-2.135,0.225)\end{array}$ \\
\hline REGULATION & $\begin{array}{l}0.778 \\
(-0.916,2.434)\end{array}$ & $\begin{array}{l}2.801 * * \\
(0.694,4.918)\end{array}$ & $\begin{array}{l}3.579 * * * \\
(1.403,5.932)\end{array}$ \\
\hline TRADE_FREEDOM & $\begin{array}{l}0.981 * * * \\
(0.301,1.595)\end{array}$ & $\begin{array}{l}0.107 \\
(-0.745,1.002)\end{array}$ & $\begin{array}{l}1.088^{* *} \\
(0.286,1.919)\end{array}$ \\
\hline \multicolumn{4}{|c|}{$\begin{array}{l}\rho=-0.286 \\
(\mathrm{t}-\text { stat: }-1.985 p \text {-value: } 0.047) \\
\mathrm{R}^{2}=0.9590, \text { Corr }^{2}=0.4123\end{array}$} \\
\hline
\end{tabular}




\section{Chapter 5: Conclusion}

All three chapters point to a shared conclusion: institutions do matter for health and development in sub-Saharan Africa. In Chapter 2, even when controlling for a number of cultural factors associated with religion, CHRISTIANITY remains significantly correlated with HIV prevalence in sub-Saharan Africa. The results of the third chapter indicate that health outcomes are positively impacted by economic freedom but not by democracy. Chapter 4 concludes that a strong legal system with protection of property and a sound money supply reduce the size of a country's informal sector. Moreover, countries that are neighbors to countries with less intrusive governments and lower taxes tend to have lower levels of informal sector activity themselves.

Nevertheless, while institutions are shown to be important for a variety of outcomes in this region, this research still leaves many questions unanswered about the precise manner in which these institutions matter. Although Christianity has been linked to HIV in Africa, it appears that there is still a more specific factor associated with the religion that remains to be uncovered. Also, determining the direction of causality between condom use and HIV will provide a better understanding of whether condoms are improving or worsening the epidemic. In Chapter 3, the interaction of SIZE_GOVT with WATER_ACCESS suggested that countries with relatively less water access may actually benefit from a larger government to coordinate the distribution of public goods. Likewise, other resources may interact in differing ways with various kinds of economic freedom. Finally, the results of the fourth chapter suggest further investigation may help to determine why fewer regulations in one country may contribute to a larger shadow economy in a neighboring country. It is possible that the model is capturing a relative contrast between countries, but it may also be a result of a different conclusion. Future research in all of these areas will contribute to determining how institutions affect growth and development, specifically in sub-Saharan Africa.

The intention of this dissertation is not to disprove that geography, climate, and natural resources matter for growth and development of a nation. Rather, the focus is on the importance of institutions in contributing to these same outcomes. By limiting the scope of this study to the sub-Saharan region, I am able to capture the variation that emerges from nations of a shared geographical location as a consequence of the differing institutional structures of each society. 
This is a significant contribution in understanding and improving these African economies and the lives of those in the region. 


\section{References}

AIDS Vaccine Advocacy Coalition (2007). "A New Way to Protect Against HIV? Understanding the Results of Male Circumcision Studies for HIV Prevention." A Publication from the AIDS Vaccine Advocacy Coalition's Anticipating and Understanding Results Series.

AVERT, International HIV \& AIDS charity (2014). "Preventing Mother-to-child Transmission of HIV." Retrieved April 6, 2014, from http://www.avert.org/preventing-mother-childtransmission-hiv.htm.

AVERT, International HIV \& AIDS charity (2011). Retrieved October 16, 2012, from http://www.avert.org/aids-hiv-charity-avert.htm.

AVERT, International HIV \& AIDS charity (2013). Retrieved August 15, 2013, from http://www.avert.org/hiv-aids-africa.htm\#contentTable2.

AVERT, International HIV \& AIDS charity (2013). "History of HIV \& AIDS in Africa." Retrieved August 15, 2013 from http://www.avert.org/history-aids-africa.htm.

Acemoglu, Simon Johnson, and James Robinson (2000). "The Colonial Origins of Comparative Development: An Empirical Investigation." The American Economic Review 91 (5), 1369-1401.

Arellano, M. and S. Bond (1991). "Some tests of specification for panel data: Monte Carlo evidence and an application to employment equations." The Review of Economic Studies, 58. pp. 277-297.

Arik, Hulya and Murat Arik (2009). "Is it Economic Growth or Socioeconomic Development? A Cross-Sectional Analysis of the Determinants of Infant Mortality." The Journal of Developing Areas 42(2): 31-55.

BBC Religion \& ethics - Islam. (2009). "Circumcision of boys." Retrieved October 18, 2012, from http://www.bbc.co.uk/religion/religions/islam/islamethics/malecircumcision. $\underline{\text { shtml }}$

Baliamoune-Lutz, Mina (2008). "Human Well-Being Effects of Institutions and Social Capital," Contemporary Economic Policy. 27(1): 54-66.

Becker, Felicitas (2007). "The Virus and the Scriptures: Muslims and AIDS in Tanzania." Journal of Religion in Africa, 37, (1), pp. 16-40.

Beckmann, Nadine. (2009) "AIDS and the Power of God: Narratives of Decline and Coping Strategies in Zanzibar." AIDS and Religious Practice in Africa. Studies of Religion in Africa, Leiden: Brill. p. 36.

Benagiano, Giuseppe, Sabina Carrara, Valentina Filippi, and Ivo Brosens (2011). "Condoms, 
HIV and the Roman Catholic Church," Reproductive BioMedicine Online 22 (7), pp. 701-709.

Benjamin, Nancy and Ahmadou Aly Mbaye (2012). "The Informal Sector, Productivity, and Enforcement in West Africa: A Firm-level Analysis." Review of Development Economics, 16 (4). 664-680.

Bible, 1 Corinthians 6:18, New International Version.

Boettke, Peter and J. Robert Subrick (2003). "Rule of Law, Development, and Human Capabilities." Supreme Court Economic Review 109-127.

Bonaglia, Federico, Jorge Braga de Macedo, and Maurizio Bussolo (2001). "How Globalisation Improves Governance.” OECD Development Centre working paper \#181, 2001.

Bonner, Kate (2001). "Male Circumcision as an HIV Control Strategy: Not a 'Natural Condom,"” Reproductive Health Matters, 9 (18), pp. 143-155.

Buchanan, James (1954). "Individual Choice in Voting and the Market." Journal of Political Economy, 62 (4) (Aug. 1954) pp. 334-343.

Carael, Michel (2006). "Twenty Years of Intervention and Controversy," The HIV/AIDS Epidemic in Sub-Saharan Africa in a Historical Perspective, Philippe Denis and Charles Becker (eds) Online edition, October 2006 pp.26-40.

Caselli, Francesco, Gerardo Equivel, and Fernando Lefort (1996). "Reopening the Convergence Debate: A New Look at Cross-Country Groth Empirics." Journal of Economic Growth, 1 (3), 363-89.

De Soto, Hernando (2000). The Mystery of Capital. New York: Basic Books.

De Waal, Alex (2006). “AIDS: A Darwinian Event?” The HIV/AIDS Epidemic in Sub-Saharan Africa in a Historical Perspective, Philippe Denis and Charles Becker (eds) Online edition, October 2006 pp. 57-72.

Deegan, Heather (2009). Africa Today: Culture, economics, religion, security. London and New York: Routledge, pp. 38-140, 197.

Denis, Philippe (2006). "Towards a Social History of HIV/AIDS in Sub-Saharan Africa." The HIV/AIDS Epidemic in Sub-Saharan Africa in a Historical Perspective, Philippe Denis and Charles Becker (eds) Online edition, October 2006. pp. 13-26.

Denis, Philippe (2011). "HIV, AIDS and religion in sub-Saharan Africa." Religion and HIV and AIDS: Charting the Terrain, Beverley Haddad (ed), South Africa: University of KwaZulu-Natal Press, pp. 57-72. 
Drain, Paul K., Jennifer S. Smith, James P. Hughes, Daniel T. Halperin, and King K. Holmes. (2004). "Correlates of National HIV Seroprevalence: An Ecological Analysis of 122 Developing Countries," Journal of Acquired Immune Deficiency Syndromes. 35 (5). pp. 407-420.

Easterly, William and Ross Levine (1998). "Troubles with the Neighbours: Africa's Problem, Africa’s Opportunity.” Journal of African Economies, 7 (1), 120-142.

Elgin, C. and Oztunali, O. (2012). "Shadow economies around the world: model based estimates.” Bogazici University Department of Economics Working Paper.

Elhorst, J. Paul (2010a). “Spatial panel data models.” In Fischer MM, Getis A (eds) Handbook of Applied Spatial Analysis. Springer, Berlin.

Fafchamps, Marcel (2004). Market Institutions in Sub-Saharan Africa. (Cambridge, MA: MIT Press).

Fafchamps, Marcel (2006). “Development and Social Capital.” Journal of Development Studies 42 (7), 1180-1198.

Fayissa, Bichaka (2001). "The Determinants of Infant and Child Mortality in Developing Countries: The Case of Sub-Sahara Africa." The Review of Black Political Economy: 83100.

Fayissa, Bichaka and Paulos Gutema (2005). "The Determinants of Health Status in SubSaharan Africa." The American Economist 49 (2), 60-66.

Fitzgerald, Ann M., Bonita F. Stanton, Nancy Terreri, Hannu Shipena, Xiaoming Li, Joshua Kahihuata, Izabel Ricardo, Jennifer Galbraith and Anna Marie de Jaeger. (1999). "Use of Western-Based HIV Risk-Reduction Interventions Targeting Adolescents in an African Setting." Journal of Adolescent Health. 25 (1), pp. 52-61.

Flachaire, Emmanuel, Cecilia Garcia-Penalosa, Maty Konte (2011). "Political versus Economic Institutions in the Growth Process." Journal of Comparative Economics In press, Available online 16 May 2013.

Food and Agriculture Organization of the United Nations (2013). Accessed August 21. 2013 from http://www.fao.org/focus/e/aids/aids1-e.htm .

Fredland, Richard A. (2001). Understanding Africa: A Political Economy Perspective. Chicago: Burnham Inc., Publishers.

Friedman, Eric, Simon Johnson, Daniel Kaufmann, and Pablo Zoido-Lobaton (2000). "Dodging the grabbing hand: the determinants of unofficial activity in 69 countries." Journal of Public Economics, 76. 459-493. 
Friedman, Milton and Rose (1990). Free to Choose: A Personal Statement. (New York: Harcourt Brace Jovanovich).

Friedman, Milton and Rose Friedman (2002). Capitalism and freedom. Chicago: University Press.

Gakidou, E. et al. (2010) Global Health Data Exchange. Institute for Health Metrics and Evaluation. http://ghdx.healthmetricsandevaluation.org/

Gallup, John, Jeffrey Sachs, and Andrew Mellinger (1999). "Geography and Economic Development.” International Regional Science Review 22 (2), 179-232.

Goel, Rajeev and James Saunoris (2014). "Global corruption and the shadow economy: spatial aspects.” Public Choice. Published online 8 January 2014.

Goldsmith, Arthur (1997). "Economic Rights and Government in Developing Countries: Cross-National Evidence on Growth and Development." Studies in Comparative International Development 32(2): 29-44.

Gray, Peter B. (2004). “HIV and Islam: Is HIV Prevalence Lower Among Muslims?” Social Science \& Medicine. 58 (9), pp. 1751-1756.

Grim, Brian J. and Roger Finke (2006). Online supplement to article in American Sociological Review, 2007, 72 pp. 633-58. "Religious Persecution in Cross-National Context: Clashing Civilizations or Regulated Religions."

Grim, Brian J. (2005). Religious Regulation's Impact on Religious Persecution: The Effects of De Facto and De Jure Religious Regulation. Unpublished PhD Dissertation, Penn State University.https://etda.libraries.psu.edu/paper/6622/1882

Gwartney, James, Robert Lawson, and Joshua Hall (2012). Economic Freedom of the World: 2012 Annual Report. Vancouver, BC: The Fraser Institute. Data retrieved from www.freetheworld.com

Gwartney, James, Robert Lawson, and Randall Holcombe (1999). "Economic Freedom and the Environment for Economic Growth," Journal of Institutional and Theoretical Economics 155(4): 1-21.

Hargrove, John. (2008) "Migration, mines and mores: the HIV epidemic in southern Africa." Southern African Journal of Science 104 (1-2), pp. 53-61.

Husain, Abhar Rukh (2002). "Life Expectancy in Developing Countries: A Cross-Section Analysis.” The Bangladesh Development Studies 28 (1), 161-178.

Imam, B. M. and S. F. Koch (2004). “The Determinants of Infant, Child and Maternal 
Mortality in Sub-Saharan Africa." Journal for Studies in Economics and Econometrics 28(2). 23-40.

Jansen, M. and E. Lee (2007). Trade and employment: challenges for policy research. Geneva: International Labour Office.

Johnson, Simon, Daniel Kaufmann, and Pablo Zoido-Lobaton (1998b). "Corruption, Public Finances and the Unofficial Economy.” World Bank Policy Research Working Paper Series No. 2169. The World Bank, Washington, D.C.

Johnson, Simon, Daniel Kaufmann, and Andrei Shleifer (1997). "The Unofficial Economy in Transition," Brookings Paper on Economic Activity, Washington, D.C.

Kabir, Mahfuz (2008). "Determinants of Life Expectancy in Developing Countries.” The Journal of Developing Areas 41 (2), 185-204.

Kaufmann, Daniel and Aleksander Kaliberda (1996). "Integrating the Unofficial Economy into the Dynamics of Post-Socialist Economies." The World Bank. Policy Research Working paper 1691.

Kelejian, Harry, Peter Murrell, and Oleksandr Shepotylo (2013). "Spatial spillovers in the development of institutions." Journal of Development Economics 101. 297-315.

Kembo, Joshua and Jeroen K. Van Ginneken (2009). "Determinants of infant and child mortality in Zimbabwe: Results of multivariate hazard analysis." Demographic Research 21(13): 367-384.

Knowles, Stephen and P. Dorian Owen (2010). "Which Institutions are Good for Your Health? The Deep Determinants of Comparative Cross-country Health Status," The Journal of Development Studies, Taylor and Francis Journals, vol. 46(4), pp 701-723.

Kudamatsu, Masayuki (2007). "Has Democratization Reduced Infant Mortality in SubSaharan Africa? Evidence from Micro Data." Journal of the European Economic Association 10(6): 1294-1317.

La Porta, Rafael, Florencio Lopez-de-Silanes, Andrei Shleifer, and Robert Vishny. (1999). "The Quality of Government," Journal of Law, Economics, and Organization. 15 (1). pp. 222-279.

LeSage, James and R. Kelley Pace (2009). Introduction to Spatial Econometrics. CRC Press, Boca Raton, FL.

Lewis, David A. (2006). “A History of the African AIDS epidemic: Review.” Sexually Transmitted Infection. 82 (3), p. 266.

Marlink, Richard G. and Alison G. Kotin (2004). Global AIDS Crisis: a Reference Handbook. 
Santa Barbara, Calif.: ABC-CLIO.

Marshall, Monty G. and Keith Jaggers., and Ted Robert Gurr (2011). Polity IV Project: Dataset Users' Manual. Center for Systemic Peace: Polity IV Project.

McIntosh, William A. and John K. Thomas (2004). "Economic and Other Societal Determinants of the Prevalence of HIV: A Test of Competing Hypotheses," The Sociological Quarterly. 45 (2) pp. 303-324.

Mileva, Elitza (2007). "Using Arellano-Bond Dynamic Panel GMM Estimators in Stata." Fordham University, Economics Department.

Miller, Terry and Kim Holmes, 2011 Index of Economic Freedom (Washington, DC: The Heritage Foundation and Dow Jones \& Company, Inc, 2011), at www.heritage.org/index.

Mishra, Vinod, Simona Bignami, Robert Greener, et al. (2007). "A Study of the association of HIV infection with wealth in sub_saharan Africa.” DHS Working Paper 31.

Morris, B.J. and R.G. Wamai (2007). "Biological basis for the protective effect conferred by male circumcision against HIV infection.” International Journal of STD \% AIDS, 23 (3).

Morse, Donald R. (2002). "Male Circumcision: A Cultural and Religious History, and Questionaaire Study,” Journal of Religion \& Psychical Research. 25 (4). pp. 183-205.

Moser, Gary and Toshihiro Ichida (2001). "Economic Growth and Poverty Reduction in SubSaharan Africa.” International Monetary Fund: IMF Working Paper 112.

Moszynski, Peter (2008). "Kenyan clerics decide to fight against use of condoms," BMJ: British Medical Journal (International Edition), 336 (7654). p. 1154.

Neuwirth, Robert (2011). “The Shadow Superpower.” Foreign Policy. Retrieved April 8, 2014 from http://www.foreignpolicy.com/articles/2011/10/28/black market_global economy ?page $=$ full.

Noel, F., S. Mehta, Y. Zhu, P.D.M. Rouzier, A. Marcelin, et al. (2008) Improving Outcomes in Infants of HIV-Infected Women in a Developing Country Setting. PLoS ONE 3(11): e3723. doi:10.1371/journal.pone.0003723.

North, Douglass C. (1989). "Institutions and Economic Growth: An Historical Introduction," World Development. 17 (9). pp. 1319-1332.

North, Douglass (1990). Institutions, Institutional Change and Economic Performance, Cambridge: Cambridge University Press. p. 3.

Potts, Malcolm, Daniel T. Halperin, Douglas Kirby, et al. (2008). "Reassessing HIV Prevention." 
Science, 320 (5877), pp. 749-750.

Omariba, D. W. R., Roderic Beaujot, and Fernando Rajulton (2007). "Determinants of infant and child mortality in Kenya: an analysis controlling for frailty effects." Population Research and Policy Review 26: 299-321.

Ortega, David, Raymon Florax, and Benoit Delbecq (2010). "Primary Determinants and the Spatial Distribution of Corruption.” Purdue University, College of Agriculture, Department of Agricultural Economics Working Papers. 10-6.

Owen, Ann and Stephen Wu (2007). "Is Trade Good for Your Health?” Review of International Economics 15(4): 660-682.

Pamuk, Elsie R., Regina Fuchs, and Wolfgang Lutz (2011). "Comparing Relative Effects of Education and Economic Resources on Infant Mortality in Developing Countries," Population and Development Review 37(4): 637-664.

Pritchett, Lant and Lawrence H. Summers (1996). "Wealthier is Healthier," Journal of Human Resouces 31 (4), 841-868.

Qur'an; Surat Al-Maidah 5:90.

Qur'an; Surat Al-‘Isra’ 17:32.

Rabinowitz, Marco (2011). "Rise of the Shadow Economy: Second Largest Economy in the World." Forbes.com. Retrieved April 8, 2014, from http://www.forbes.com/sites/benzingainsights/2011/11/07/rise-of-the-shadow-economysecond-largest-economy-in-the-world/.

Rauch, James and Peter Evans (2000). "Bureaucratic structure and bureaucratic performance in less developed countries.” Journal of Public Economics 75, pp. 49-71.

Rizvi, S.A.H., S.A.A. Naqvi, M. Hussain and A.S. Hasan (1999). "Religious circumcision: a Muslim view," BJU International, 83 (1), pp. 13-16.

Roodman, David (2009). "How to do xtabond2: An introduction to difference and system GMM in Stata. The Stata Journal 9 (1), 86-136.

Ruge, Marcus (2010). "Determinants and size of the shadow economy." International Economic Journal, 24. 511-523.

Sachs, Jeffrey and Andrew Warner (2001). "The curse of natural resources." European Economic Review 45, 827-838.

Schneider, Friedrich (2012). "The Shadow Economy and Work in the Shadow: What Do We (Not) Know?” IZA Discussion Paper No. 6423. 
Schneider, Friedrich, Andreas Buehn, and Claudio E. Montenegro (2010). "Shadow Economies All over the World.” World Bank Policy Research Working Paper 5356.

Schneider, Friedrich and Dominik Enste (2000). "Shadow Economies: Size, Causes, and Consequence." Journal of Economic Literature 38, 77-114.

Shelton, JD, MM Cassell, J Adetunji (2005). "Is poverty or wealth at the root of HIV?" Lancet 366: 1057-58.

Shleifer, Andrei and Robert Vishny (1993). "Corruption." The Quarterly Journal of Economics 108 (3), pp. 599-617.

Silverman, Eric K. “Anthropology and Circumcision” (2004) Annual Review of Anthropology, 33 (1), pp. 410-445.

Simmons, Beth and Zachary Elkins (2004). "The Globalization of Liberalization: Policy Diffusion in the International Political Economy." American Political Science Review. 98, 1. 171-189.

Sindima, Harvey J. (1998). Religious and Political Ethics in Africa. Westpot, Connecticut: Greenwood Press.

Stiglitz, Joseph (2002). "Employment, social justice and societal well-being.” International Labour Review 141(1-2): 9-29.

Stroup, Michael (2006). "Economic Freedom, Democracy, and the Quality of Life." World Development 35(1): 52-66.

Stroup, Michael (2008). "Separating the influence of capitalism and democracy on women's well-being.” Journal of Economic Behavior \& Organization 67: 560-572.

Tiruneh, Gizachew (2009). "Determinants of Adult HIV/AIDS Prevalence in Africa: Do Cultural Variations Matter?” Midsouth Political Science Review. 10 (1), pp. 103-124.

Tracy, Melissa, Margaret Kruk, Christine Harper, and Sandro Galea (2010). "Neo-liberal Economic Practices and Population Health: A Cross-National Analysis, 1980-2004." Health Economics, Policy and Law, 5 (2), 171-99.

UNAIDS. World AIDS Day Report 2011. Retrieved October 16, 2012, from http://www.unaids.org/en/media/unaids/contentassets/documents/unaidspublication/2011/ JC2216_WorldAIDSday_report_2011_en.pdf

UNAIDS (2009). "Condoms and HIV prevention: Position statement by UNAIDS, UNFPA and WHO.” Retrieved 8 August 2013, from http://www.unaids.org/en/resources/presscentre/ featurestories/2009/march/20090319preventionposition/ 
UNAIDS (2013). “About UNAIDS.” Retrieved August 15, 2013 from http://www.unaids.org/en/ aboutunaids/

UNAIDS and WHO (2003). "A History of the HIV/AIDS Epidemic with Emphasis on Africa." Workshop on HIV/AIDS and Adult Mortality in Developing Countries: New York. pp. 112.

UNDP Human Development Report (2006). "Beyond Scarcity: Power, poverty and the global water crisis." United Nations, p. 53

Vanhanen, Tatu (2011). Measures of Democracy 1810-2010 [computer file]. FSD1289, version 5.0 (2011-07-07). Tampere: Finnish Social Science Data Archive [distributor].

WHO (2011). "Global status report on alcohol and health" Retrieved August 8, 2013 from http://www.who.int/substance abuse/publications/global alcoholreport/msbgsruprofiles. pdf

WHO (2014). "Global Health Observatory.” Accessed 26 February 2014 from http://www.who.int/gho/mortality_burden_disease/life_tables/situation_trends_text/en/

Williams B.G., Lloyd-Smith J.O., Gouws E, Hankins C, Getz W.M., et al. (2006) "The Potential Impact of Male Circumcision on HIV in Sub-Saharan Africa." PLoS Med 3(7): e262. doi:10.1371/journal.pmed.0030262

Williamson, Claudia (2008). "Foreign Aid and Human Development: The Impact of Foreign Aid to the Health Sector." Southern Economic Journal 75(1): 188-201.

Wittman (1989). "Why Democracies Produce Efficient Results." The Journal of Political Economy. 9 (6). pp. 1395-1424.

World Bank. (2013). Data retrieved August 14, 2013, from World Development Indicators Online (WDI) database.

World Bank (2014). World Development Indicators. Accessed February 12, 2014 from www.worldbank.com

World Bank. (2014). Data retrieved February 24, 2014, from World Development Indicators Online (WDI) database.

World Economic Forum 2007. Global Competitiveness Report 2006-2007. Geneva. 